\title{
Theoretical estimates of equilibrium carbon and hydrogen isotope effects in microbial methane production and anaerobic oxidation of methane
}

\author{
Jonathan Gropp ${ }^{1, *}$, Mark A. Iron ${ }^{2}$, and Itay Halevy ${ }^{1}$ \\ ${ }^{1}$ Department of Earth and Planetary Sciences, Weizmann Institute of Science, Rehovot 7610001, Israel \\ ${ }^{2}$ Computational Chemistry Unit, Department of Chemical Research Support, Weizmann Institute of Science, \\ Rehovot 7610001, Israel \\ *Corresponding author, E-mail address: jonathan.gropp@weizmann.ac.il (J. Gropp)
}

\begin{abstract}
Microbial production and consumption of methane are widespread in natural and artificial environments, with important economic and climatic implications. Attempts to use the isotopic composition of methane to identify its sources are complicated by incomplete understanding of the mechanisms of variation in methane's isotopic composition. Knowledge of the equilibrium isotope fractionations among the large organic intracellular intermediates in the microbial pathways of methane production and consumption must form the basis of any exploration of the mechanisms of isotopic variation, but estimates of these equilibrium isotope fractionations are currently unavailable. To address this gap, we calculated the equilibrium isotopic fractionation of carbon $\left({ }^{13} \mathrm{C} /{ }^{12} \mathrm{C}\right)$ and hydrogen $(\mathrm{D} / \mathrm{H})$ isotopes among compounds in the anaerobic methane metabolisms, as well as the abundance of double isotope substitutions ("clumping," i.e., a single ${ }^{13} \mathrm{C}-\mathrm{D}$ bond or two ${ }^{12} \mathrm{C}-\mathrm{D}$ bonds) in these compounds. The density functional theory calculations are at the M06-L/def2-TZVP level of theory with the SMD implicit solvation model, which we have recently tested against measured equilibrium isotope fractionations. The computed ${ }^{13} \beta$ and ${ }^{2} \beta$ values decrease with decreasing average oxidation state of the carbon atom in the molecules, resulting in a preference for enrichment in ${ }^{13} \mathrm{C}$ and $\mathrm{D}$ of the molecules with more oxidized carbon. Using the computed $\beta$ values, we calculated the equilibrium isotope fractionation factors in the prominent methanogenesis pathways (hydrogenotrophic, methylotrophic and acetoclastic) and in the pathway for anaerobic oxidation of methane (AOM) over a temperature range of $0-700{ }^{\circ} \mathrm{C}$. Our calculated equilibrium fractionation factors compare favorably with experimental constrains, where available, and we then used them to investigate the relation between the apparent isotope fractionation during methanogenesis or AOM and the
\end{abstract}


thermodynamic drive for these reactions. We show that a detailed map of the equilibrium fractionation factors along these metabolic pathways allows for an evaluation of the contribution of equilibrium and kinetic isotope effects to apparent isotope fractionations observed in laboratory, natural and artificial settings. The comprehensive set of equilibrium isotope fractionation factors calculated in this study provides a firm basis for future explorations of isotope effects in methane metabolism. 


\subsection{General}

The isotopic distributions in thermodynamic equilibria can be predicted with quantum mechanical calculations. These theoretical predictions are invaluable in exploring isotope fractionation systematics where experimental data are lacking or hard to obtain (e.g., Rustad et al., 2008; Eldridge et al., 2016), such as for the intracellular components of biological production and oxidation of methane (methanogenesis and methanotrophy, respectively). Theoretical approaches, in particular density functional theory (DFT), have been widely applied to small molecules (Li \& Liu, 2011; Fujii et al., 2014), and recently also to large organic molecules (Black et al., 2007; Rustad, 2009; Wang et al., 2009a,b, 2013; Moynier \& Fujii, 2017; Iron \& Gropp, 2019) in the gas, aqueous and solid phases. The application of DFT is of special interest in methanogenesis and methanotrophy since these processes involve large organic molecules, which have received less attention than small molecules due to issues of calculation cost and accuracy (Iron \& Gropp, 2019). Consequently, studies to date of the isotopic compositions in methanogenesis and methanotrophy have focused on the extracellular substrates and products, mainly $\mathrm{H}_{2}, \mathrm{CO}_{2}, \mathrm{CH}_{4}$ and $\mathrm{H}_{2} \mathrm{O}$, but have neglected the intracellular components of these processes. To bridge this gap, we $(i)$ provide a novel set of constraints on the temperature-dependent carbon and hydrogen isotope equilibrium fractionation factors (EFFs) among the intracellular molecules involved in the methanogenesis and methanotrophy pathways, (ii) compare these results to previous reports, mostly of the pathway end-members, and (iii) discuss the possible applications and the associated caveats of these results in geochemical and bioisotopic models.

\subsection{Methanogenesis and anaerobic methanotrophy}

\subsubsection{Physiology of methanogens and methanotrophs}

Methanogenic organisms produce methane by fixing $\mathrm{CO}_{2}$ in the hydrogenotrophic pathway or by reducing methylated compounds, such as acetate (i.e., acetoclastic methanogenesis) or methanol (i.e., methylotrophic methanogenesis), as described in the following net reactions:

$$
\begin{aligned}
\mathrm{CO}_{2}+4 \mathrm{H}_{2} & \rightleftarrows \mathrm{CH}_{4}+2 \mathrm{H}_{2} \mathrm{O}, \\
\mathrm{CH}_{3} \mathrm{COOH} & \rightleftarrows \mathrm{CH}_{4}+\mathrm{CO}_{2}, \\
4 \mathrm{CH}_{3} \mathrm{OH} & \rightleftarrows 3 \mathrm{CH}_{4}+\mathrm{CO}_{2}+2 \mathrm{H}_{2} \mathrm{O} .
\end{aligned}
$$

These three metabolic pathways have been described in detail (Thauer et al., 2008) and all are assumed to originate from a single, common ancestor that utilized a version of the hydrogenotrophic pathway (Berghuis et al., 2019) (Fig. 1). In the hydrogenotrophic pathway (Eq. 1), $\mathrm{CO}_{2}$ is reduced 
to methane in seven, consecutive enzymatic reactions, with four reduction steps, which are mediated by the electron carriers ferredoxin $(\mathrm{Fd})$, coenzyme $\mathrm{F}_{420}\left(\mathrm{~F}_{420}\right)$ and coenzyme $\mathrm{B}(\mathrm{HS}-\mathrm{CoB})$. In acetoclastic methanogenesis (Eq. 2), acetate $\left(\mathrm{CH}_{3} \mathrm{COO}^{-}\right)$is initially activated to acetyl- $\mathrm{CoA}\left(\mathrm{CH}_{3}-\right.$ COSCoA). The methyl group is then transferred to tetrahydromethanopterin $\left(\mathrm{H}_{4} \mathrm{MPT}\right)$ and then into the classic hydrogenotrophic pathway (Welte \& Deppenmeier, 2014), while the CoA-bound carbonyl carbon is oxidized to $\mathrm{CO}_{2}$. In the methylotrophic pathway (Eq. 3), the methyl group is transferred from methanol directly to HS-CoM to form methyl coenzyme $\mathrm{M}\left(\mathrm{CH}_{3}-\mathrm{SCoM}\right)$. The $\mathrm{CH}_{3}-\mathrm{SCoM}$ is then either oxidized to $\mathrm{CO}_{2}$ in the oxidative direction of the methanogenesis pathway or reduced to methane. The reductive and oxidative branches of this pathway operate at a ratio of $\sim 3: 1$, to balance the electrons needed for the reduction of $\mathrm{CH}_{3}-\mathrm{SCoM}$ (Vanwonterghem et al., 2016).

Anaerobic oxidation of methane (AOM) is an important process in mitigating the emission of methane from anoxic sediments to the atmosphere (Egger et al., 2018). More specifically, AOM is mediated by anaerobic methanotrophs (ANME) in a modified reverse-methanogenesis pathway, where the same enzymes of the hydrogenotrophic pathway catalyze methane oxidation. The oxidation is generally coupled to syntrophic sulfate, nitrate or ferric iron reduction (Scheller et al., 2010; Thauer, 2011; McGlynn, 2017; Scheller et al., 2017) or to nonsyntrophic formation of elemental sulfur (Milucka et al., 2012).

\subsubsection{Isotopic composition of methane}

The hydrogen $(\mathrm{D} / \mathrm{H})$ and carbon $\left({ }^{13} \mathrm{C} /{ }^{12} \mathrm{C}\right)$ isotope ratios of methane have been extensively used to distinguish among environmental methane sources (Whiticar, 1999), yet the sources often overlap in their characteristic isotopic compositions (e.g., Alstad \& Whiticar, 2011), masking the source of methane. Recent developments in the precise measurement of the abundance of the doublysubstituted ("clumped") isotopologues of methane (i.e., ${ }^{13} \mathrm{CH}_{3} \mathrm{D}$ and ${ }^{12} \mathrm{CH}_{2} \mathrm{D}_{2}$ ) further constrain the temperature of methane formation under equilibrium conditions (Stolper et al., 2014a; Ono et al., 2014; Stolper et al., 2015; Ash et al., 2019). However, disequilibrium clumped isotope compositions are common in laboratory and natural settings (Wang et al., 2015; Gruen et al., 2018; Young et al., 2017; Young, 2019; Ono et al., 2020), and the mechanisms that control these departures from equilibrium are not fully understood.

Bioisotopic models have the potential to reveal details of the elusive mechanisms that control such isotopic fingerprints. Such models have been successfully applied to microbial sulfate reduction by demonstrating how the sulfur isotope fractionations of individual steps in the pathway combine to control the net fractionation (Wing \& Halevy, 2014; Bradley et al., 2016; Zaarur et al., 2017; Wenk et al., 2017; Sim et al., 2019). A similar hypothesis was suggested for carbon and hydrogen isotopes in methanogenesis (Valentine et al., 2004). Previous applications of simplified isotope mass-balance models to the hydrogenotrophic methanogenesis pathway assign EFFs of the 
intracellular intermediate reactions as free parameters without any theoretical or experimental constraints (Wang et al., 2015; Stolper et al., 2015; Cao et al., 2019). To address this gap, to facilitate the application of bioisotopic models to microbial production and consumption of methane, and to allow a better understanding of data from laboratory experiments and natural environments, we provide hydrogen and carbon isotope and clumped isotopologue EFF values for the three main pathways of methanogenesis and for 'reverse-methanogenesis' AOM.

\subsection{Calculating equilibrium fractionation factors}

Experimentally-measured EFFs are the basis for understanding the distributions of isotopes in many geochemical systems, but the scope of these methods is often limited by long equilibration times at low temperatures, potential fractionation during the sampling processes, and complex separation procedures of the reactants and products. Early studies demonstrated that EFFs can be calculated from the observed molecular vibrational frequencies using a simplified quantum mechanical model of the experimentally measured molecular vibrations and rotations and expressed as a reduced partition function ratio (RPFR) (Urey, 1947; Bigeleisen \& Mayer, 1947). Subsequently, computational methods such as Hartree-Fock (HF) (Roothaan, 1951) and DFT (Hohenberg \& Kohn, 1964; Kohn \& Sham, 1965) provided an independent means of estimating the vibrational frequencies. These approaches have been extensively used to study several systems of geochemical interest, primarily for small molecules in the gaseous and aqueous phases, including sulfur compounds (Otake et al., 2008; Eldridge et al., 2016), metals (Domagal-Goldman \& Kubicki, 2008; Fujii et al., 2014) and crystalline solids (e.g., Méheut et al., 2007). The application to large organic molecules in the aqueous phase has remained limited due to computational cost and inaccurate results. Accordingly, in methanogenesis, experimental and theoretical work so far has focused on the small gaseous endmembers, namely the $\mathrm{H}_{2} \mathrm{O}-\mathrm{H}_{2}, \mathrm{CH}_{4}-\mathrm{H}_{2}$ and $\mathrm{CO}_{2}-\mathrm{CH}_{4}$ systems (e.g., Suess, 1949; Bottinga, 1969; Horibe \& Craig, 1995; Horita, 2001), and not on the intracellular organic intermediates.

There have been attempts to calculate EFFs among large organic molecules for some elements, such as Mg (Black et al., 2007; Moynier \& Fujii, 2017), C (Rustad, 2009), Cu (Tennant et al., 2017) and H (Wang et al., 2009a,b, 2013). Wang et al. (2009a; 2013) compared experimental and DFT calculations (B3LYP/6-311G**) of hydrogen isotope EFFs of the $\mathrm{C}_{\alpha}$ positions in ketones finding a good overall agreement. The B3LYP functional is commonly used in geochemical DFT calculations, and is the most commonly used functional in general. However, there are more modern and cost-effective methods (Zhao et al., 2011; Mardirossian et al., 2016), and until recently the accuracy of these and other functionals in predicting EFFs of large organic molecules has not been systematically compared. We recently conducted a thorough examination of various DFT functionals and basis sets to determine the uncertainty associated with the prediction of EFFs of $\mathrm{H}, \mathrm{C}, \mathrm{N}$ and $\mathrm{O}$ stable isotopes among large soluble organic molecules (Iron \& Gropp, 2019). The mean unsigned error (MUE) of these calculations in predicting the hydrogen fractionation in the 
$\mathrm{C}_{\alpha}$ position of linear and cyclic ketones is $20.8 \%$, comparable to the results of Wang et al. (2009a; 2013). For $\mathrm{C}, \mathrm{N}$ and $\mathrm{O}$ isotopes, there was an insignificant difference between the various methods, but the M06-L functional with the def2-TZVP basis set and the SMD solvation model yielded the best fits, with an MUE of 2.3\% for carbon isotopes. In this study, we employed the best-fit DFT model (M06-L functional, def2-TZVP basis set, SMD solvation model) to calculate a novel set of carbon and hydrogen equilibrium fractionation factors for the species involved in the core methanogenesis and AOM pathways. These calculations can aid in the interpretation of isotopic fractionations during methanogenesis and anaerobic oxidation of methane, in both laboratory cultures and natural environments. Moreover, there calculations eliminate a degree of freedom from future bioisotopic models, which could potentially be used to understand methane isotope compositions out-of-equilibrium and their physiological and environmental implications. We will discuss the uncertainties in our predictions and their implications for the observations of the isotopic composition of methane in various systems. 


\section{METHODS}

\subsection{Overview: the Bigeleisen-Mayer equation}

The RPFR is the equilibrium fractionation factor of a given isotope pair in a given molecule:

$$
\mathrm{RPFR}=\frac{\sigma}{\sigma^{*}} \prod_{i=1}^{3 N-6(5)} \frac{u_{i}^{*}}{u_{i}} \cdot \frac{\exp \left(-u_{i}^{*} / 2\right)}{\exp \left(-u_{i} / 2\right)} \cdot \frac{1-\exp \left(-u_{i}\right)}{1-\exp \left(-u_{i}^{*}\right)}
$$

where $u_{i}=h c \omega_{i} / k_{B} \mathrm{~T}, h$ is the Planck constant, $c$ is the speed of light, $\omega_{i}$ are the vibrational frequencies, $k_{B}$ is the Boltzmann constant, $\mathrm{T}$ is the absolute temperature, $\sigma$ is the molecular symmetry number (most large organic molecules lack any symmetry so this term is often unity), and the asterisk denotes the species with the heavy isotope(s). The product runs over the $3 N-5$ or $3 N-6$ vibrational frequencies of linear and nonlinear molecules, respectively, where $N$ is the number of atoms in the molecule. The three ratios in the product are the classical factor accounting for rotational and translational energy, the zero-point energy (ZPE) contribution, and the excitation factor. The RPFR is related to the $\beta$ factor, which is the RPFR of a compound and an ideal monoatomic gas. For single isotope substitutions, when the excess factors are ignored, $\beta=\mathrm{RPFR}$, and the (temperature-dependent) EFF between two species $(\alpha)$ that contain the rare isotope $r$ is the ratio of the respective $\beta \mathrm{s}:{ }^{r} \alpha_{\mathrm{A}-\mathrm{B}}^{\mathrm{eq}}={ }^{r} \beta_{\mathrm{A}} /{ }^{r} \beta_{\mathrm{B}}$.

We also calculated the EFFs of doubly-substituted (clumped) isotopologues that contain a single ${ }^{13} \mathrm{C}-\mathrm{D}$ bond or two ${ }^{12} \mathrm{C}-\mathrm{D}$ bonds. The abundance of clumped isotopologues is commonly reported as the deviation from the expected stochastic distribution, $\Delta_{i}^{\mathrm{eq}} \equiv\left(R_{i}^{\mathrm{eq}} / R_{i}^{*}-1\right)$ where $i$ is the isotopologue of interest, $R_{i}^{\mathrm{eq}}$ is the abundance of the clumped isotopologue relative to the nonsubstituted isotopologue at equilibrium, and $R_{i}^{*}$ is its abundance at a stochastic distribution of the rare isotopes. We calculated $\Delta_{i}^{\mathrm{eq}}$ from RPFRs following Cao and Liu (2012), who suggested that $\Delta_{i}^{\mathrm{eq}}$ of the clumped isotopologue $\mathrm{V}^{\prime} \mathrm{Y}^{\prime} \mathrm{Y}_{n-1}$, where $\mathrm{V}^{\prime}$ and $\mathrm{Y}^{\prime}$ are the rare isotopes of atoms $\mathrm{V}$ and $\mathrm{Y}$, respectively, and $n$ is the number of $\mathrm{Y}$ atoms in the molecule $\mathrm{VY}_{n}$, can be calculated by the general relation:

$$
\Delta_{\mathrm{V}^{\prime} \mathrm{Y}^{\prime} \mathrm{Y}_{n-1}}=\left(\frac{\left(\sigma^{*} / \sigma\right) \times \mathrm{V}^{\prime} \mathrm{Y}^{\prime} \mathrm{RPFR}_{\mathrm{VY}_{n}}}{\mathrm{~V}^{\prime} \beta_{\mathrm{VY}_{n}} \times \mathrm{Y}^{\prime} \beta_{\mathrm{VY}_{n}}}\right)
$$

where ${ }^{\mathrm{V}^{\prime} \mathrm{Y}^{\prime}} \mathrm{RPFR}_{\mathrm{VY}_{n}}$ is the RPFR of the clumped isotopologue of interest. ${ }^{\mathrm{V}^{\prime}} \beta_{\mathrm{VY}_{n}}$ and ${ }^{\mathrm{Y}^{\prime}} \beta_{\mathrm{VY}_{n}}$ are approximately equal to the $\beta$ values of single substitutions of $\mathrm{V}^{\prime}$ and $\mathrm{Y}^{\prime}$ in $\mathrm{VY}_{n}$ (Cao \& Liu, 2012). In addition to the internal equilibrium distribution of $\mathrm{V}^{\prime}-\mathrm{Y}^{\prime}$ bonds in the molecule $\mathrm{VY}_{n}$ (Eq. 5), we are interested in the distribution of $\mathrm{V}^{\prime}-\mathrm{Y}^{\prime}$ bonds in large organic molecules of the general form $x \mathrm{VY}_{n}$, where $x$ denotes an arbitrary organic moiety. We calculated the EFFs of reactions that include a clumped isotopologue and distinguish between equilibrium isotope effects in which a new $\mathrm{V}^{\prime}-\mathrm{Y}^{\prime}$ bond is formed or broken:

$$
{ }^{\mathrm{V}^{\prime} \mathrm{Y}^{\prime}} \alpha_{a \mathrm{~V}^{\prime} \mathrm{Y}, b \mathrm{VY}^{\prime} / c \mathrm{~V}^{\prime} \mathrm{Y}^{\prime}}={ }^{\mathrm{V}^{\prime}} \beta_{a \mathrm{~V}^{\prime} \mathrm{Y}} \times{ }^{\mathrm{Y}^{\prime}} \beta_{b \mathrm{VY}^{\prime}} /{ }^{\mathrm{V}^{\prime} \mathrm{Y}^{\prime}} \mathrm{RPFR}_{c \mathrm{~V}^{\prime} \mathrm{Y}^{\prime}}
$$


and equilibrium isotope effects in which the original $\mathrm{V}^{\prime}-\mathrm{Y}^{\prime}$ bond remains intact:

$$
\mathrm{V}^{\prime} \mathrm{Y}^{\prime} \alpha_{a \mathrm{~V}^{\prime} \mathrm{Y}^{\prime} / c \mathrm{~V}^{\prime} \mathrm{Y}^{\prime}}={ }^{\mathrm{V}^{\prime} \mathrm{Y}^{\prime}} \mathrm{RPFR}_{a \mathrm{~V}^{\prime} \mathrm{Y}^{\prime}} / \mathrm{V}^{\prime} \mathrm{Y}^{\prime} \mathrm{RPFR}_{c \mathrm{~V}^{\prime} \mathrm{Y}^{\prime}} .
$$

By analogy to the terminology for kinetic isotope effects, we refer to these as primary and secondary equilibrium isotopes effects. As suggested by Wang et al. (2015), the clumped isotope fractionation factors can be expressed as ${ }^{13,2} \alpha^{\mathrm{eq}}={ }^{13} \alpha^{\mathrm{eq}} \times{ }^{2} \alpha^{\mathrm{eq}} \times{ }^{13,2} \gamma^{\mathrm{eq}}$ and ${ }^{2,2} \alpha^{\mathrm{eq}}={ }^{2} \alpha^{\mathrm{eq}} \times{ }^{2} \alpha^{\mathrm{eq}} \times{ }^{2,2} \gamma^{\mathrm{eq}}$. The unitless ${ }^{13,2} \gamma^{\text {eq }}$ and ${ }^{2,2} \gamma^{\text {eq }}$ factors are a measure of the deviation of the actual fractionation factor from a simple product of the fractionation factors of the singly-substituted isotopologues. Though originally proposed for KFFs, the $\gamma^{\mathrm{eq}}$ notation may be used to express similar deviations in EFFs, and we adopt it here for consistency with the existing literature. By definition $\alpha^{\text {eq }}=\alpha^{-} / \alpha^{+}$, where $\alpha^{-}$and $\alpha^{+}$are the backwards and reverse kinetic isotope effects, respectively, and it can be shown that based on this relation $\gamma^{\mathrm{eq}}=\gamma^{-} / \gamma^{+}$, where $\gamma^{-}$and $\gamma^{+}$are the backwards and forward kinetic $\gamma$ factors, respectively.

\subsection{Quantum mechanical calculations of partition coefficients for large or- ganic molecules}

All calculations were done with GAUSSIAN16 revisions A.03, B.01 and C.01 (Frisch et al., 2016). Based on its performance in predicting EFFs in large organic molecules (Iron \& Gropp, 2019), we chose the M06-L DFT exchange-correlation functional and def2-TZVP basis set (Andrae et al., 1990; Kaupp et al., 1991; Leininger et al., 1996; Metz et al., 2000; Weigend \& Ahlrichs, 2005). The use of scaling factors has been shown to provide more accurate predictions of vibrational frequencies (see Kesharwani et al. (2016) and references therein). As discussed in our benchmark study (Iron \& Gropp, 2019), two scaling factors were used in Eq. 4, one for the zero-point (vibrational) energy term (the second term in product, specifically, $\lambda_{\mathrm{ZPE}}=0.9825$ ) and another for the harmonic frequencies in the other two terms (specifically, $\lambda_{\text {harm }}=0.9965$ ).

The original derivation of RPFR by Bigeleisen and Mayer suited molecules in a gas phase, but biochemical reactions within the cells usually occur in the aqueous phase. Adding explicit water molecules should, in principle, yield more accurate results for reactions in aqueous solution, but this also increases the size of the system and associated calculation costs. Implicit solvation models, which assume that the solvent effects can be described by the free energy cost of solvation alone, thereby offering a substantial reduction in computational cost, are a common solution to this issue (Tomasi et al., 2005). We generated the RPFRs of the end-member molecules in both the gaseous and aqueous phases. To account for the aqueous phase, we used the SMD solvation model of Truhlar and coworkers (Marenich et al., 2009).

In this work, we use the singly substituted hydrogen isotopologues as a proxy for the bulk $\mathrm{D} / \mathrm{H}$ ratios of the compounds, which is a common practice for isotopologues with atoms in equivalent positions (Galimov, 2006; Wang et al., 2009a; Liu et al., 2010). We perform our DFT calculations 
for frozen-geometry molecules, which produce distinct RPFR values for substitution of $\mathrm{D}$ for $\mathrm{H}$ in the different positions of the methyl groups. The free rotation of the methyl group makes the three $\mathrm{C}-\mathrm{H}$ bonds equivalent and chemically indistinguishable, and we therefore calculate the RPFR of the deuterated molecule from the geometric mean of RPFR values determined from the distinct site-specific D/H-substitutions (Wang et al., 2009a).

Liu et al. (2010) considered a number of corrections to the Bigeleisen-Mayer equation, including anharmonic effects and vibrational-rotational couplings. However, they studied small, triatomic molecules, where these corrections are small. In our previous study, where we considered much larger molecules, it was found that these terms were actually detrimental to the accuracy of the results (Iron \& Gropp, 2019). We hypothesized that the degradation of accuracy may result from the inclusion of these terms violating the underlying assumptions of the Bigeleisen-Mayer equation, specifically, the assumptions of a rigid rotor and a harmonic oscillator, which in turn allow the use of the Teller-Redlich product rule. As noted by Webb \& Miller (2014) in the their study comparing path integral Monte Carlo (PIMC) methods with the Urey-harmonic oscillator model, the latter takes advantage of substantial error cancellation.

PIMC methods, which are based on potential energy surface fits to DFT or CCSD(T) data, have recently been used to determine EFFs (e.g., Webb et al., 2017; Eldridge et al., 2019). However, these methods are limited to very small molecules such as methane (Eldridge et al., 2019) or ethane (Webb et al., 2017), and their application to the much larger organic molecules studied here as part of the methanogenesis pathways would be a Herculean task and beyond the scope of the current study. He et al. (2020) recently suggested that truncating large organic molecules to ease the calculation cost may have a negligible effect on ${ }^{13} \alpha$ predictions when used with an implicit solvation model. We chose to model the entire molecules, especially since none were too large for the available computer hardware. He et al. used the more expensive Møller-Plesset (MP2) method, yet we found that reliable results can be obtained using cheaper DFT methods and, in fact, MP2 is inferior to many DFT functionals in predicting vibrational frequencies, which are the basis of the Bigeleisen-Mayer equation (Eq. 4) (Iron \& Gropp, 2019). In addition, in some cases long-range interactions, such as hydrogen bonds, may affect the vibrational frequency of the primary site, and these effects might be overlooked if truncations are applied without the appropriate considerations. A careful truncation of molecules can be effective, but it does introduce a new potential source of error. 


\section{RESULTS}

We calculated the RPFRs for position-specific single ${ }^{13} \mathrm{C}$ or D substitutions and double ${ }^{13} \mathrm{C}$ and D or $\mathrm{D}$ and $\mathrm{D}$ substitutions of the molecules that participate in anaerobic methane metabolisms at the M06-L/def2-TZVP level of theory at 0-700 ${ }^{\circ} \mathrm{C}$ (Full details in Section 2.2). The results of these calculations are presented in Tables $2-5$, and Tables S.1 and S.2. The ${ }^{13} \beta$ and ${ }^{2} \beta$ values at $0-100$ ${ }^{\circ} \mathrm{C}$, the temperature range that is relevant for biological activity and the large organic molecules on which we focus, are presented in Fig. 2. In general, ${ }^{13} \beta$ and ${ }^{2,2} \mathrm{RPFR}$ at $25{ }^{\circ} \mathrm{C}$ covary with the carbon oxidation state, with the exception of the ${ }^{13} \beta$ values for the methyl and carbonyl groups in $\mathrm{CH}_{3}-\mathrm{COSCoA}$ and the ${ }^{13} \beta$ for the methyl group in $\mathrm{CH}_{3}-\mathrm{COOH}$. The ${ }^{2} \beta$ and ${ }^{13,2} \mathrm{RPFR}$ values also covary with the carbon oxidation state, though only for oxidation states between zero and -4 .

We calculated the EFFs $\left(\alpha^{\mathrm{eq}}\right)$ for the enzymatic reactions in the hydrogenotrophic, acetoclastic and methylotrophic methanogenesis pathways. The full results at $25{ }^{\circ} \mathrm{C}, 50{ }^{\circ} \mathrm{C}$ and $75{ }^{\circ} \mathrm{C}$ are provided in Tables 6, 8 and 9 and Figs. 3-4. For each reaction, we report $\alpha$-values based on $\beta$ and RPFR values through the relation ${ }^{r} \alpha_{\mathrm{A}-\mathrm{B}}^{\mathrm{eq}}=\beta_{\mathrm{A}} / \beta_{\mathrm{B}}$, where we arbitrarily chose compound $\mathrm{A}$ to be upstream of compound $\mathrm{B}$ in the methanogenesis pathway. For convenience, we follow the convention of reporting EFFs as the natural logarithm of ${ }^{r} \alpha_{\mathrm{A}-\mathrm{B}}^{\mathrm{eq}}$ in permil (\%0) units (1000ln $\left.\alpha\right)$. The fractionations of reactions involving $\mathrm{H}_{2} \mathrm{O}$ are reported relative to $\mathrm{H}_{2} \mathrm{O}_{(1)}$. As calculation of the RPFR for liquid $\mathrm{H}_{2} \mathrm{O}$ is notoriously challenging, we chose to apply the approach used by Wang et al. (2009a) and calculate ${ }^{2} \beta$ of $\mathrm{H}_{2} \mathrm{O}_{(\mathrm{g})}$ and use the ${ }^{2} \alpha_{\mathrm{H}_{2} \mathrm{O}_{(\mathrm{l})}-\mathrm{H}_{2} \mathrm{O}_{(\mathrm{g})}}^{\mathrm{eq}}$ reported for the range 0-374 ${ }^{\circ} \mathrm{C}$ (Horita \& Wesolowski, 1994), where ${ }^{2} \beta_{\mathrm{H}_{2} \mathrm{O}_{(\mathrm{l})}}={ }^{2} \beta_{\mathrm{H}_{2} \mathrm{O}_{(\mathrm{g})}} \times{ }^{2} \alpha_{\mathrm{H}_{2} \mathrm{O}_{(\mathrm{l})}-\mathrm{H}_{2} \mathrm{O}_{(\mathrm{g})}}^{\mathrm{eq}}$.

Notably, the carbon isotope fractionations of the reactions in the hydrogenotrophic pathway, which add up to the net $\mathrm{CO}_{2}-\mathrm{CH}_{4}$ carbon isotope fractionation, distribute almost evenly among four steps in the pathway, three of which are carbon reduction reactions. The $\mathrm{CO}_{2}-\mathrm{CHO}-\mathrm{MFR}$, $\mathrm{CH} \equiv \mathrm{H}_{4} \mathrm{MPT}^{+}-\mathrm{CH}_{2}=\mathrm{H}_{4} \mathrm{MPT}, \mathrm{CH}_{2}=\mathrm{H}_{4} \mathrm{MPT}-\mathrm{CH}_{3}-\mathrm{H}_{4} \mathrm{MPT}$ and $\mathrm{CH}_{3}-\mathrm{H}_{4} \mathrm{MPT}-\mathrm{CH}_{3}-\mathrm{SCoM}$ carbon isotope fractionations are all between $\sim 15 \%$ and $\sim 18 \%$ at $25^{\circ} \mathrm{C}$, whereas the other reactions yield smaller positive or small negative fractionations (Table 6). For hydrogen, primary equilibrium isotope effects, in which a $\mathrm{C}-\mathrm{H}$ bond is broken or made, produce larger positive or negative hydrogen isotope fractionations than secondary equilibrium isotope effects, in which $\mathrm{C}-\mathrm{H}$ bonds remain intact, except for the reaction between $\mathrm{F}_{4} 2 \mathrm{OH}_{2}$ and $\mathrm{CH}_{3}-\mathrm{H}_{4} \mathrm{MPT}$ that has a smaller primary EFF than its secondary EFFs (Fig. 4).

Using the ${ }^{13} \beta,{ }^{2} \beta,{ }^{2,2}$ RPFR and ${ }^{13,2}$ RPFR values of the intermediates in the methanogenic pathways, we calculated these metabolites' equilibrium deviation of clumped isotopologue abundance from a stochastic distribution ( $\Delta_{i}^{\mathrm{eq}}$, where $i$ is the isotopologue of interest). The $\Delta_{i}^{\mathrm{eq}}$ values for ${ }^{13} \mathrm{C}-$ D clumping increase with decreasing oxidation state, from $\Delta_{13}^{\mathrm{eq}} \mathrm{CDO}-\mathrm{H}_{4} \mathrm{MPT}=4.211 \%$ to $\Delta_{13}^{\mathrm{eq}} \mathrm{CH}_{3} \mathrm{D}=$ $5.738 \%$ at $25{ }^{\circ} \mathrm{C}$, while $\Delta_{i}^{\mathrm{eq}}$ values for D-D clumping are larger, ranging from $\Delta_{12}^{\mathrm{eq}} \mathrm{CD}_{2}=\mathrm{H}_{4} \mathrm{MPT}=$ $13.38 \%$ to $\Delta_{12}^{\mathrm{eq}} \mathrm{CH}_{2} \mathrm{D}_{2}=18.50 \%$ at $25^{\circ} \mathrm{C}$, and they all depend inversely on temperature (Fig. 5 and 
246 Table 7). We also calculated the clumped isotope fractionations of reactions that involve doubly${ }_{247}$ substituted isotopologues $\left({ }^{13,2} \alpha^{\mathrm{eq}}\right.$ and $\left.{ }^{2,2} \alpha^{\mathrm{eq}}\right)$, and the deviation of these values from the product ${ }_{248}$ of the ${ }^{13} \alpha^{\text {eq }}$ and ${ }^{2} \alpha^{\text {eq }}$ values $\left({ }^{13,2} \gamma^{\text {eq }}\right.$ and $\left.{ }^{2,2} \gamma^{\text {eq }}\right)$. In general, the ${ }^{13,2} \alpha^{\text {eq }}$ values are similar in magnitude, but not identical, to the corresponding product of ${ }^{13} \alpha^{\mathrm{eq}}$ and ${ }^{2} \alpha^{\mathrm{eq}}$. For secondary equilibrium isotope effects, where the ${ }^{13} \mathrm{C}-\mathrm{D}$ or the ${ }^{12} \mathrm{C}-\mathrm{D}$ bonds remain intact, ${ }^{13,2} \gamma^{\mathrm{eq}}$ and ${ }^{2,2} \gamma^{\text {eq }}$ are very close to unity, with a mean values of 0.9998 and 0.9994 at $25^{\circ} \mathrm{C}$, respectively. For primary equilibrium isotope effects, where a ${ }^{13} \mathrm{C}-\mathrm{D}$ or ${ }^{12} \mathrm{C}-\mathrm{D}$ bond is formed or broken, ${ }^{13,2} \gamma^{\mathrm{eq}}$ and ${ }^{2,2} \gamma^{\mathrm{eq}}$ are larger, with mean values of 0.9951 and 0.9849 , respectively. A complete list of $\gamma^{\text {eq }}$ values is in Tables S.5 and S.6. 


\section{DISCUSSION}

\subsection{Beta values}

The principles of equilibrium isotopic fractionation can explain the general trends observed in the calculated ${ }^{13} \beta$ values. At a given temperature, these values decrease with the carbon oxidation state (from +4 in $\mathrm{CO}_{2}$ to -4 in $\mathrm{CH}_{4}$ ), which exerts first-order control over the carbon bonding environment. The correlation of the ${ }^{2} \beta,{ }^{13,2} \mathrm{RPFR}$ and ${ }^{2,2} \mathrm{RPFR}$ values with the carbon oxidation state is less trivially understood, as the hydrogen's bonding environment is also affected by the $\mathrm{S}, \mathrm{N}$ and $\mathrm{O}$ atoms to which the carbon is often bound and by the orbital hybridization of the molecules. Irrespective of the mechanism(s), similar correlations of $\beta$ values and oxidation state were observed for S (Eldridge et al., 2016), Fe (Fujii et al., 2014), and Se (Li \& Liu, 2011) isotopic fractionations. A natural consequence of this correlation is that, in general, we may expect carbon reduction reactions to have carbon, hydrogen and clumped isotope EFFs larger than unity.

\subsection{Uncertainties in calculated fractionation factors}

The uncertainties in our predicted EFFs would best be estimated by comparison with experimentally determined isotopic fractionations. However, experimental evaluations of carbon, hydrogen and clumped isotopic fractionations among the intermediate, intracellular metabolites of all three methanogenic pathways have not yet been reported, with the exception of one investigation of the carbon and hydrogen isotopic fractionation among $\mathrm{CH}_{3}-\mathrm{SCoM}$, $\mathrm{HS}-\mathrm{CoB}$ and $\mathrm{CH}_{4}$. Moreover, in the methylotrophic and acetoclastic pathways, even measurements of equilibrium isotopic fractionations between the pathway end-members have not been reported. In the absence of experimental constraints on the isotopic fractionation factors, we follow the approach taken in previous studies for assessing the accuracy of DFT calculations of EFFs of large organic molecules. The 95\% confidence interval (CI95) associated with the comparison of calculated and experimental hydrogen EFFs was found to be $\pm 5 \%$ o to $\pm 10 \%$ or for linear ketones (Wang et al., 2009a) and $\pm 10 \%$ o to $\pm 30 \%$ o for cyclic ketones (Wang et al., 2013), at the B3LYP/6-311G** level of theory. More recently, we extended the evaluation to isotopes of C, N and O (Iron \& Gropp, 2019). The associated CI95 for $\mathrm{C}, \mathrm{N}$ and $\mathrm{O}$ isotopes is $\pm 2.5 \%$. However, CI95 represents only the uncertainty in the parameters of the regression model, and the predictive power of our DFT calculations is more rigorously captured by the $95 \%$ prediction interval (PI95). The nonsimultaneous observation bounds of the PI95s are $\pm 30 \%$ for hydrogen isotopes and $\pm 8 \%$ for carbon isotopes. While the benchmark database on which these PI95 are based is limited in its coverage of different functional groups, we suggest that it is currently the most suitable alternative to experimental constraints when attempting to determine the actual magnitude of the uncertainty. 


\subsection{Comparisons with previous experimental and theoretical studies}

To validate our calculated EFFs, we compare our results with previous experimental observations and theoretical predictions of EFFs.

\subsubsection{Isotopic fractionation in the $\mathrm{CO}_{2}-\mathrm{CH}_{4}-\mathrm{H}_{2} \mathrm{O}-\mathrm{H}_{2}$ system}

The small, volatile end-members of the hydrogenotrophic methanogenesis pathway have been well characterized in both theoretical and experimental studies, and the efforts to better constrain the isotopic fractionations among them are ongoing. Four EFFs are of interest: (i) the $\mathrm{CO}_{2}-\mathrm{CH}_{4}$ carbon isotopic fractionation, (ii) the $\mathrm{H}_{2} \mathrm{O}-\mathrm{H}_{2}$ hydrogen isotopic fractionation, (iii) the $\mathrm{CH}_{4}-\mathrm{H}_{2}$ hydrogen isotopic fractionation, and (iv) the $\mathrm{CH}_{4}-\mathrm{H}_{2} \mathrm{O}$ hydrogen isotopic fractionation. For hydrogen isotopes, we also present here the results using the HCTH/def2-TZVP level of theory. Overall, our predictions based on the M06-L/def2-TZVP and HCTH/def2-TZVP levels of theory yield good agreement with previous estimates of the fractionation factors, as discussed below.

Our results for case (i) agree with $1000 \ln ^{13} \alpha_{\mathrm{CO}_{2}-\mathrm{CH}_{4}}^{\mathrm{eq}}$ values calculated using measured vibrational frequencies over a temperature range of $0-700{ }^{\circ} \mathrm{C}$ (Richet et al., 1977) and with experimental observations of $1000 \ln ^{13} \alpha_{\mathrm{CO}_{2}-\mathrm{CH}_{4}}^{\mathrm{eq}}$ over a temperature range of 200-700 ${ }^{\circ} \mathrm{C}$ (Horita, 2001; Kueter et al., 2019) (Fig. 7A). To the best of our knowledge, $\mathrm{CO}_{2}-\mathrm{CH}_{4}$ carbon isotopic fractionations have not been experimentally measured below $200{ }^{\circ} \mathrm{C}$, but the agreement of our theoretical predictions with the available, high-temperature experimental data provides confidence in our predictions at lower temperatures.

For case (ii), our $1000 \ln ^{2} \alpha_{\mathrm{H}_{2} \mathrm{O}-\mathrm{H}_{2}}^{\mathrm{eq}}$ values generally agree with previous experimental measurements at low and high temperatures (Cerrai et al., 1954; Rolston et al., 1976) (Fig. 7B). Rolston et al. (1976) measured fractionation between $\mathrm{H}_{2} \mathrm{O}_{(1)}$ and $\mathrm{H}_{2(\mathrm{~g})}$. Our $\mathrm{H}_{2} \mathrm{O}-\mathrm{H}_{2}$ hydrogen isotopic fractionations using M06-L are comparable but slightly higher than other modeling studies based on spectroscopic data rather than DFT (Suess, 1949; Bardo \& Wolfsberg, 1976). Our $\mathrm{H}_{2} \mathrm{O}-\mathrm{H}_{2}$ hydrogen isotopic fractionation based on the HCTH functional produce a better fit to the observations, which is identical to the prediction of Bardo \& Wolfsberg (1976).

In case (iii), our $1000 \ln ^{2} \alpha_{\mathrm{CH}_{4}-\mathrm{H}_{2}}^{\mathrm{eq}}$ values calculated at the M06-L level of theory are larger by $40-45 \%$ than the values measured in the temperature range $200-500{ }^{\circ} \mathrm{C}$ (Horibe \& Craig, 1995) (Fig. 7C), while the HCTH level of theory produces a better fit in this temperature range (only 10-30\% larger than the experimental values). At this range of temperatures, there is disagreement between published theoretical estimates of the $\mathrm{CH}_{4}-\mathrm{H}_{2}$ equilibrium hydrogen isotopic fractionation (Bottinga, 1969; Richet et al., 1977). Our results agree with those of Richet et al. (1977) and are smaller by 0-30\% than the fractionations calculated by Bottinga (1969). Of all published theoretical estimates of the $\mathrm{CH}_{4}-\mathrm{H}_{2}$ equilibrium hydrogen isotopic fractionation, our calculations at the HCTH level of theory are closest to the available high-temperature measurements. At tem- 
peratures below $100{ }^{\circ} \mathrm{C}$, which are relevant for biological activity, there are no experimentallydetermined $\mathrm{CH}_{4}-\mathrm{H}_{2}$ equilibrium hydrogen isotopic fractionations. At these temperatures, there is an even larger discrepancy between all available theoretical predictions and a linear regression of ${ }^{2} \alpha_{\mathrm{CH}_{4}-\mathrm{H}_{2}}^{\mathrm{eq}}$ on $10^{6} / \mathrm{T}$, extrapolated from experimental results at $200-500{ }^{\circ} \mathrm{C}$ (Horibe \& Craig, 1995). Reconciling these discrepancies is beyond the scope of the current study, requiring experiments to determine the $\mathrm{CH}_{4}-\mathrm{H}_{2}$ equilibrium hydrogen isotopic fractionations at temperatures below $200{ }^{\circ} \mathrm{C}$.

For case $(i v)$, there are no direct measurements of the $\mathrm{CH}_{4}-\mathrm{H}_{2} \mathrm{O}$ equilibrium hydrogen isotopic fractionation, $1000 \mathrm{ln}^{2} \alpha_{\mathrm{CH}_{4}-\mathrm{H}_{2} \mathrm{O}_{(1)}}^{\mathrm{eq}}$, and a common practice is to combine available values for $1000 \ln ^{2} \alpha_{\mathrm{CH}_{4}-\mathrm{H}_{2}}^{\mathrm{eq}}$ and $1000 \ln ^{2} \alpha_{\mathrm{H}_{2}-\mathrm{H}_{2} \mathrm{O}_{(1)}}^{\mathrm{eq}}$. As observed in a previous work (Wang et al., 2015), there is a striking disagreement among the different combinations of $1000 \ln ^{2} \alpha_{\mathrm{CH}_{4}-\mathrm{H}_{2}}^{\mathrm{eq}}$ and $1000 \ln ^{2} \alpha_{\mathrm{H}_{2}-\mathrm{H}_{2} \mathrm{O}_{(1)}}^{\mathrm{eq}}$ values, with $1000 \mathrm{ln}^{2} \alpha_{\mathrm{CH}_{4}-\mathrm{H}_{2} \mathrm{O}_{(\mathrm{l})}}^{\mathrm{eq}}$ ranging from -110 to $-300 \%$ at $0{ }^{\circ} \mathrm{C}$ and from -85 to $-210 \%$ at $60{ }^{\circ} \mathrm{C}$ (Fig. 8A). Most of this spread stems from the uncertainty in $1000 \ln ^{2} \alpha_{\mathrm{CH}_{4}-\mathrm{H}_{2}}^{\mathrm{eq}}$ values at low temperatures. To date, most interpretations of environmental $1000 \ln ^{2} \alpha_{\mathrm{CH}_{4}-\mathrm{H}_{2} \mathrm{O}_{(1)}}^{\mathrm{eq}}$ values rely on the extrapolation of the $200-500{ }^{\circ} \mathrm{C}$ experimental results (Horibe \& Craig, 1995) to environmentallyrelevant temperatures (e.g., Proskurowski et al., 2006; Wang et al., 2017). As noted above, this extrapolation does not agree with any method of theoretical calculation. To get a better understanding of this disparity, we compiled from the literature 165 environmental samples of biological origin, from marine sediments and gas reservoirs located below the sulfate-methane transition zone (Table S.11). We compared the measured $\mathrm{CH}_{4}-\mathrm{H}_{2} \mathrm{O}_{(1)}$ hydrogen isotopic fractionation to the calculated temperature-dependent $1000 \ln ^{2} \alpha_{\mathrm{CH}_{4}-\mathrm{H}_{2} \mathrm{O}_{(1)}}^{\mathrm{eq}}$ (Fig. 8A-B). We also compiled 183 values of measured $\mathrm{CO}_{2}-\mathrm{CH}_{4}$ carbon isotopic fractionations from the same locations and their deviation from the expected temperature-dependent $1000 \ln ^{13} \alpha_{\mathrm{CO}_{2}-\mathrm{CH}_{4}}^{\text {eq }}$ (Fig. 8C). We found that the distribution of the deviations of the $\mathrm{CO}_{2}-\mathrm{CH}_{4}$ apparent carbon isotopic fractionation from isotopic equilibrium has a distinct peak at zero, which we interpret as evidence of carbon isotope equilibration in the $\mathrm{CO}_{2}-\mathrm{CH}_{4}$ system. This may suggest that the hydrogen isotopes in the $\mathrm{CH}_{4}-\mathrm{H}_{2} \mathrm{O}$ system are also at (or close to) isotopic equilibrium. If this is the case, the distribution of compiled apparent hydrogen isotopic fractionations from environmental samples may inform the choice of DFT theory and constrain the error on our calculated hydrogen isotopic fractionation factors. The distribution of the deviation of the $\mathrm{CH}_{4}-\mathrm{H}_{2} \mathrm{O}_{(1)}$ apparent hydrogen isotopic fractionation from isotopic equilibrium calculated with the M06-L functional has a distinct peak at zero, whereas with HCTH the distribution peaks at $\sim 20 \%$, suggesting that the former provides a more accurate prediction in this case.

\subsubsection{Isotopic fractionation between large organic molecules in the methanogenesis pathway}

To our knowledge, the equilibrium hydrogen isotopic fractionation between $\mathrm{CH}_{3}-\mathrm{SCoM}$ and $\mathrm{CH}_{4}$ $\left(\ln ^{2} \alpha_{\mathrm{CH}_{3}-\mathrm{SCoM}-\mathrm{CH}_{4}}^{\mathrm{eq}}\right)$ is the only experimentally determined fractionation between intracellular intermediate metabolites in the methanogenesis pathway. Scheller et al. (2013) investigated the ki- 
netic isotopic fractionation in the Mcr-catalyzed reaction, the final step in methanogenesis. EFFs can be calculated from the kinetic fractionation factors (KFFs) of the reverse and forward reactions: ${ }^{r} \alpha_{\mathrm{A}-\mathrm{B}}^{\mathrm{eq}}={ }^{r} \alpha_{\mathrm{B} \rightarrow \mathrm{A}}^{\mathrm{kin}} /{ }^{r} \alpha_{\mathrm{A} \rightarrow \mathrm{B}}^{\mathrm{kin}}$, where ${ }^{r} \alpha_{\mathrm{B} \rightarrow \mathrm{A}}^{\mathrm{kin}}$ and ${ }^{r} \alpha_{\mathrm{A} \rightarrow \mathrm{B}}^{\mathrm{kin}}$ are the reverse and forward KFFs, respectively. The KFF is defined as the ratio of the rate constants for reaction of the heavy isotope to the light isotope (i.e., ${ }^{13} k /{ }^{12} k$ for carbon isotopes and ${ }^{\mathrm{D}} k /{ }^{\mathrm{H}} k$ hydrogen isotopes). For a normal KFF, where the light isotope reacts more rapidly than the heavy isotope, ${ }^{r} \alpha^{\mathrm{kin}}$ is less than unity and its natural logarithm is negative. While Scheller et al. (2013) did not explicitly report $1000 \ln ^{2} \alpha_{\mathrm{CH}_{3}-\mathrm{SCoM}-\mathrm{CH}_{4}}^{\mathrm{eq}}$, we calculated a value of $17 \pm 42 \%$ at $60{ }^{\circ} \mathrm{C}$ based on their measured ${ }^{2} \alpha_{\mathrm{CH}_{3}-\mathrm{SCoM} \rightarrow \mathrm{CH}_{4}}(0.840 \pm 0.01)$ and ${ }^{2} \alpha_{\mathrm{CH}_{4} \rightarrow \mathrm{CH}_{3} \text {-SCoM }}(0.855 \pm 0.05)$, taking into account error propagation. Our calculated value of $40.4 \%$ at this temperature is within error of the experimental value.

\subsection{3 $\Delta_{13}^{\mathrm{eq}} \mathrm{CH}_{3} \mathrm{D}$ and $\Delta_{12}^{\mathrm{eq}} \mathrm{CH}_{2} \mathrm{D}_{2}$}

For methane, our predictions of $\Delta_{13}^{\mathrm{eq}} \mathrm{CH}_{3} \mathrm{D}$ in thermodynamic equilibrium agree well with previous theoretical and experimental estimates (Webb \& Miller, 2014; Liu \& Liu, 2016; Eldridge et al., 2019) (Fig. 6A). Our predictions also agree with the theoretical and experimental estimates of $\Delta_{12}^{\mathrm{eq}} \mathrm{CH}_{2} \mathrm{D}_{2}$ (Young et al., 2017; Eldridge et al., 2019), though in this case our predictions are systemically lower by $\sim 0.8 \%$ in the temperature range of $0{ }^{\circ} \mathrm{C}$ to $100{ }^{\circ} \mathrm{C}$ (Fig. 6B). There are currently no available measurements of the intermediates in the methanogenesis pathway to which we can compare our results.

\subsection{Implications of predicted EFFs for methanogenesis and anaerobic oxi- dation of methane}

Methanogenesis is characterized by large and variable $\mathrm{CO}_{2}-\mathrm{CH}_{4}$ carbon isotopic fractionations (tens of permil) and $\mathrm{CH}_{4}-\mathrm{H}_{2} \mathrm{O}$ hydrogen isotopic fractionations (hundreds of permil). Variations within these ranges have been hypothesized to be controlled by the degree of reversibility of the enzymatically-catalyzed reactions (Valentine et al., 2004; Wang et al., 2015; Stolper et al., 2015). The net isotopic fractionation of any individual biochemical reaction varies between the thermodynamic and kinetic end-members. The thermodynamic end-member is the product of a fully reversible reaction, and it gives rise to a substrate-product isotopic fractionation equal to the EFF between these compounds. The kinetic end-member is well-defined for a single reaction as the isotopic fractionation when that reaction is unidirectional, and it is equal to the ratio of the isotopespecific rate constants of the reaction. The kinetic end-member depends on the reaction mechanism, which depends on the structure of the enzyme catalyzing the reaction, and on the exact substrates participating in the reaction. Thus, the kinetic end-member may vary for different microbial strains and physiological conditions. 
As a single reaction departs from equilibrium, for example in response to an increase in substrate concentration, its isotopic fractionation will transition from the equilibrium to the kinetic fractionation (DePaolo, 2011; Wing \& Halevy, 2014). For the reaction $r \rightleftarrows p$, the net isotopic fractionation from metabolite pools $r$ and $p$ at steady state $\left(\alpha_{r-p}^{\text {net }}\right)$ can be calculated from the EFF $\left(\alpha_{r-p}^{\mathrm{eq}}\right)$, the forward KFF $\left(\alpha_{r \rightarrow p}^{\mathrm{kin}}\right)$ and the ratio of the backward and forward mass fluxes of the reaction $\left(f_{p, r}\right)$ :

$$
\alpha_{r-p}^{\text {net }}=\left(\alpha_{r-p}^{\mathrm{eq}}-\alpha_{r \rightarrow p}^{\mathrm{kin}}\right) f_{p, r}+\alpha_{r \rightarrow p}^{\mathrm{kin}} .
$$

The thermodynamic end-member is expressed when the reaction is fully reversible $\left(f_{p, r}=1\right)$ and Eq. 8 reduces to $\alpha_{r-p}^{\text {net }}=\alpha_{r-p}^{\mathrm{eq}}$. The kinetic end-member is expressed when the reaction is unidirectional $\left(f_{p, r}=0\right)$ and Eq. 8 reduces to $\alpha_{r-p}^{\text {net }}=\alpha_{r \rightarrow p}^{\text {kin }}$. In a linear reaction network with metabolite pools $s, r$ and $p$ such that $s \rightleftarrows r \rightleftarrows p$, different steps have fractionations that differentially depart from their individual thermodynamic equilibrium fractionation end-members to give a range of disequilibrium fractionations of the total reaction network (Wing \& Halevy, 2014). The net isotopic fractionation between $s$ and $p$ at a steady state can be calculated from the recursive expression:

$$
\alpha_{s-p}^{\text {net }}=\left(\alpha_{r-p}^{\text {net }} \times \alpha_{s-r}^{e q}-\alpha_{s \rightarrow r}^{\mathrm{kin}}\right) f_{r, s}+\alpha_{s \rightarrow r}^{\mathrm{kin}}
$$

(See Appendix A and Wing \& Halevy (2014) for details). In this case, the thermodynamic endmember is expressed when both reactions are fully reversible $\left(f_{r, s}=f_{p, r}=1\right)$ and Eq. 9 reduces to $\alpha_{s-p}^{\text {net }}=\alpha_{r-p}^{\mathrm{eq}} \times \alpha_{s-r}^{\mathrm{eq}}$. The kinetic end-member is expressed when the most upstream reaction is unidirectional $\left(f_{r, s}=0\right)$ and Eq. 9 reduces to $\alpha_{s-p}^{\text {net }}=\alpha_{s \rightarrow r}^{\text {kin }}$. A range of disequilibrium net isotopic fractionations between these values is expressed upon progressive departure from equilibrium (e.g., with increasingly negative $\Delta \mathrm{G}_{\mathrm{r}}$ ), and the transition may not be monotonic due to the dependence on the reversibilities and KFFs of individual reactions. This approach is only applicable to linear metabolic networks, and we use it here to explore the possible effect of the $\Delta \mathrm{G}_{\mathrm{r}}$ (and rate) of hydrogenotrophic and acetoclastic methanogenesis and anaerobic methanotrophy on the carbon isotopic fractionation (Sections 4.4.1, 4.4.4 and 4.4.5).

In some metabolic networks, the isotope exchange reaction involves three compounds rather than two, such as for hydrogen atoms in the hydrogenotrophic pathway. For example, in the reaction $a \mathrm{Y}_{n}+b \mathrm{Y}_{m} \rightleftarrows c \mathrm{Y}_{n+m}$, where $a, b$ and $c$ are arbitrary organic moieties, $\mathrm{Y}$ is the atom of interest and $n$ and $m$ are the stoichiometric coefficients of Y. For brevity, we will denote this reaction as $r_{1}+r_{2} \rightleftarrows p$, where $r_{1}$ is $a \mathrm{Y}_{n}, r_{2}$ is $b \mathrm{Y}_{m}$ and $\mathrm{p}$ is $c \mathrm{Y}_{n+m}$. The change in the isotopic composition of compound $p$ with time can be expressed as:

$$
\begin{aligned}
\frac{d R_{p}}{d t}=\frac{1}{[p]}\left[\phi _ { r p } \left(n \cdot \alpha_{r_{1} \rightarrow p}^{\mathrm{kin}} R_{r_{1}}+m\right.\right. & \left.\cdot \alpha_{r_{2} \rightarrow p}^{\mathrm{kin}} R_{r_{2}}\right)- \\
& \left.\phi_{p r} \cdot R_{p}\left(n \cdot \alpha_{p \rightarrow r_{1}}^{\mathrm{kin}}+m \cdot \alpha_{p \rightarrow r_{2}}^{\mathrm{kin}}\right)-R_{p}(m+n)\left(\phi_{r p}-\phi_{p r}\right)\right],
\end{aligned}
$$

where $\phi_{r p}$ and $\phi_{p r}$ are the net forward and reverse mass fluxes, respectively, and $R_{r_{1}}, R_{r_{2}}$ and $R_{p}$ are the ratios of the rare and abundant isotopes in pools $r_{1}, r_{2}$ and $p$, respectively. In the specific case of 
a chemical and isotopic steady state, the isotopic composition of $p$ is constant, and $\frac{d}{d t}\left([p] \cdot R_{p}\right)=0$. Rearranging Eq. 10 yields an analytical solution for $R_{p}$ at a steady state:

$$
R_{p}=\frac{\phi_{r p}\left(n \cdot \alpha_{r_{1} \rightarrow p}^{\mathrm{kin}} R_{r_{1}}+m \cdot \alpha_{r_{2} \rightarrow p}^{\mathrm{kin}} R_{r_{2}}\right)}{\phi_{p r}\left(n \cdot \alpha_{p \rightarrow r_{1}}^{\mathrm{kin}}+m \cdot \alpha_{p \rightarrow r_{2}}^{\mathrm{kin}}\right)+(m+n)\left(\phi_{r p}-\phi_{p r}\right)}
$$

(see full derivation of Eqs. 10 and 11 in Appendix B.1). In a metabolic network with multiple sources of the atom of interest, extending Eq. 11 is impractical unless we impose constraints over the values of the mass fluxes and isotope effects (e.g., Cao et al., 2019). To avoid prior assumptions, the net isotopic fractionations in such a system can be determined numerically by solving an isotopic mass balance, such as in Eq. 10, for each metabolite as a set of ordinary differential equations. The numerical solutions do not provide the same intuition as analytical expressions, but in some cases the systems can be simplified to produce an approximate analytical solution. We will discuss one such simplified analytical solution for the hydrogen isotopic fractionation between $\mathrm{CH}_{4}$ and $\mathrm{H}_{2} \mathrm{O}$ in the hydrogenotrophic pathway (Section 4.4.2) and a numerical solution for carbon isotopic fractionation in the methylotrophic pathway (Section 4.4.3). In both cases we discuss the isotopic fractionations observed in laboratory cultures or environmental samples. These apparent isotopic fractionations between compounds $\mathrm{A}$ and $\mathrm{B}$ are defined by ${ }^{r} \alpha_{\mathrm{A}-\mathrm{B}} \equiv{ }^{r} R_{\mathrm{A}} /{ }^{r} R_{\mathrm{B}}$ and presented using the $1000 \ln ^{r} \alpha_{\mathrm{A}-\mathrm{B}}$ notation. These isotopic fractionations represent combinations of the equilibrium and kinetic isotopic fractionations (Section 4.4) and should not be confused with the EFFs $\left(1000 \ln ^{r} \alpha_{\mathrm{A}-\mathrm{B}}^{\mathrm{eq}}\right)$ or KFFs $\left(1000 \ln ^{r} \alpha_{\mathrm{A} \rightarrow \mathrm{B}}^{\mathrm{kin}}\right)$.

\subsubsection{Carbon isotopes in the hydrogenotrophic pathway}

Fractionation of carbon isotopes in the hydrogenotrophic methanogenesis pathway $\left(1000 \ln ^{13} \alpha_{\mathrm{CO}_{2}-\mathrm{CH}_{4}}\right)$ ranges from $\sim 10 \%$ to $\sim 90 \%$ in laboratory cultures, and correlates with the net $\Delta \mathrm{G}_{\mathrm{r}}$ and the cellspecific rate of methanogenesis (Valentine et al., 2004; Penning et al., 2005; Takai et al., 2008; Okumura et al., 2016; Topçuoğlu et al., 2019). Cocultures and enrichment experiments of methanogens grown at small negative $\Delta \mathrm{G}_{\mathrm{r}}$ (e.g., low concentrations of $\mathrm{H}_{2}$ ) often have $1000 \ln ^{13} \alpha_{\mathrm{CO}_{2}-\mathrm{CH}_{4}}$ values larger than the equilibrium carbon isotopic fractionation (the temperature-dependent EFF) (Valentine et al., 2004; Penning et al., 2005; Hattori et al., 2012; Topçuoğlu et al., 2019). We compiled the apparent $1000 \ln ^{13} \alpha_{\mathrm{CO}_{2}-\mathrm{CH}_{4}}$ values available in the literature for pure culture, coculture and enrichment experiments. Comparing these measurements with the calculated temperature-dependent EFFs, we found a bimodal distribution with peaks at $+10 \%$ and $-20 \%$ (Fig. S.1). Most of the values larger than the corresponding temperature-dependent EFF are from batch culture experiments. However, we only considered data that was not affected by Rayleigh distillation, that is, experiments where the isotopic composition of the substrates was similar to the initial isotopic composition throughout the experiment.

Previous models of microbial methanogenesis suggested various scenarios in which the reversibility of the metabolic pathway shapes the relationship between $1000 \ln ^{13} \alpha_{\mathrm{CO}_{2}-\mathrm{CH}_{4}}$ and $\Delta \mathrm{G}_{\mathrm{r}}$ 
or the cell-specific methanogenesis rate. In these models, the EFFs and $f$ s for the various steps in the reaction network were treated as free parameters. We used our calculated EFFs at $25{ }^{\circ} \mathrm{C}$ and the mathematical framework for linear metabolic networks outlined in Section 4.4 to explore some of the previously suggested scenarios:

(i) gradual and uniform departure from equilibrium of all steps in the pathway (Wang et al., 2015).

(ii) isotopic equilibrium between $\mathrm{CO}_{2}$ and $\mathrm{CH}_{3}-\mathrm{H}_{4} \mathrm{MPT}$ or $\mathrm{CH}_{3}-\mathrm{SCoM}$, and variable reversibility of the Mtr- or Mcr-catalyzed reactions (Alperin \& Hoehler, 2009; Stolper et al., 2015).

(iii) differential reversibility of the different reactions in the pathway (Cao et al., 2019).

For each scenario, we used some combination of $f$ values in the recursive term in Eq. 9 to estimate $1000 \ln ^{13} \alpha_{\mathrm{CO}_{2}-\mathrm{CH}_{4}}$ (Table 10). We assigned $1000 \ln ^{13} \alpha^{\mathrm{kin}}$ of $-20 \%$ for all the reactions in the pathway, except for $1000 \ln ^{13} \alpha_{\mathrm{CH}_{3}-\mathrm{SCoM} \rightarrow \mathrm{CH}_{4}}^{\mathrm{kin}}$, which has been experimentally measured to be $\sim$ $40 \%$ (Scheller et al., 2013). Though the KFFs other than $1000 \ln ^{13} \alpha_{\mathrm{CH}_{3}-\mathrm{SCoM} \rightarrow \mathrm{CH}_{4}}$ are unknown and were treated here as free parameters, the findings and conclusions below are robust within a reasonable range of these KFFs between $0 \%$ and $-50 \%$. Details of the calculations are in Appendix A.

In scenario $(i)$ of uniform departure from reversibility, the minimal, kinetic end-member $1000 \ln ^{13} \alpha_{\mathrm{CO}_{2}-\mathrm{CH}_{4}}$ value (i.e., when $f=0$ ) is $-20 \%$, consistent with fractionations measured at large negative $\Delta \mathrm{G}_{\mathrm{r}}$. In this case, only the KFF of the most upstream, Fmd-catalyzed reaction $\left(\ln ^{13} \alpha_{\mathrm{CO}_{2} \rightarrow \mathrm{CHO}-\mathrm{MFR}}^{\mathrm{kin}}\right)$ is expressed, and the net fractionations of the other reactions in the network (in this case, all ${ }^{13} \alpha^{\text {kin }}$ values, as $f=0$ ) are not expressed (Eq. 9). The maximal $1000 \ln ^{13} \alpha_{\mathrm{CO}_{2}-\mathrm{CH}_{4}}$ depends on the ${ }^{13} \alpha^{\text {kin }}$ values assigned to the different reactions. For ${ }^{13} \alpha^{\text {kin }}$ values more positive than $-60 \%$, the maximal $1000 \ln ^{13} \alpha_{\mathrm{CO}_{2}-\mathrm{CH}_{4}}$ is the thermodynamic equilibrium carbon isotopic fractionation of $69 \%$. Larger-than-equilibrium $1000 \ln ^{13} \alpha_{\mathrm{CO}_{2}-\mathrm{CH}_{4}}$ values require ${ }^{13} \alpha^{\text {kin }}$ values more negative than $-60 \%$. For example, a $1000 \ln ^{13} \alpha_{\mathrm{CO}_{2}-\mathrm{CH}_{4}}$ value of $75 \%$ at $25{ }^{\circ} \mathrm{C}$ would require ${ }^{13} \alpha^{\text {kin }}$ values of $\sim-80 \%$ o for the reactions catalyzed by Mtd, Mer and Mtr. Though we cannot rule them out, to the best of our knowledge carbon isotope KFFs of such magnitude have not been measured. Within the limits of observed carbon isotope KFFs, the assumption of a uniform departure from equilibrium places a hard limit on the maximum value of $1000 \ln ^{13} \alpha_{\mathrm{CO}_{2}-\mathrm{CH}_{4}}$, which is smaller than the observed net carbon isotopic fractionation.

In scenario (ii), the reactions from $\mathrm{CO}_{2}$ to $\mathrm{CH}_{3}-\mathrm{SCoM}$ are fully reversible (i.e., $f=1$ ), and only the most downstream, Mcr-catalyzed reaction departs from reversibility. When implemented in the framework described above, the range of possible $10001{ }^{13} \alpha_{\mathrm{CO}_{2}-\mathrm{CH}_{4}}$ is $69-106 \%$. The maximal $1000 \ln ^{13} \alpha_{\mathrm{CO}_{2}-\mathrm{CH}_{4}}$ value is due to substitution of the small $\mathrm{CH}_{3}-\mathrm{SCoM}-\mathrm{CH}_{4}$ EFF (we calculated $1.6 \%$ at $25{ }^{\circ} \mathrm{C}$ ) by the much larger KFF of the Mcr-catalyzed step ( $-40 \%$; Scheller et al., 2013). In 
this scenario, $1000 \ln ^{13} \alpha_{\mathrm{CO}_{2}-\mathrm{CH}_{4}}$ cannot be smaller than $69 \%$, which is inconsistent with the large number of $1000 \ln ^{13} \alpha_{\mathrm{CO}_{2}-\mathrm{CH}_{4}}$ measurements that are smaller than this value, suggesting that the departure from equilibrium of the last steps in the pathway cannot be the sole process responsible for the observed range of $\mathrm{CO}_{2}-\mathrm{CH}_{4}$ carbon isotopic fractionation.

In scenario (iii), Cao et al. (2019) explored combinations of differential reversibility in methanogenesis, focusing on clumped isotopologues. They suggested binary $f$ values (either 0 or 1 ) for the reactions catalyzed by Fmd, Mtd, Mer and Mcr. Using our calculated EFFs, we find that the binary scenarios yield $1000 \ln ^{13} \alpha_{\mathrm{CO}_{2}-\mathrm{CH}_{4}}$ covering the range of observed values (20-106\%0). The

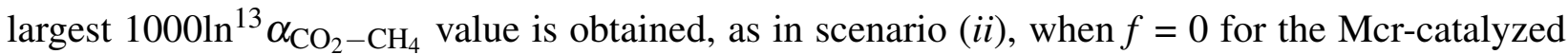
reaction and $f=1$ for all other reactions in the pathway. In this case, a combination of the KFF of the Mcr-catalyzed reaction (-40\%) with the equilibrium $\mathrm{CO}_{2}-\mathrm{CH}_{3}-\mathrm{SCoM}$ carbon isotopic fractionation ( $26 \%$ ) leads to a net $1000 \ln ^{13} \alpha_{\mathrm{CO}_{2}-\mathrm{CH}_{4}}$ of $109 \%$. The smallest $1000 \ln ^{13} \alpha_{\mathrm{CO}_{2}-\mathrm{CH}_{4}}$ is obtained, as in scenario $(i)$, when $f=0$ for the Fmd-catalyzed reaction, leading to expression of only the KFF of that reaction (prescribed to be $-20 \%$ ).

We conclude that both scenarios $(i)$ and (iii) are capable of covering the entire range of observed $1000 \ln ^{13} \alpha_{\mathrm{CO}_{2}-\mathrm{CH}_{4}}$. However, both scenarios invoke arbitrary combinations of the reversibility of the steps in the pathway, and scenario $(i)$ also requires unrealistic carbon isotope KFFs. We note that in all models suggested to date, the reaction reversibilities were assigned rather than calculated, and it seems that a more detailed metabolic model is required to explain the nuances in the dependence of $1000 \ln ^{13} \alpha_{\mathrm{CO}_{2}-\mathrm{CH}_{4}}$ on $\Delta \mathrm{G}_{\mathrm{r}}$.

\subsubsection{Hydrogen isotopes in the hydrogenotrophic pathway}

Fractionation of hydrogen isotopes during hydrogenotrophic methanogenesis in laboratory cultures ranges from $\sim-100 \%$ to $-600 \%$ and displays a weaker dependence on $\Delta \mathrm{G}_{\mathrm{r}}$ than the carbon isotopic fractionation (Valentine et al., 2004; Stolper et al., 2015; Okumura et al., 2016). Ob-

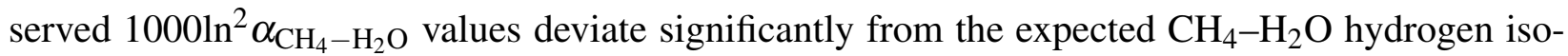
tope EFF (Fig. 7). For example, in two different experiments grown at $55^{\circ} \mathrm{C}$ and low $\mathrm{H}_{2}$ concentrations $(<10 \mu \mathrm{M})$, one a coculture and the other a deep aquifer groundwater incubation, the $1000 \ln ^{2} \alpha_{\mathrm{CH}_{4}-\mathrm{H}_{2} \mathrm{O}}$ values of $-320 \pm 12 \%$ and $-393 \pm 43 \%$, respectively, are significantly more negative than the temperature-dependent equilibrium fractionation of $-175 \%$ (Yoshioka et al., 2008; Hattori et al., 2012). Similar to carbon isotopes, such deviations of $1000 \ln ^{2} \alpha_{\mathrm{CH}_{4}-\mathrm{H}_{2} \mathrm{O}}$ from the temperature-dependent hydrogen isotope EFF may arise from variations in the reversibility of the metabolic pathway, depending on the $\Delta \mathrm{G}_{\mathrm{r}}$. In contrast to carbon isotopes, hydrogen isotope deviations from the EFF may also arise from mixing of hydrogen atom sources through direct incorporation of hydrogen atoms from $\mathrm{H}_{2}$ in the Hmd-catalyzed reaction. There is ample evidence that this only occurs at high $\mathrm{H}_{2}$ pressure or during exponential cell growth (e.g., Kawagucci et al., 2014; Okumura et al., 2016). Thus, it seems likely that the large, negative $1000 \ln ^{2} \alpha_{\mathrm{CH}_{4}-\mathrm{H}_{2} \mathrm{O}}$ values 
observed in cultures grown at low $\mathrm{H}_{2}$ concentrations are due to departure from equilibrium and expression of KFFs, not incorporation of hydrogen from $\mathrm{H}_{2}$.

Hydrogenotrophic methanogenesis involves the stepwise addition of four hydrogen atoms in four individual reactions (Fig. 1). Each of these additions is characterized by an individual net $\mathrm{CH}_{4}-\mathrm{H}_{2} \mathrm{O}$ hydrogen isotopic fractionation, which depends on the reaction reversibility and the equilibrium and kinetic end-member fractionations. The overall $1000 \ln ^{2} \alpha_{\mathrm{CH}_{4}-\mathrm{H}_{2} \mathrm{O}}$ value depends on these individual fractionations in ways that may not be intuitive. In the extreme case that all hydrogen addition reactions are unidirectional (i.e., $f=0$ ), for example at very large negative $\Delta \mathrm{G}_{\mathrm{r}}$ of the methanogenesis reaction, the overall $1000 \ln ^{2} \alpha_{\mathrm{CH}_{4}-\mathrm{H}_{2} \mathrm{O}}$ value will be the average of the four KFFs associated with these reactions. As primary hydrogen isotope KFFs are generally large (e.g., $1000^{2} \alpha_{\mathrm{CH}_{3}-\mathrm{SCoM} \rightarrow \mathrm{CH}_{4}}$ is $\sim-890 \%$ at $60{ }^{\circ} \mathrm{C}$; Scheller et al., 2013), the expectation in this case is a substantially larger-than-equilibrium net $1000 \ln ^{2} \alpha_{\mathrm{CH}_{4}-\mathrm{H}_{2} \mathrm{O}}$, as found in the majority of laboratory culture experiments (Fig. S.1). This phenomenon is also apparent in non canonical methanogenic pathways, such as the nitrogenase-catalyzed formation of methane by nitrogen fixers, where $1000 \mathrm{ln}^{2} \alpha_{\mathrm{CH}_{4}-\mathrm{H}_{2} \mathrm{O}}$ reaches $-730 \%$ at ambient temperatures (Luxem et al., 2020).

Unlike carbon isotopes, for which the reaction network is linear, there are four distinct steps in which exchange of hydrogen isotopes between methane and water may occur. The exchange does not occur directly with intracellular water but through various intracellular metabolites with isotopic compositions that are related to that of the intracellular water. For example, in the Mcr-catalyzed reaction, one hydrogen atom is transferred from $\mathrm{HS}-\mathrm{CoB}$ to $\mathrm{CH}_{3}-\mathrm{SCoM}$ yielding methane with a net $\mathrm{CH}_{4}-\mathrm{H}_{2} \mathrm{O}$ hydrogen isotopic fractionation that depends on the reversibility of this reaction. If the Mcr-catalyzed reaction fully departs from equilibrium $(f=0)$ to express its KFF, the total $1000 \ln ^{2} \alpha_{\mathrm{CH}_{4}-\mathrm{H}_{2} \mathrm{O}}$ will deviate from the calculated EFF, even if the other three hydrogen addition reactions result only in equilibrium isotope effects. In this case (See Appendix B.1 for full derivation), the net $\mathrm{CH}_{4}-\mathrm{H}_{2} \mathrm{O}$ hydrogen isotope fractionation at a steady state between $\mathrm{HS}-\mathrm{CoB}$ and methane is:

$$
{ }^{2} \alpha_{\mathrm{CH}_{4}-\mathrm{H}_{2} \mathrm{O}}^{\text {net }}=\frac{3}{4}\left({ }^{2} \alpha_{\mathrm{CH}_{3}-\mathrm{SCoM} \rightarrow \mathrm{CH}_{4}}^{\mathrm{kin}} /{ }^{2} \alpha_{\mathrm{H}_{2} \mathrm{O}-\mathrm{CH}_{3}-\mathrm{SCoM}}^{\mathrm{eq}}\right)+\frac{1}{4}\left({ }^{2} \alpha_{\mathrm{HS}-\mathrm{CoB} \rightarrow \mathrm{CH}_{4}}^{\mathrm{kin}} /{ }^{2} \alpha_{\mathrm{H}_{2} \mathrm{O}-\mathrm{HS}-\mathrm{CoB}}^{\mathrm{eq}}\right) .
$$

In other words, even if three of the four hydrogen atoms in $\mathrm{CH}_{4}$ reflect equilibrium between $\mathrm{H}_{2} \mathrm{O}$ and an intracellular $\mathrm{CH}_{3}-\mathrm{S}-\mathrm{CoM}$ intermediate, departure of the last hydrogen addition reaction from

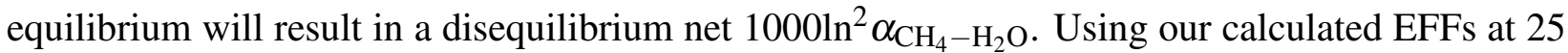
${ }^{\circ} \mathrm{C}$ and literature KFFs for this reaction $\left({ }^{2} \alpha_{\mathrm{CH}_{3}-\mathrm{SCoM} \rightarrow \mathrm{CH}_{4}}^{\mathrm{kin}}=0.85\right.$ and ${ }^{2} \alpha{ }_{\mathrm{HSCoB} \rightarrow \mathrm{CH}_{4}}^{\mathrm{kin}}=0.41$; Scheller et al., 2013), Eq. 12 yields a $1000 \ln ^{2} \alpha_{\mathrm{CH}_{4}-\mathrm{H}_{2} \mathrm{O}}$ value of $-507 \%$, compared to the calculated EFF of $-195 \%$. The standard $\Delta \mathrm{G}_{\mathrm{r}}\left(\Delta \mathrm{G}_{\mathrm{r}}^{0}\right)$ of $\mathrm{Mcr}$ is $\sim-30 \mathrm{~kJ} \mathrm{~mol}^{-1}$, and it has been suggested that during methanogenesis the last hydrogen addition reaction is effectively irreversible (Thauer, 2011). Eq. 12 demonstrates how the KFFs that are associated with Mcr are sufficient to drive deviations of the net $\mathrm{CH}_{4}-\mathrm{H}_{2} \mathrm{O}$ hydrogen isotopic fractionation from equilibrium by more than $300 \%$. 


\subsubsection{Methylotrophic pathway}

The methylotrophic pathway is underrepresented in the literature compared to the hydrogenotrophic pathway, and thus there is a smaller database with which to compare our results. Most of the data are from laboratory experiments, which are important as they are often used to assess the specific pathway of microbial methane production in the environment (e.g., Zhuang et al., 2018). However, the main controls on carbon and hydrogen isotopic fractionation in these pathways remain unclear, as do their dependencies on $\Delta \mathrm{G}_{\mathrm{r}}$. Below, we discuss the implications of our predicted EFFs for the methylotrophic pathway, focusing on carbon isotopes.

Net carbon isotopic fractionation between methanol and methane $1000 \ln ^{13} \alpha_{\text {methanol- } \mathrm{CH}_{4}}$ during methylotrophic methanogenesis in laboratory cultures spans a relatively narrow range of $67-83 \%$ (Krzycki et al., 1987; Londry et al., 2008; Penger et al., 2012, 2014), and methylotrophic enrichment cultures have carbon isotopic fractionations of up to 90\% (Rosenfeld \& Silverman, 1959). It is unclear whether these limited observations cover the entire range of physiologically relevant

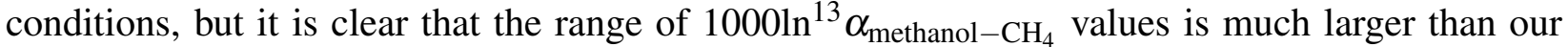
predicted EFFs that are 19.1-20.9\% at $25-40{ }^{\circ} \mathrm{C}$. Methanol conversion to methane is a disproportionation pathway, where methanol molecules are either fully oxidized to $\mathrm{CO}_{2}$ or reduced to methane (Fig. 1). Assuming that all methanol is used to produce chemical energy and not to generate biomass, a 3:1 ratio of reduction:oxidation $\left(R_{\mathrm{r} / \mathrm{o}}\right)$ is expected to account for cycling of the electron carriers. However, $R_{\mathrm{r} / \mathrm{o}}$ may vary if the cells utilize some of the methanol to generate biomass, which requires reducing equivalents. The reducing equivalents in this case are reduced coenzyme $\mathrm{F}_{420}$ and ferredoxin, which are produced in the reverse methanogenesis pathway from $\mathrm{CH}_{3}-\mathrm{S}-\mathrm{CoM}$ to $\mathrm{CO}_{2}$.

We explored the dependence of $1000 \ln ^{13} \alpha_{\text {methanol- }-\mathrm{CH}_{4}}$ and $1000 \ln ^{13} \alpha_{\text {methanol- }-\mathrm{CO}_{2}}$ on the reversibility of the pathway and on $R_{\mathrm{r} / \mathrm{o}}$, and to this end developed a simplified isotopic mass balance to find the isotopic fractionation in the methyltrophic pathway at steady state (see Appendix B.2). We reduced the pathway to its three main branches: (1) from methanol to $\mathrm{CH}_{3}-\mathrm{S}-\mathrm{CoM}$, (2) from $\mathrm{CH}_{3}-\mathrm{S}-\mathrm{CoM}$ to $\mathrm{CH}_{4}$, and (3) from $\mathrm{CH}_{3}-\mathrm{S}-\mathrm{CoM}$ to $\mathrm{CO}_{2}$. We assign KFFs in the range $-30 \%$ to $-50 \%$, assign a value to $R_{r / o}$, and use our calculated EFFs at $25^{\circ} \mathrm{C}$. We assume $75 \%$ reversibility between $\mathrm{CH}_{3}-\mathrm{SCoM}$ and $\mathrm{CO}_{2}\left(f_{3}=0.75\right)$, repeatedly $(\mathrm{N}=10,000)$ pick random reversibility values for reactions $1\left(f_{1}\right)$ and $2\left(f_{2}\right)$ from a uniform distribution between 0 and 1 , and calculate the possible range of $1000 \ln ^{13} \alpha_{\text {methanol- }-\mathrm{CH}_{4}}$ and $1000 \ln ^{13} \alpha_{\text {methanol- }-\mathrm{CO}_{2}}$ values (Table 10).

For $R_{r / o}=3: 1,1000 \ln ^{13} \alpha_{\text {methanol- }-\mathrm{CH}_{4}}$ is $55-70 \%$, covering the lower range of the experimental observations. At $R_{\mathrm{r} / \mathrm{o}}=1: 1$, the range of $1000 \mathrm{ln}^{13} \alpha_{\text {methanol- } \mathrm{CH}_{4}}$ shifts to $60-90 \%$ (Fig. 9 , left), closer to the observed range and suggesting that the ratio of methanol reduction to oxidation may, in some cases, be appreciably lower than 3:1 due to a biosynthetic shunt. At the theoretical extreme case of $R_{\mathrm{r} / \mathrm{o}}=20: 1$, there is almost no oxidation of methanol to $\mathrm{CO}_{2}$, and the $1000 \ln ^{13} \alpha_{\text {methanol-CH}}$ range is $35-55 \%$. These small $1000 \ln ^{13} \alpha_{\text {methanol- }-\mathrm{CH}_{4}}$ values indicate that 
the oxidation to $\mathrm{CO}_{2}$ is required to generate the observed range of carbon isotopic fractionation between methanol and $\mathrm{CH}_{4}$. There are currently no known available measurements of methanol limitation conditions, and we have no indication whether at very low rates of methylotrophic methanogenesis $1000 \ln ^{13} \alpha_{\text {methanol- }-\mathrm{CH}_{4}}$ values approach the EFF.

In this study, we calculated an equilibrium methanol- $\mathrm{CO}_{2}$ carbon isotopic fractionation $\left(1000 \ln ^{13} \alpha_{\text {methanol-CO }}^{\mathrm{eq}}\right.$ of $-47.8 \%$ at $25{ }^{\circ} \mathrm{C}$, while at $R_{\mathrm{r} / \mathrm{o}}=3: 1$ our model predicts a range of net carbon isotopic fractionations between $-25 \%$ and $0 \%$ (Fig. 9, right). At $R_{\mathrm{r} / \mathrm{o}}=1: 1$, the range shifts to $-20 \%$ to $20 \%$. The upper end of this range is similar to the $\sim 20 \%$ fractionations measured in a laboratory cultures (Penger et al., 2012). These values are complemented by the methanol-biomass and methanol-lipid carbon isotopic fractionations, which are also large and positive ( $>30 \%$; Londry et al., 2008) and which stem from the same metabolic branch. In our model, the large, positive $1000 \ln ^{13} \alpha_{\text {methanol }-\mathrm{CO}_{2}}$ values required that the reversibility of the $\mathrm{CH}_{3}-\mathrm{SCoM}$ to $\mathrm{CO}_{2}$ branch be lower than $75 \%$, because the calculated EFF is large and negative. At low reversibility of the methanol oxidation reaction, the net methanol- $\mathrm{CO}_{2}$ fractionation shifts from the large, negative EFF to the large, positive KFF. Overall, this suggests a dominance of kinetic isotope effects in methylotrophic methanogenesis, at least under the conditions explored in laboratory culture experiments.

\subsubsection{Acetoclastic pathway}

The isotope effects in the acetoclastic pathway, similar to the methylotrophic pathway, are not well studied. During acetoclastic methanogenesis, acetate dissociates to a methyl group $\left(\mathrm{C}_{1}\right)$, which is reduced to $\mathrm{CH}_{3}-\mathrm{H}_{4} \mathrm{MPT}$ and later released as $\mathrm{CH}_{4}$, and to a carboxyl group $\left(\mathrm{C}_{2}\right)$, which is released as $\mathrm{CO}_{2}$. The acetoclastic pathway has a smaller carbon isotopic fractionation between the substrate and $\mathrm{CH}_{4}\left(1000 \ln ^{13} \alpha_{\left.\text {acetate }\left(\mathrm{C}_{1}\right)-\mathrm{CH}_{4}\right)}\right)$ than the hydrogenotrophic and methylotrophic pathways, with a range of 7-35\% (Krzycki et al., 1987; Gelwicks et al., 1994; Penning et al., 2006; Londry et al., 2008; Goevert \& Conrad, 2009). Published measurements of the fractionation between the carboxyl group of acetate and $\mathrm{CO}_{2}\left(1000 \ln ^{13} \alpha_{\text {acetate }}\left(\mathrm{C}_{2}\right)-\mathrm{CO}_{2}\right)$ are in the range of 35$47 \%$ in laboratory experiments and as low as $9 \%$ in a rice field soil incubation (Goevert \& Conrad, 2009). We calculated the acetate- $\mathrm{CH}_{4}$ and acetate- $\mathrm{CO}_{2}$ carbon isotope EFFs of $16.3 \%$ and $13.3 \%$, respectively, at $25{ }^{\circ} \mathrm{C}$. The equilibrium carbon isotopic fractionations between the $\mathrm{C}_{1}$ atoms in acetate and those in acetyl-CoA and $\mathrm{CH}_{3}-\mathrm{H}_{4} \mathrm{MPT}$ are $-0.4 \%$ and $-3.3 \%$, respectively. The largest equilibrium carbon isotopic fractionation in this pathway is associated with the methyl group transfer between $\mathrm{CH}_{3}-\mathrm{H}_{4} \mathrm{MPT}$ and $\mathrm{CH}_{3}-\mathrm{S}-\mathrm{CoM}(17.9 \%)$.

We explored the dependence of $1000 \ln ^{13} \alpha_{\text {acetate }\left(\mathrm{C}_{1}\right)-\mathrm{CH}_{4}}$ and $1000 \ln ^{13} \alpha_{\text {acetate }\left(\mathrm{C}_{2}\right)-\mathrm{CO}_{2}}$ on the reversibility of reactions in the pathway using the recursive expression in Eq. 9 for linear metabolic networks (details in Appendix A). A scenario of full reversibility (i.e., isotopic equilibrium) in the steps before the Mcr-catalyzed reaction and variable expression of ${ }^{13} \alpha_{\mathrm{CH}_{3}-\mathrm{SCoM} \rightarrow \mathrm{CH}_{4}}^{\mathrm{kin}}$ yields a 
$1000 \ln { }^{13} \alpha_{\text {acetate }\left(\mathrm{C}_{1}\right)-\mathrm{CH}_{4}}$ value between $16 \%$ and $53 \%$ at $25{ }^{\circ} \mathrm{C}$ depending on the reversibility of the Mcr-catalyzed reaction (Table 10). This calculated range covers most of the range observed in laboratory experiments, but it also dictates that $1000 \ln ^{13} \alpha_{\text {acetate }\left(\mathrm{C}_{2}\right)-\mathrm{CO}_{2}}$ is equal to the acetate- $-\mathrm{CO}_{2}$ carbon isotope EFF $(-13 \%)$, much lower than the observed range. This suggests that the observed ranges of carbon isotopic fractionations between acetate and $\mathrm{CO}_{2}$ or $\mathrm{CH}_{4}$ are due to expression of kinetic isotope effects not only in the Mcr-catalyzed reaction but also in the first two reactions in the acetoclastic pathway (catalyzed by Ack/Pta and Cdh, Table 1).

\subsubsection{Anaerobic methane oxidation}

In reverse-methanogenesis AOM, the EFFs are the inverse of those in hydrogenotrophic methanogenesis, with the expected $1000 \ln ^{13} \alpha_{\mathrm{CH}_{4}-\mathrm{CO}_{2}}^{\text {eq }}$ in the range of $-50 \%$ to $-70 \%$ depending on temperature. To date, there are only a few measured $1000 \ln ^{13} \alpha_{\mathrm{CH}_{4}-\mathrm{CO}_{2}}$ and $1000 \ln ^{2} \alpha_{\mathrm{CH}_{4}-\mathrm{H}_{2} \mathrm{O}}$ values of AOM in laboratory cultures, with ranges of 12-38\% and 103-274\%, respectively (Holler et al., 2009). This enrichment of methane in ${ }^{13} \mathrm{C}$ and $\mathrm{D}$ contradicts the trends predicted by the EFFs for these reactions, suggesting that under the conditions of the available experimental results, the kinetic fractionation of carbon and hydrogen isotopes of steps in the pathway contributed to the observed net fractionations. There are limited observations at low sulfate availability $(<0.5 \mathrm{mM})$, in which methane is depleted in ${ }^{13} \mathrm{C}$ during AOM activity (Yoshinaga et al., 2014; Chuang et al., 2018). More specifically, Chuang et al. (2018) observed an apparent $\mathrm{CH}_{4}-\mathrm{CO}_{2}$ fractionation of $-54.3 \%$ in the sulfate-methane transition zone (SMTZ), compared to the expected temperaturedependent EFF of $-76.1 \%$ at $5{ }^{\circ} \mathrm{C}$. In the case of $\mathrm{AOM}$, a positive apparent $1000 \ln ^{13} \alpha_{\mathrm{CH}_{4}-\mathrm{CO}_{2}}$ is indicative of strong kinetic control over the system, whereas negative values, though not as negative as the EFFs, are indicative of joint expression of equilibrium and kinetic isotope effects.

To explore the possible control of the reversibility on $1000 \ln ^{13} \alpha_{\mathrm{CH}_{4}-\mathrm{CO}_{2}}$ during reverse-methanogenesis AOM, we used the recursive expression in Eq. 9 for linear metabolic networks (details in Appendix A). We applied the approach of Cao et al. (2019) for methanogenesis, where we followed the carbon isotope reservoir effect of the seven reactions in the pathway (Table 10). We used the EFFs calculated in the present study at $25{ }^{\circ} \mathrm{C}$, and calculated a $1000 \ln ^{13} \alpha_{\mathrm{CH}_{4} \rightarrow \mathrm{CH}_{3}-\mathrm{SCoM}}^{\mathrm{kin}}$ value of $-38 \%$ based on the measured $1000 \ln ^{13} \alpha_{\mathrm{CH}_{3}-\mathrm{SCoM} \rightarrow \mathrm{CH}_{4}}^{\mathrm{kin}}$ value (-40\%, Scheller et al., 2013) and our calculated $1000 \ln ^{13} \alpha_{\mathrm{CH}_{4}-\mathrm{CH}_{3}-\mathrm{SCoM}}^{\mathrm{eq}}(-2 \%)$. For the rest of the pathway, we assumed arbitrary but reasonable $1000 \ln ^{13} \alpha^{\text {kin }}$ values of $-5 \%$ or $-40 \%$ (Table 10 ).

We find that at steady state, a gradual expression of $1000 \ln ^{13} \alpha_{\mathrm{CH}_{4} \rightarrow \mathrm{CH}_{3}-\mathrm{SCoM}}^{\mathrm{kin}}$ (moving from $f$ $=1$ to 0 ) yields the largest $1000 \ln ^{13} \alpha_{\mathrm{CH}_{4}-\mathrm{CO}_{2}}$ range of $-69 \%$ to $37 \%$. The minimum value in this case is the calculated EFF, and the maximum value is the complete expression of $1000 \ln ^{13} \alpha_{\mathrm{CH}_{4} \rightarrow \mathrm{CH}_{3}-\mathrm{SCoM}}^{\mathrm{kin}}$ blocking any expression of isotope effects downstream of the reaction catalyzed by Mcr (Table 11). This covers the entire observed range of AOM $1000 \mathrm{ln}^{13} \alpha_{\mathrm{CH}_{4}-\mathrm{CO}_{2}}$ in laboratory cultures (12-38\%). However, it is not clear whether this reaction can actually be fully irreversible due to its large- 
positive $\Delta \mathrm{G}_{\mathrm{r}}^{0}\left(+30 \mathrm{~kJ} \mathrm{~mol}^{-1}\right)$ (Thauer, 2011). Net forward reaction would likely require substantial adjustment of the intracellular metabolite concentrations so that the actual $\Delta \mathrm{G}_{\mathrm{r}}$ is a small negative number (i.e., relatively close to equilibrium). The observed range of AOM $1000 \ln ^{13} \alpha_{\mathrm{CH}_{4}-\mathrm{CO}_{2}}$ can also be obtained if the next downstream step, between $\mathrm{CH}_{3}-\mathrm{SCoM}$ and $\mathrm{CH}_{3}-\mathrm{H}_{4} \mathrm{MPT}$, imposes a reservoir effect and assuming a $1000 \mathrm{ln}^{13} \alpha_{\mathrm{CH}_{3}-\mathrm{SCoM} \rightarrow \mathrm{CH}_{3}-\mathrm{H}_{4} \mathrm{MPT}}$ of $-40 \%$, similar to the approach taken by Alperin \& Hoehler (2009). As the isotope reservoir effect occurs further downstream in the AOM pathway, the range of net carbon isotopic fractionation becomes smaller, until finally the maximal $1000 \ln ^{13} \alpha_{\mathrm{CH}_{4}-\mathrm{CO}_{2}}$ is between $-50 \%$ and $-15 \%$, depending on the magnitude of ${ }^{13} \alpha_{\mathrm{CHO}-\mathrm{MFR} \rightarrow \mathrm{CO}_{2}}^{\text {kin }}$.

\subsubsection{Mixing and combinatorial effects in clumped isotopologues}

Recent years have seen a surge in measurements of the abundances of the clumped methane isotopologues $\Delta^{13} \mathrm{CH}_{3} \mathrm{D}$ and $\Delta^{12} \mathrm{CH}_{2} \mathrm{D}_{2}$ from natural environments and laboratory cultures (e.g., Stolper et al., 2014a; Wang et al., 2015; Douglas et al., 2016; Shuai et al., 2018; Ash et al., 2019; Giunta et al., 2019). Further analytical advances have allowed measurements of clumped-isotopologue abundances of other hydrocarbons (e.g., ethane; Clog et al., 2018), but the application to other organic molecules has so far been limited. Natural samples of methane from marine sediments, natural gas and methane hydrates often have equilibrium $\Delta^{13} \mathrm{CH}_{3} \mathrm{D}$ and $\Delta^{12} \mathrm{CH}_{2} \mathrm{D}_{2}$ compositions (Stolper et al., 2014a; Giunta et al., 2019; Ash et al., 2019). However, methane from laboratory cultures and some natural environments is mostly at $\Delta^{13} \mathrm{CH}_{3} \mathrm{D}$ and $\Delta^{12} \mathrm{CH}_{2} \mathrm{D}_{2}$ disequilibrium (Stolper et al., 2015; Wang et al., 2015, 2016; Douglas et al., 2016; Young et al., 2016, 2017; Giunta et al., 2019; Gruen et al., 2018; Douglas et al., 2020). There is an ongoing effort to explain the mechanisms responsible for these disequilibrium clumped-isotope compositions, and the current models invoke a dependence on the rate of methanogeneis through expression of KIEs (Stolper et al., 2014b; Wang et al., 2015; Douglas et al., 2020; Cao et al., 2019; Douglas et al., 2020), quantum tunneling (Young et al., 2017; Young, 2019), mixing of methane sources (Young et al., 2016; Douglas et al., 2016), and combinatorial effects, which are a specific case of mixing of hydrogen sources, relevant mainly for D-D clumps (Yeung, 2016; Röckmann et al., 2016; Young et al., 2017; Taenzer et al., 2020). Most of the modeling efforts require parameters such as the EFFs and KFFs of the reactions in the methanogenesis and AOM pathways, and so far, there have been only a few reports of these values (e.g., Wang et al., 2016; Whitehill et al., 2017; Gruen et al., 2018; Ono et al., 2020). Furthermore, the available reports usually reflect the net isotopic fractionation (i.e., a combination of EFFs and KFFs associated with the reaction network) rather than reaction-specific EFFs or KFFs, and in most cases they lump together the primary and secondary KFFs. Our calculations of the EFFs may be useful when implementing such models to explain disequilibrium methane clumped-isotope compositions.

Cao et al. (2019) explored the effects of the reversibility of the enzymatically-catalyzed re- 
actions in hydrogenotrophic methanogenesis on the $\Delta^{13} \mathrm{CH}_{3} \mathrm{D}-\Delta{ }^{12} \mathrm{CH}_{2} \mathrm{D}_{2}$ space (Section 4.4.1). They defined scenarios, denoted by binary reversibility (i.e., $f=0$ or 1 ) vectors of the four hydrogen addition reactions (e.g., $[1,1,1,1]$ when all reactions are reversible, $[0,0,0,0]$ when all reactions are irreversible). They assumed an identical hydrogen isotope KFF for each of the four reactions, an identical EFF for all four reactions, and hydrogen isotopic equilibrium between the intracellular hydrogen pools $\left(\mathrm{F}_{420} \mathrm{H}_{2}, \mathrm{HS}-\mathrm{CoB}\right.$ and $\left.\mathrm{H}_{2} \mathrm{O}\right)$. Drawing from a wide distribution of KFF and EFF values, Cao et al. (2019) showed that the predicted range of $\Delta^{13} \mathrm{CH}_{3} \mathrm{D}$ and $\Delta \Delta^{12} \mathrm{CH}_{2} \mathrm{D}_{2}$ covers the entire range of laboratory and natural observations of microbial methane. Using a comparable conceptual framework and EFFs calculated for metal-catalyzed abiotic formation of methane, Young (2019) similarly found that the entire laboratory and environmental ranges of $\Delta^{13} \mathrm{CH}_{3} \mathrm{D}$ and $\Delta^{12} \mathrm{CH}_{2} \mathrm{D}_{2}$ could be reproduced. However, in the absence of EFFs relevant to the large organic molecules involved in hydrogenotrophic methanogenesis, both studies made assumptions (identical EFFs and KFFs), allowances (wide distributions of EFF and KFF values), and analogies (microbial methanogenesis versus metal-catalyzed radical reactions) that may not be appropriate.

We used the framework presented in Table 1 in Cao et al. (2019) to recalculate the $\Delta^{13} \mathrm{CH}_{3} \mathrm{D}-$ $\Delta^{12} \mathrm{CH}_{2} \mathrm{D}_{2}$ ranges using our calculated EFFs and $\Delta_{i}^{\mathrm{eq}}$ values together with the forward and reverse KFFs of the Mcr-catalyzed reaction as measured by Scheller et al. (2013). As we currently do not have good estimates for the KFFs other than that of the Mcr-catalyzed reaction, we adopted the distributions used by Cao et al. (2019) for these KFFs. Under these conditions, the range of $\Delta^{13} \mathrm{CH}_{3} \mathrm{D}$ and $\Delta^{12} \mathrm{CH}_{2} \mathrm{D}_{2}$ values were significantly offset from those calculated by Cao et al. (2019) under all three reversibility scenarios (Fig. 10). Our calculated $\Delta^{12} \mathrm{CH}_{2} \mathrm{D}_{2}$ values in all three scenarios are more negative by $\sim 20-100 \%$ than values typical of hydrogenotrophic methanogenesis, which are not lower than $-20 \%$ (Giunta et al., 2019; Young et al., 2017). It is unlikely that the binary reversibility vectors are responsible for this significant $\Delta^{12} \mathrm{CH}_{2} \mathrm{D}_{2}$ 'anti-clumping', as these arbitrary, end-member scenarios should cover the possible range of $\Delta^{12} \mathrm{CH}_{2} \mathrm{D}_{2}$ values. Instead, these results may implicate the assumption of an equilibrium between the intracellular hydrogen pools as the cause of the mismatch between observed and calculated $\Delta^{12} \mathrm{CH}_{2} \mathrm{D}_{2}$ values. This theoretical exercise clearly highlights the importance of using robust EFFs and a more realistic description of the metabolic pathway to shed light on the possible determinants of methane clumped-isotope signatures. 


\section{CONCLUSIONS}

This study provides a set of equilibrium carbon, hydrogen and clumped isotope fractionation factors associated with methanogenesis and anaerobic oxidation of methane, calculated by DFT at the M06-L/def2 TZVP level of theory with the SMD implicit solvation model. We compared our calculations to previous experimentally measured carbon and hydrogen isotope EFFs of the small, volatile end-members of these metabolic pathways $\left(\mathrm{CO}_{2}, \mathrm{CH}_{4}, \mathrm{H}_{2} \mathrm{O}, \mathrm{H}_{2}\right)$. Notably, we suggest that the $\mathrm{CH}_{4}-\mathrm{H}_{2} \mathrm{O}$ hydrogen isotope $\mathrm{EFF}$ at low (biologically-relevant) temperatures is probably more positive than the values obtained from extrapolation from high-temperature $\left(>200{ }^{\circ} \mathrm{C}\right)$ experimental results. Experimental results with which one would normally compare our calculated EFFs are mostly absent, and we based our computational pipeline on a previous exploration of the optimal method of calculating of EFFs for large organic molecules.

We used our calculated EFFs to probe the isotopic fractionation among molecules in the most important metabolic pathways of anaerobic production and oxidation of methane-hydrogenotrophic, methylotrophic and acetoclastic methanogenesis - and anaerobic oxidation of methane. In these pathways, the net isotopic fractionation between the reactants and products are determined by a combination of EFFs and KFFs, and the degree of expression of each depends on the metabolic state of the organisms. In extremely energy-limited environments, the extracellular reactants and products may be in isotopic equilibrium. In this case, the intracellular reactions will also be at or close to equilibrium, each expressing its respective EFF. If more energy is available, departure from equilibrium of some (but not necessarily all) of the intracellular reactions in the pathway results in net fractionations that reflect a combination of their respective EFF and KFF, the contribution of which depends on the degree of departure of the reactions from equilibrium.

In the hydrogenotrophic methanogenesis pathway, we suggest that the large range of $\mathrm{CO}_{2}-$ $\mathrm{CH}_{4}$ carbon isotope fractionations is a product of differential departure from reversibility along the metabolic pathway rather than a uniform departure of all reactions or a departure of only one of the reactions from equilibrium. In the methylotrophic pathway, the calculated $\mathrm{CH}_{3} \mathrm{OH}-\mathrm{CH}_{4}$ carbon isotope fractionation is smaller than the apparent fractionations observed in environmental and laboratory culture samples by at least 50\%. Using a numerical solution to a simplified model of the methylotrophic pathway, we suggest that the large observed carbon isotope fractionations are due to utilization of some of the electrons from methanol to fix biomass rather than to produce methane, resulting in a higher proportion of methanol oxidation to $\mathrm{CO}_{2}$ than reaction stoichiometry would dictate in the absence of biomass fixation.

We also used our calculated EFFs to probe the clumped-isotope compositions of methane in the hydrogenotrophic pathway based on several scenarios for reaction reversibility. Using a common assumption of isotopic equilibrium between $\mathrm{H}_{2} \mathrm{O}$ and the intracellular hydrogen donors, we found that the abundance of the ${ }^{12} \mathrm{CH}_{2} \mathrm{D}_{2}$ clumped isotopogue of methane is lower than observed 
in laboratory cultures. Mixing (combinatorial) effects of hydrogen transferred to methane from intracellular hydrogen pools $\left(\mathrm{F}_{420} \mathrm{H}_{2}\right.$ and $\left.\mathrm{HS}-\mathrm{CoB}\right)$ that are out of equilibrium with the intracellular water is a possible explanation for this mismatch. We suggest that incorporating realistic EFFs and KFFs in future models and using more accurate descriptions of the metabolic pathway will be critical in gaining a better understanding of the biochemical mechanisms that govern the clumped isotopic compositions of methane and other organic molecules.

The EFF values we discussed in this work are universal among all organisms that utilize similar organic compounds, irrespective of possible inter-species differences in the enzymes that catalyze reactions among these compounds. In contrast, KFFs may often be strain-specific, due to differences in the transition state of the reaction enforced by the enzyme active site (Bradley et al., 2016). Moreover, theoretical predictions of KFFs are currently considered harder to obtain than EFFs, and also often less accurate. To date, there is an experimental estimate of only a single KFF in the methanogenesis pathway (for Mcr; Scheller et al. 2013), from a single organism. Further studies of KFFs for the other enzymes in the pathway, preferably from several organisms, are sorely needed to complement the EFFs provided here.

The simplified examples discussed in this work provide a glimpse of the insights into complex biological systems, made available by accurate determination of equilibrium isotope fractionation factors. In the future, the comprehensive set of EFFs calculated here can be used in investigations of biologically-induced isotope effects in methanogenesis and AOM, to expand our understanding of the interaction between microorganisms and their environment, and the way in which these interactions are recorded in the stable isotope composition of natural materials. 
${ }_{796}$ RESEARCH DATA

797 All code and data for the models presented here are posted in a GitHub repository (https://github.com/jagropp/EFFs

\section{ACKNOWLEDGMENTS}

799 We would like to thank Shuhei Ono, Wil Leavitt and an anonymous reviewer for suggestions and comments that helped to improve this manuscript. I.H. acknowledges support from a European Research Council Starting Grant No. 337183. J.G. acknowledges support from the Weizmann 802 Institute Sustainability and Energy Research Initiative. 
Table 1: Enzymes that are included in this report and the reactions they catalyze. The hydrogen and carbon atoms of interest are shown in bold. Note that we include only the reactions that participate in carbon and hydrogen isotope exchange during methanogenesis and AOM.

\begin{tabular}{|c|c|c|c|c|}
\hline$\#$ & Enzyme & Reactant & & Product \\
\hline 1 & Fmd* & $\mathrm{CO}_{2}+\mathrm{Fd}_{\mathrm{red}}+\mathrm{MFR}+2 \mathrm{H}^{+}$ & $\rightleftarrows$ & CHO-MFR $+\mathrm{Fd}_{\mathrm{Ox}}+\mathrm{H}_{2} \mathrm{O}$ \\
\hline 2 & Ftr & CHO-MFR $+\mathrm{H}_{4} \mathrm{MPT}$ & $\rightleftarrows$ & $\mathbf{C H O}-\mathrm{H}_{4} \mathrm{MPT}+\mathrm{MFR}$ \\
\hline 3 & Mch & CHO-H $4 \mathrm{MPT}+\mathrm{H}^{+}$ & $\rightleftarrows$ & $\mathbf{C H} \equiv \mathrm{H}_{4} \mathrm{MPT}^{+}+\mathrm{H}_{2} \mathrm{O}$ \\
\hline 4 & Mtd & $\mathbf{C H} \equiv \mathrm{H}_{4} \mathrm{MPT}^{+}+\mathrm{F}_{420} \mathbf{H}_{2}$ & $\rightleftarrows$ & $\mathbf{C H}_{2}=\mathrm{H}_{4} \mathrm{MPT}+\mathrm{F}_{420}+\mathrm{H}^{+}$ \\
\hline 5 & Hmd & $\mathbf{C H} \equiv \mathrm{H}_{4} \mathrm{MPT}^{+}+\mathbf{H}_{2}$ & $\rightleftarrows$ & $\mathbf{C H}_{2}=\mathrm{H}_{4} \mathrm{MPT}$ \\
\hline 6 & Mer & $\mathbf{C H}_{2}=\mathrm{H}_{4} \mathrm{MPT}+\mathrm{F}_{420} \mathbf{H}_{2}$ & $\rightleftarrows$ & $\mathbf{C H}_{3}-\mathrm{H}_{4} \mathrm{MPT}+\mathrm{F}_{420}$ \\
\hline 7 & Mtr & $\mathbf{C H}_{3}-\mathrm{H}_{4} \mathrm{MPT}+\mathrm{HS}-\mathrm{CoM}$ & $\rightleftarrows$ & $\mathbf{C H}_{3}-\mathrm{SCoM}+\mathrm{H}_{4} \mathrm{MPT}$ \\
\hline 8 & Mcr & $\mathbf{C H}_{3}-\mathrm{SCoM}+\mathbf{H S}-\mathrm{CoB}$ & $\rightleftarrows$ & $\mathbf{C H}_{4}+\mathrm{CoM}-\mathrm{S}-\mathrm{S}-\mathrm{CoB}$ \\
\hline 9 & $\operatorname{Frh}^{*}$ & $\mathrm{H}_{2}+\mathrm{F}_{420}$ & $\rightleftarrows$ & $\mathrm{F}_{420} \mathbf{H}_{2}$ \\
\hline 10 & $\mathrm{Hdr}^{*}$ & $\mathrm{H}_{2}+$ CoM-S-S-CoB $+\mathrm{Fd}_{\mathrm{ox}}$ & $\rightleftarrows$ & $\mathbf{H S}-\mathrm{CoB}+\mathrm{HS}-\mathrm{CoM}+\mathrm{Fd}_{\mathrm{red}}+2 \mathrm{H}^{+}$ \\
\hline 11 & Mta & $\mathbf{C H}_{3} \mathrm{OH}+\mathrm{HS}-\mathrm{CoM}$ & $\rightleftarrows$ & $\mathbf{C H}_{3}-\mathrm{SCoM}+\mathrm{H}_{2} \mathrm{O}$ \\
\hline 12 & Ack/Pta & $\mathbf{C H}_{3}-\mathbf{C O O}^{-}+\mathrm{ATP}+\mathrm{CoA}-\mathrm{SH}$ & $\rightleftarrows$ & $\mathbf{C H}_{3}-\mathbf{C O S C o A}+\mathrm{ADP}+\mathrm{HPO}_{4}^{2-}$ \\
\hline 13 & $\mathrm{Cdh}$ & $\mathbf{C H}_{3}-\mathbf{C O S C o A}+\mathrm{H}_{4} \mathrm{MPT}+\mathrm{Fd}_{\mathrm{ox}}$ & $\rightleftarrows$ & $\mathbf{C H}_{3}-\mathrm{H}_{4} \mathrm{MPT}+\mathbf{C O}_{2}+\mathrm{CoA}-\mathrm{SH}+\mathrm{Fd}_{\mathrm{red}}$ \\
\hline
\end{tabular}

* In these reactions, the source of the hydrogen atom is a proton from $\mathrm{H}_{2} \mathrm{O}$, while $\mathrm{H}_{2}$ is the electron donor of the reaction.

Abbreviations: Fmd - formyl-methanofuran dehydrogenase; Ftr - formyl transferase; Mch methylene- $\mathrm{H}_{4} \mathrm{MPT}$ cyclohydrolase; Mtd - $\mathrm{F}_{420}$-dependent methylene- $\mathrm{H}_{4} \mathrm{MPT}$ dehydrogenase; Hmd - $\mathrm{H}_{2}$-forming methylene dehydrogenase; Mer - methylene- $\mathrm{H}_{4} \mathrm{MPT}$ reductase; Mtr - methyl transferase; Mcr - methyl-CoM reductase; Frh - $\mathrm{F}_{420}$-reducing hydrogenase; Hdr - heterodisulfide reductase; Mta - methanol:coenzyme M methyltransferase; Ack - acetate kinase; Pta - phosphotransacetylase; Cdh - CO-dehydrogenase/acetyl-CoA synthase; MFR - methanofuran; $\mathrm{H}_{4} \mathrm{MPT}$ tetrahydromethanopterin; $\mathrm{F}_{420}$ - oxidized coenzyme $\mathrm{F}_{420} ; \mathrm{F}_{420} \mathrm{H}_{2}$ - reduced coenzyme $\mathrm{F}_{420} ; \mathrm{Fd}$ ferredoxin; HS-CoM - Coenzyme M; HS-CoB - Coenzyme B; CoM-S-S-CoB - heterodisulfide; CoA-SH - coenzyme A. 
Table 2: Coefficients for the fourth-order polynomial fits to ${ }^{2} \beta$ values. Computed at the M06-L/def2TZVP level of theory, between 273.15 and $973.15 \mathrm{~K}\left(0-700{ }^{\circ} \mathrm{C}\right)$. The fit to all values is of the form $\mathrm{A} \times 10^{12} / \mathrm{T}^{4}+\mathrm{B} \times 10^{9} / \mathrm{T}^{3}+\mathrm{C} \times 10^{6} / \mathrm{T}^{2}+\mathrm{D} \times 10^{3} / \mathrm{T}+\mathrm{E}$. For compounds with two or more inequivalent hydrogen atoms, the position-specific isotope substitutions are marked in bold font. For compounds with steric centers, we present the relevant stereoisomers (pro-R or pro-S). For a full list of the RPFR values see Tables S.1 and S.2.

\begin{tabular}{lccccccc}
\hline Compound & $\mathrm{A} \times 10^{-3}$ & $\mathrm{~B} \times 10^{-2}$ & $\mathrm{C} \times 10^{-2}$ & $\mathrm{D} \times 10^{-2}$ & $\mathrm{E}$ & ${ }^{2} \beta\left(25^{\circ} \mathrm{C}\right)$ & $\mathrm{C}$ valence \\
\hline $\mathrm{CHO}-\mathrm{MFR}$ & 167.555 & -84.343 & 246.766 & -219.067 & 1.879 & 11.6617 & +2 \\
$\mathrm{CHO}-\mathrm{H}_{4} \mathrm{MPT}$ & 168.547 & -85.518 & 249.729 & -222.961 & 1.89616 & 11.5740 & +2 \\
$\mathrm{CH} \equiv \mathrm{H}_{4} \mathrm{MPT}^{+}$ & 195.478 & -101.046 & 288.642 & -259.554 & 2.04363 & 12.4210 & +2 \\
$\mathrm{CH}_{2}=\mathrm{H}_{4} \mathrm{MPT}$ (pro-S) & 230.033 & -120.302 & 338.561 & -317.557 & 2.27702 & 13.4320 & 0 \\
$\mathrm{CH}_{2}=\mathrm{H}_{4} \mathrm{MPT}$ (pro-R) & 230.714 & -121.129 & 341.502 & -322.530 & 2.30194 & 13.3951 & 0 \\
$\mathrm{CH}_{3}-\mathrm{OH}$ & 182.591 & -91.671 & 267.380 & -238.241 & 1.95795 & 12.5648 & -2 \\
$\mathrm{CH}_{3}-\mathrm{H}_{4} \mathrm{MPT}$ & 180.957 & -91.660 & 267.497 & -239.266 & 1.96388 & 12.3466 & -2 \\
$\mathrm{CH}_{3}-\mathrm{SCoM}$ & 164.319 & -82.161 & 242.168 & -210.262 & 1.84204 & 11.8269 & -2 \\
$\mathrm{CH}_{3}-\mathrm{COO}-$ & 155.320 & -77.350 & 230.683 & -198.767 & 1.79846 & 11.5532 & -3 \\
$\mathrm{CH}_{3}-\mathrm{COSCoA}$ & 157.643 & -78.365 & 232.909 & -200.537 & 1.80484 & 11.6615 & -3 \\
$\mathrm{CH}_{4}$ (g) & 130.627 & -62.458 & 194.656 & -158.370 & 1.63645 & 11.1873 & -4 \\
$\mathrm{H}_{2} \mathrm{O}$ (g) & 137.421 & -64.383 & 204.176 & -151.087 & 1.61410 & 12.6136 & - \\
$\mathrm{H}_{2}$ (g) & 4.783 & -1.839 & 16.090 & 23.524 & 0.92746 & 3.4378 & - \\
$\mathrm{F}_{420} \mathbf{H}_{2}$ (pro-S) & 184.583 & -94.693 & 273.108 & -247.161 & 1.99267 & 12.0564 & - \\
$\mathbf{H S}_{-} \mathrm{CoB}$ & 34.348 & -14.865 & 63.062 & -30.632 & 1.11648 & 5.9213 & - \\
\hline
\end{tabular}

Table 3: Coefficients for the fourth-order polynomial fits to ${ }^{13} \beta$ values. Computed at the M06-L/def2TZVP level of theory, between 273.15 and $973.15 \mathrm{~K}\left(0-700{ }^{\circ} \mathrm{C}\right)$. The fit to all values is of the form $\mathrm{A} \times$ $10^{12} / \mathrm{T}^{4}+\mathrm{B} \times 10^{9} / \mathrm{T}^{3}+\mathrm{C} \times 10^{6} / \mathrm{T}^{2}+\mathrm{D} \times 10^{3} / \mathrm{T}+\mathrm{E}$. For compounds with two or more inequivalent carbon atoms, the position-specific isotope substitutions are marked in bold font. For a full list of the RPFR values see Tables S.1 and S.2.

\begin{tabular}{lccccccc}
\hline Compound & $\mathrm{A} \times 10^{-6}$ & $\mathrm{~B} \times 10^{-5}$ & $\mathrm{C} \times 10^{-4}$ & $\mathrm{D} \times 10^{-4}$ & $\mathrm{E}$ & $13 \beta\left(25^{\circ} \mathrm{C}\right)$ & $\mathrm{C}$ valence \\
\hline $\mathrm{CO}_{2}(\mathrm{~g})$ & 337.660 & -380.158 & 215.297 & 194.858 & 0.99085 & 1.1977 & +4 \\
$\mathrm{CH}_{3}-\mathrm{COO}{ }^{-}$ & 376.418 & -496.601 & 301.421 & -55.714 & 1.00117 & 1.1818 & +3 \\
$\mathrm{CH}_{3}-\mathrm{COSCoA}$ & 220.645 & -331.492 & 228.555 & -3.505 & 0.99906 & 1.1578 & +3 \\
$\mathrm{CHO}-\mathrm{MFR}$ & 342.806 & -451.468 & 266.672 & 16.754 & 0.998 & 1.1769 & +2 \\
$\mathrm{CHO}-\mathrm{H}_{4} \mathrm{MPT}$ & 365.873 & -466.108 & 272.013 & -3.047 & 0.99925 & 1.1747 & +2 \\
$\mathrm{CH} \equiv \mathrm{H}_{4} \mathrm{MPT}$ & 284.386 & -389.139 & 249.574 & 32.095 & 0.99791 & 1.1786 & +2 \\
$\mathrm{CH}_{2}=\mathrm{H}_{4} \mathrm{MPT}$ & 277.203 & -354.319 & 223.792 & 20.167 & 0.99867 & 1.1586 & 0 \\
$\mathrm{CH}_{3}-\mathrm{OH}$ & 234.470 & -310.213 & 180.119 & 90.771 & 0.99613 & 1.1418 & -2 \\
$\mathrm{CH}_{3}-\mathrm{H}_{4} \mathrm{MPT}$ & 243.089 & -301.290 & 177.597 & 80.947 & 0.99658 & 1.1406 & -2 \\
$\mathrm{CH}_{3}-\mathrm{SCOM}$ & 152.839 & -197.916 & 126.247 & 114.374 & 0.99526 & 1.1203 & -2 \\
$\mathrm{CH}_{3}-\mathrm{COOH}$ & 100.086 & -177.146 & 136.586 & 125.940 & 0.99473 & 1.1364 & -3 \\
$\mathbf{C H}_{3}-\mathrm{COSCoA}$ & 202.747 & -257.052 & 158.118 & 103.706 & 0.99558 & 1.1369 & -3 \\
$\mathrm{CH}_{4}(\mathrm{~g})$ & 96.945 & -144.788 & 91.262 & 196.812 & 0.99193 & 1.1182 & -4 \\
\hline
\end{tabular}


Table 4: Coefficients for the fourth-order polynomial fits to ${ }^{13,2}$ RPFR values. Computed at the M06L/def2-TZVP level of theory, between 273.15 and $973.15 \mathrm{~K}\left(0-700{ }^{\circ} \mathrm{C}\right)$. The fit to all values is of the form $\mathrm{A} \times 10^{12} / \mathrm{T}^{4}+\mathrm{B} \times 10^{9} / \mathrm{T}^{3}+\mathrm{C} \times 10^{6} / \mathrm{T}^{2}+\mathrm{D} \times 10^{3} / \mathrm{T}+\mathrm{E}$. For compounds with prochiral centers, we present the relevant stereoisomers (pro-R or pro-S). For a full list of the RPFR values see Tables S.1 and S.2.

\begin{tabular}{lccccccc}
\hline Compound & $\mathrm{A} \times 10^{-3}$ & $\mathrm{~B} \times 10^{-2}$ & $\mathrm{C} \times 10^{-2}$ & $\mathrm{D} \times 10^{-2}$ & $\mathrm{E}$ & ${ }^{13,2} \mathrm{RPFR}\left(25{ }^{\circ} \mathrm{C}\right)$ & $\mathrm{C}$ valence \\
\hline${ }^{13} \mathrm{CDO}-\mathrm{MFR}$ & 243.909 & -128.453 & 359.899 & -341.736 & 2.37839 & 13.786 & +2 \\
${ }^{13} \mathrm{CDO}-\mathrm{H}_{4}$ MPT & 244.502 & -129.601 & 362.748 & -345.432 & 2.39398 & 13.658 & +2 \\
${ }^{13} \mathrm{CD} \equiv \mathrm{H}_{4} \mathrm{MPT}^{+}$ & 284.794 & -153.837 & 424.386 & -407.709 & 2.64816 & 14.711 & +2 \\
${ }^{13} \mathrm{CHD}=\mathrm{H}_{4} \mathrm{MPT}$ (pro-S) & 324.191 & -176.815 & 483.570 & -477.038 & 2.93127 & 15.643 & 0 \\
${ }^{13} \mathrm{CHD}=\mathrm{H}_{4} \mathrm{MPT}$ (pro-R) & 324.277 & -177.147 & 484.820 & -479.472 & 2.94235 & 15.599 & 0 \\
${ }^{13} \mathrm{CH}_{2} \mathrm{D}-\mathrm{OH}$ & 249.049 & -130.131 & 366.133 & -344.898 & 2.39117 & 14.429 & -2 \\
${ }^{13} \mathrm{CH}_{2} \mathrm{D}-\mathrm{H}_{4} \mathrm{MPT}$ & 246.024 & -129.336 & 364.234 & -344.048 & 2.39097 & 14.161 & -2 \\
${ }^{13} \mathrm{CH}_{2} \mathrm{D}-\mathrm{SCoM}$ & 216.035 & -111.966 & 319.046 & -293.357 & 2.18153 & 13.327 & -2 \\
${ }^{13} \mathrm{CH}_{2} \mathrm{D}-\mathrm{COO}-$ & 209.806 & -108.220 & 309.711 & -283.216 & 2.14019 & 13.201 & -3 \\
${ }^{13} \mathrm{CH}_{2} \mathrm{D}-\mathrm{COSCoA}$ & 214.231 & -110.773 & 316.256 & -290.118 & 2.16833 & 13.330 & -3 \\
${ }^{13} \mathrm{CH}_{3} \mathrm{D}$ (g) & 168.779 & -83.028 & 247.554 & -213.261 & 1.85576 & 12.583 & -4 \\
\hline
\end{tabular}

Table 5: Coefficients for the fourth-order polynomial fits to ${ }^{2,2}$ RPFR values. Computed at the M06L/def2-TZVP level of theory, between 273.15 and $973.15 \mathrm{~K}\left(0-700{ }^{\circ} \mathrm{C}\right)$. The fit to all values is of the form $\mathrm{A} \times 10^{12} / \mathrm{T}^{4}+\mathrm{B} \times 10^{9} / \mathrm{T}^{3}+\mathrm{C} \times 10^{6} / \mathrm{T}^{2}+\mathrm{D} \times 10^{3} / \mathrm{T}+\mathrm{E}$. For a full list of the RPFR values see Tables S.1 and S.2.

\begin{tabular}{lccccccc}
\hline Compound & $\mathrm{A} \times 10^{-1}$ & $\mathrm{~B}$ & $\mathrm{C}$ & $\mathrm{D}$ & $\mathrm{E}$ & ${ }^{2,2} \mathrm{RPFR}\left(25{ }^{\circ} \mathrm{C}\right)$ & $\mathrm{C}$ valence \\
\hline${ }^{12} \mathrm{CD}_{2}=\mathrm{H}_{4} \mathrm{MPT}$ & 205.153 & -143.588 & 381.662 & -438.791 & 184.900 & 185.1934 & 0 \\
${ }^{12} \mathrm{CHD}_{2}-\mathrm{OH}$ & 160.503 & -110.846 & 293.114 & -335.342 & 141.135 & 160.2113 & -2 \\
${ }^{12} \mathrm{CHD}_{2}-\mathrm{H}_{4} \mathrm{MPT}$ & 156.170 & -107.879 & 285.365 & -326.515 & 137.466 & 158.4884 & -2 \\
${ }^{12} \mathrm{CHD}_{2}-\mathrm{SCoM}$ & 135.033 & -92.796 & 245.092 & -279.893 & 117.863 & 143.8200 & -2 \\
${ }^{12} \mathrm{CHD}_{2}-\mathrm{COO}^{-}$ & 125.327 & -85.838 & 226.473 & -258.318 & 108.785 & 135.5578 & -3 \\
${ }^{12} \mathrm{CHD}_{2}-\mathrm{COSCoA}$ & 128.799 & -88.306 & 233.059 & -265.928 & 111.982 & 138.0637 & -3 \\
${ }^{12} \mathrm{CH}_{2} \mathrm{D}_{2}(\mathrm{~g})$ & 106.778 & -72.203 & 189.641 & -215.319 & 90.609 & 128.7908 & -4 \\
\hline
\end{tabular}


Table 6: Equilibrium carbon and hydrogen isotope fractionation factors at $25{ }^{\circ} \mathrm{C}, 50{ }^{\circ} \mathrm{C}$ and $75{ }^{\circ} \mathrm{C}$. Notations: (g) gas phase, (l) liquid phase, $(\mathrm{S})$ is a $\mathrm{D}$ substitution in the pro-S face, and $(\mathrm{R})$ is a $\mathrm{D}$ substitution in the pro- $\mathrm{R}$ face of molecules with a prochiral center. In the acetoclastic pathway, $\mathrm{C}_{1}$ is the methyl-bound carbon atom, and $\mathrm{C}_{2}$ is the carboxyl or CoA-bound carbon atom. The full reactions are listed in Table 1 .

\begin{tabular}{|c|c|c|c|c|c|c|c|c|}
\hline \multirow[t]{2}{*}{ Enzyme } & \multirow[t]{2}{*}{ Reactant } & \multirow[t]{2}{*}{ Product } & \multicolumn{3}{|c|}{$1000 \ln ^{13} \alpha^{\mathrm{eq}}(\% 0)$} & \multicolumn{3}{|c|}{$1000 \ln ^{2} \alpha^{\mathrm{eq}}(\% 0)$} \\
\hline & & & $25^{\circ} \mathrm{C}$ & $50{ }^{\circ} \mathrm{C}$ & $75^{\circ} \mathrm{C}$ & $25^{\circ} \mathrm{C}$ & $50^{\circ} \mathrm{C}$ & $75^{\circ} \mathrm{C}$ \\
\hline \multicolumn{9}{|c|}{ Hydrogenotrophic pathway } \\
\hline Net & $\mathrm{CO}_{2(\mathrm{~g})} / \mathrm{H}_{2} \mathrm{O}_{(\mathrm{l})}$ & $\mathrm{CH}_{4(\mathrm{~g})}$ & 69.4 & 61.0 & 56.9 & 195.3 & 177.9 & 165.6 \\
\hline Fmd & $\mathrm{CO}_{2(\mathrm{~g})} / \mathrm{H}_{2} \mathrm{O}_{(\mathrm{l})}$ & CHO-MFR & 17.5 & 16.4 & 15.6 & 153.2 & 149.7 & 148.2 \\
\hline Ftr & CHO-MFR & $\mathrm{CHO}-\mathrm{H}_{4} \mathrm{MPT}$ & 1.9 & 1.9 & 1.9 & 8.5 & 8.5 & 8.3 \\
\hline Mch & $\mathrm{CHO}-\mathrm{H}_{4} \mathrm{MPT}$ & $\mathrm{CH} \equiv \mathrm{H}_{4} \mathrm{MPT}^{+}$ & -3.3 & -2.9 & -2.7 & -70.5 & -65.2 & -61.1 \\
\hline Mtd & $\mathrm{F}_{420} \mathrm{H}_{2}(\mathrm{~S})$ & $\mathrm{CH}_{2}=\mathrm{H}_{4} \mathrm{MPT}(\mathrm{R})$ & - & - & - & -105.2 & -94.0 & -84.3 \\
\hline Mtd & $\mathrm{CH} \equiv \mathrm{H}_{4} \mathrm{MPT}^{+}$ & $\mathrm{CH}_{2}=\mathrm{H}_{4} \mathrm{MPT}(\mathrm{S})$ & 16.9 & 15.6 & 14.8 & -78.2 & -68.3 & -59.5 \\
\hline Hmd & $\mathrm{H}_{2}$ & $\mathrm{CH}_{2}=\mathrm{H}_{4} \mathrm{MPT}(\mathrm{R})$ & - & - & - & -1359.0 & -1202.1 & -1069.6 \\
\hline Mer & $\mathrm{F}_{420} \mathrm{H}_{2}(\mathrm{~S})$ & $\mathrm{CH}_{3}-\mathrm{H}_{4} \mathrm{MPT}$ & - & - & - & -23.9 & -25.8 & -27.0 \\
\hline Mer (s) & $\mathrm{CH}_{2}=\mathrm{H}_{4} \mathrm{MPT}(\mathrm{R})$ & $\mathrm{CH}_{3}-\mathrm{H}_{4} \mathrm{MPT}$ & 15.8 & 13.2 & 12.0 & 81.3 & 68.2 & 57.3 \\
\hline Mer & $\mathrm{CH}_{2}=\mathrm{H}_{4} \mathrm{MPT}(\mathrm{S})$ & $\mathrm{CH}_{3}-\mathrm{H}_{4} \mathrm{MPT}$ & - & - & - & 84.0 & 71.0 & 60.2 \\
\hline Mtr & $\mathrm{CH}_{3}-\mathrm{H}_{4} \mathrm{MPT}$ & $\mathrm{CH}_{3}-\mathrm{SCoM}$ & 18.1 & 15.9 & 14.9 & 42.9 & 38.2 & 34.1 \\
\hline Mcr & HS-CoB & $\mathrm{CH}_{4(\mathrm{~g})}$ & - & - & - & -635.8 & -580.0 & -531.6 \\
\hline Mcr & $\mathrm{CH}_{3}-\mathrm{SCoM}$ & $\mathrm{CH}_{4(\mathrm{~g})}$ & 2.1 & 0.8 & 0.2 & 55.4 & 44.2 & 35.3 \\
\hline \multicolumn{9}{|c|}{ Acetoclastic pathway } \\
\hline Net & $\mathrm{CH}_{3}-\mathrm{COO}^{-}\left(\mathrm{C}_{1}\right)$ & $\mathrm{CH}_{4(\mathrm{~g})}$ & 15.7 & 13.5 & 12.1 & 31.9 & 23.6 & 17.2 \\
\hline Net & $\mathrm{CH}_{3}-\mathrm{COO}^{-}\left(\mathrm{C}_{2}\right)$ & $\mathrm{CO}_{2(\mathrm{~g})} / \mathrm{H}_{2} \mathrm{O}_{(\mathrm{l})}$ & -13.3 & -13.4 & -13.5 & -162.1 & -153.7 & -147.4 \\
\hline Ack/Pta & $\mathrm{CH}_{3}-\mathrm{COO}^{-}\left(\mathrm{C}_{1}\right)$ & $\mathrm{CH}_{3}-\mathrm{COSCoA}\left(\mathrm{C}_{1}\right)$ & -0.4 & -0.4 & -0.3 & -9.4 & -8.5 & -7.7 \\
\hline Cdh & $\mathrm{CH}_{3}-\operatorname{COSCoA}\left(\mathrm{C}_{1}\right)$ & $\mathrm{CH}_{3}-\mathrm{H}_{4} \mathrm{MPT}$ & -3.2 & -2.8 & -2.6 & -57.0 & -50.2 & -44.5 \\
\hline \multicolumn{9}{|c|}{ Methylotrophic pathway } \\
\hline Net & $\mathrm{CH}_{3} \mathrm{OH}$ & $\mathrm{CH}_{4(\mathrm{~g})}$ & 20.3 & 18.0 & 16.5 & 115.8 & 98.9 & 85.0 \\
\hline Net & $\mathrm{CH}_{3} \mathrm{OH}$ & $\mathrm{CO}_{2(\mathrm{~g})} / \mathrm{H}_{2} \mathrm{O}_{(\mathrm{l})}$ & -46.7 & -42.9 & -40.4 & -79.3 & -79.1 & -81.0 \\
\hline Mta & $\mathrm{CH}_{3} \mathrm{OH}$ & $\mathrm{CH}_{3}-\mathrm{SCoM}$ & 18.6 & 17.2 & 16.3 & 60.4 & 54.8 & 49.7 \\
\hline \multicolumn{9}{|c|}{ Electron cycling } \\
\hline Frh & $\mathrm{H}_{2} \mathrm{O}_{(1)}$ & $\mathrm{F}_{420} \mathrm{H}_{2}(\mathrm{~S})$ & - & - & - & 120.9 & 121.4 & 123.2 \\
\hline Hdr & $\mathrm{H}_{2} \mathrm{O}_{(1)}$ & HS-CoB & - & - & - & 831.1 & 757.9 & 697.2 \\
\hline
\end{tabular}


Table 7: Doubly-substituted ("clumped") isotopologue compositions in methanogenesis at $0{ }^{\circ} \mathrm{C}, 25$ ${ }^{\circ} \mathrm{C}, 50{ }^{\circ} \mathrm{C}, 75{ }^{\circ} \mathrm{C}$ and $100{ }^{\circ} \mathrm{C}$. Computed at the M06-L/def2-TZVP level of theory. The deviation of the abundance of the ${ }^{13} \mathrm{C}-\mathrm{D}$ and $\mathrm{D}-\mathrm{D}$ clumped isotopologue from the stochastic distribution is expressed as $\Delta_{i}^{\mathrm{eq}}=\left(R_{i} / R_{i}^{*}\right)-1$, where $R_{i}$ is the calculated ratio of the doubly-substituted isotopologue to the unsubstituted isotopologue, and $R_{i}^{*}$ is this ratio at a stochastic distribution of the rare isotopes.

\begin{tabular}{|c|c|c|c|c|c|}
\hline \multirow[t]{2}{*}{ Compound } & \multicolumn{5}{|c|}{$\Delta_{i}^{\mathrm{eq}}(\%)$} \\
\hline & $0{ }^{\circ} \mathrm{C}$ & $25^{\circ} \mathrm{C}$ & $50{ }^{\circ} \mathrm{C}$ & $75^{\circ} \mathrm{C}$ & $100^{\circ} \mathrm{C}$ \\
\hline \multicolumn{6}{|c|}{${ }^{13} \mathbf{C}-\mathbf{D}$} \\
\hline${ }^{13} \mathrm{CDO}-\mathrm{MFR}$ & 5.197 & 4.482 & 3.898 & 3.412 & 3.002 \\
\hline${ }^{13} \mathrm{CDO}-\mathrm{H}_{4} \mathrm{MPT}$ & 4.850 & 4.211 & 3.686 & 3.248 & 2.872 \\
\hline${ }^{13} \mathrm{CD} \equiv \mathrm{H}_{4} \mathrm{MPT}^{+}$ & 5.159 & 4.560 & 4.060 & 3.644 & 3.286 \\
\hline${ }^{13} \mathrm{CHD}=\mathrm{H}_{4} \mathrm{MPT}$ (pro-S) & 5.382 & 4.692 & 4.119 & 3.636 & 3.217 \\
\hline${ }^{13} \mathrm{CHD}=\mathrm{H}_{4} \mathrm{MPT}$ (pro-R) & 5.533 & 4.826 & 4.239 & 3.745 & 3.316 \\
\hline${ }^{13} \mathrm{CH}_{2} \mathrm{D}-\mathrm{OH}$ & 6.350 & 5.499 & 4.796 & 4.212 & 3.718 \\
\hline${ }^{13} \mathrm{CH}_{2} \mathrm{D}-\mathrm{H}_{4} \mathrm{MPT}$ & 5.989 & 5.219 & 4.582 & 4.039 & 3.581 \\
\hline${ }^{13} \mathrm{CH}_{2} \mathrm{D}-\mathrm{SCoM}$ & 6.302 & 5.491 & 4.819 & 4.253 & 3.770 \\
\hline${ }^{13} \mathrm{CH}_{2} \mathrm{D}-\mathrm{COO}^{-}$ & 5.959 & 5.206 & 4.581 & 4.052 & 3.599 \\
\hline${ }^{13} \mathrm{CH}_{2} \mathrm{D}-\mathrm{COSCoA}$ & 5.971 & 5.218 & 4.589 & 4.065 & 3.615 \\
\hline${ }^{13} \mathrm{CH}_{3} \mathrm{D}(\mathrm{g})$ & 6.606 & 5.738 & 5.017 & 4.413 & 3.896 \\
\hline \multicolumn{6}{|c|}{ D-D } \\
\hline${ }^{12} \mathrm{CD}_{2}=\mathrm{H}_{4} \mathrm{MPT}$ & 15.694 & 13.287 & 11.281 & 9.604 & 8.198 \\
\hline${ }^{12} \mathrm{CHD}_{2}-\mathrm{OH}$ & 19.577 & 16.141 & 13.372 & 11.128 & 9.303 \\
\hline${ }^{12} \mathrm{CHD}_{2}-\mathrm{H}_{4} \mathrm{MPT}$ & 18.865 & 15.608 & 12.968 & 10.819 & 9.062 \\
\hline${ }^{12} \mathrm{CHD}_{2}-\mathrm{SCoM}$ & 18.876 & 15.606 & 12.958 & 10.804 & 9.043 \\
\hline${ }^{12} \mathrm{CHD}_{2}-\mathrm{COO}^{-}$ & 20.334 & 16.756 & 13.872 & 11.535 & 9.631 \\
\hline${ }^{12} \mathrm{CHD}_{2}-\mathrm{COSCoA}$ & 19.591 & 16.132 & 13.345 & 11.089 & 9.253 \\
\hline${ }^{12} \mathrm{CH}_{2} \mathrm{D}_{2}(\mathrm{~g})$ & 22.621 & 18.497 & 15.209 & 12.571 & 10.442 \\
\hline
\end{tabular}


Table 8: Equilibrium ${ }^{13} \mathrm{C}-\mathrm{D}$ clumped isotopologue fractionation factors at $25{ }^{\circ} \mathrm{C}, 50{ }^{\circ} \mathrm{C}$ and $75{ }^{\circ} \mathrm{C}$. The deviation of the clumped isotopologue equilibrium fractionation factors (EFFs) from the product of the hydrogen and carbon EFFs is denoted by ${ }^{13,2} \gamma^{\mathrm{eq}}$ where ${ }^{13,2} \gamma^{\mathrm{eq}}={ }^{13,2} \alpha^{\mathrm{eq}} /\left({ }^{13} \alpha^{\mathrm{eq}} \times{ }^{2} \alpha^{\mathrm{eq}}\right)$. Notation: (g) gas phase. The full reactions are listed in Table 1.

\begin{tabular}{|c|c|c|c|c|c|c|c|c|}
\hline \multirow[t]{2}{*}{ Enzyme } & \multirow[t]{2}{*}{ Reactant/s } & \multirow[t]{2}{*}{ Product } & \multicolumn{3}{|c|}{$1000 \ln ^{13,2} \alpha^{\text {eq }}(\%)$} & \multicolumn{3}{|c|}{$13,2 \gamma^{\mathrm{eq}}$} \\
\hline & & & $25^{\circ} \mathrm{C}$ & $50{ }^{\circ} \mathrm{C}$ & $75^{\circ} \mathrm{C}$ & $25^{\circ} \mathrm{C}$ & $50^{\circ} \mathrm{C}$ & $75^{\circ} \mathrm{C}$ \\
\hline \multicolumn{9}{|c|}{ Hydrogenotrophic pathway } \\
\hline Fmd & ${ }^{13} \mathrm{CO}_{2}+\mathrm{HDO}$ & ${ }^{13} \mathrm{CDO}-\mathrm{MFR}$ & 166.2 & 162.2 & 160.4 & 0.9955 & 0.9961 & 0.9966 \\
\hline Ftr & ${ }^{13} \mathrm{CDO}-\mathrm{MFR}$ & ${ }^{13} \mathrm{CDO}-\mathrm{H}_{4} \mathrm{MPT}$ & 10.6 & 10.6 & 10.4 & 1.0003 & 1.0002 & 1.0002 \\
\hline Mch & ${ }^{13} \mathrm{CDO}-\mathrm{H}_{4} \mathrm{MPT}$ & ${ }^{13} \mathrm{CD}-\mathrm{H}_{4} \mathrm{MPT}$ & -74.2 & -68.5 & -64.0 & 0.9997 & 0.9996 & 0.9996 \\
\hline Mtd & ${ }^{13} \mathrm{CH}-\mathrm{H}_{4} \mathrm{MPT}+\mathrm{F}_{420} \mathrm{HD}$ & ${ }^{13} \mathrm{CHD}_{-} \mathrm{H}_{4} \mathrm{MPT}^{\dagger}$ & -92.6 & -82.5 & -73.7 & 0.9953 & 0.9959 & 0.9964 \\
\hline Mtd & ${ }^{13} \mathrm{CD}-\mathrm{H}_{4} \mathrm{MPT}+\mathrm{F}_{420} \mathrm{H}_{2}$ & ${ }^{13} \mathrm{CHD}^{-\mathrm{H}_{4} \mathrm{MPT}^{\ddagger}}$ & -61.2 & -52.9 & -45.4 & 0.9997 & 0.9998 & 0.9999 \\
\hline Hmd & ${ }^{13} \mathrm{CH}-\mathrm{H}_{4} \mathrm{MPT}+\mathrm{HD}$ & ${ }^{13} \mathrm{CHD}_{-} \mathrm{H}_{4} \mathrm{MPT}^{\dagger}$ & -1346.4 & -1190.6 & -1059.0 & 0.9953 & 0.9959 & 0.9964 \\
\hline Mer & ${ }^{13} \mathrm{CH}_{2}-\mathrm{H}_{4} \mathrm{MPT}+\mathrm{F}_{420} \mathrm{HD}$ & ${ }^{13} \mathrm{CH}_{2} \mathrm{D}-\mathrm{H}_{4} \mathrm{MPT}$ & -13.9 & -17.6 & -20.2 & 0.9948 & 0.9954 & 0.9960 \\
\hline Mer & ${ }^{13} \mathrm{CHD}-\mathrm{H}_{4} \mathrm{MPT}^{\dagger}+\mathrm{F}_{420} \mathrm{H}_{2}$ & ${ }^{13} \mathrm{CH}_{2} \mathrm{D}-\mathrm{H}_{4} \mathrm{MPT}$ & 96.0 & 80.5 & 67.8 & 0.9995 & 0.9995 & 0.9996 \\
\hline Mer & ${ }^{13} \mathrm{CHD}_{-} \mathrm{H}_{4} \mathrm{MPT}^{+}+\mathrm{F}_{420} \mathrm{H}_{2}$ & ${ }^{13} \mathrm{CH}_{2} \mathrm{D}-\mathrm{H}_{4} \mathrm{MPT}$ & 98.8 & 83.5 & 70.8 & 0.9996 & 0.9997 & 0.9997 \\
\hline Mtr & ${ }^{13} \mathrm{CH}_{2} \mathrm{D}-\mathrm{H}_{4} \mathrm{MPT}$ & ${ }^{13} \mathrm{CH}_{2} \mathrm{D}-\mathrm{SCoM}$ & 61.0 & 54.2 & 48.4 & 0.9997 & 0.9998 & 0.9998 \\
\hline Mcr & ${ }^{13} \mathrm{CH}_{3}-\mathrm{SCoM}+\mathrm{DS}-\mathrm{CoB}$ & ${ }^{13} \mathrm{CH}_{3} \mathrm{D}(\mathrm{g})$ & -639.5 & -584.2 & -536.2 & 0.9943 & 0.9950 & 0.9956 \\
\hline Mcr & ${ }^{13} \mathrm{CH}_{2} \mathrm{D}-\mathrm{SCoM}+\mathrm{HS}-\mathrm{CoB}$ & ${ }^{13} \mathrm{CH}_{3} \mathrm{D}(\mathrm{g})$ & 57.1 & 44.7 & 35.0 & 0.9998 & 0.9998 & 0.9998 \\
\hline \multicolumn{9}{|c|}{ Acetoclastic pathway } \\
\hline Ack/Pta & ${ }^{13} \mathrm{CH}_{2} \mathrm{D}-\mathrm{COO}^{-}$ & ${ }^{13} \mathrm{CH}_{2} \mathrm{D}-\mathrm{COSCoA}$ & -10.0 & -9.0 & -8.2 & 1.0000 & 1.0000 & 1.0000 \\
\hline $\mathrm{Cdh}$ & ${ }^{13} \mathrm{CH}_{2} \mathrm{D}-\mathrm{COSCoA}$ & ${ }^{13} \mathrm{CH}_{2} \mathrm{D}-\mathrm{H}_{4} \mathrm{MPT}$ & -60.1 & -52.9 & -46.9 & 1.0000 & 1.0000 & 1.0000 \\
\hline \multicolumn{9}{|c|}{ Methylotrophic pathway } \\
\hline Mta & ${ }^{13} \mathrm{CH}_{2} \mathrm{D}-\mathrm{OH}$ & ${ }^{13} \mathrm{CH}_{2} \mathrm{D}-\mathrm{SCoM}$ & 79.6 & 72.2 & 65.6 & 1.0000 & 1.0000 & 1.0000 \\
\hline
\end{tabular}

Notes: $(\dagger){ }^{13} \mathrm{CHD}-\mathrm{H}_{4}$ MPT with D in the pro-R face. $(\ddagger){ }^{13} \mathrm{CHD}-\mathrm{H}_{4}$ MPT with $\mathrm{D}$ in the pro-S face. 
Table 9: Equilibrium D-D clumped isotopologue fractionation factors at $25{ }^{\circ} \mathrm{C}, 50{ }^{\circ} \mathrm{C}$ and $75{ }^{\circ} \mathrm{C}$. The deviation of the clumped isotopologue equilibrium fractionation factors (EFFs) from the product of the hydrogen EFFs is denoted by ${ }^{2,2} \gamma^{\mathrm{eq}}$ where ${ }^{2,2} \gamma^{\mathrm{eq}}={ }^{2,2} \alpha^{\mathrm{eq}} /\left({ }^{2} \alpha^{\mathrm{eq}} \times{ }^{2} \alpha^{\mathrm{eq}}\right)$. Notation: (g) gas phase. The full reactions are listed in Table 1.

\begin{tabular}{|c|c|c|c|c|c|c|c|c|}
\hline \multirow[t]{2}{*}{ Enzyme } & \multirow[t]{2}{*}{ Reactant/s } & \multirow[t]{2}{*}{ Product } & \multicolumn{3}{|c|}{$1000 \ln ^{2,2} \alpha^{\mathrm{eq}}(\%)$} & \multicolumn{3}{|c|}{$2,2 \gamma^{\mathrm{eq}}$} \\
\hline & & & $25^{\circ} \mathrm{C}$ & $50{ }^{\circ} \mathrm{C}$ & $75^{\circ} \mathrm{C}$ & $25^{\circ} \mathrm{C}$ & $50{ }^{\circ} \mathrm{C}$ & $75^{\circ} \mathrm{C}$ \\
\hline \multicolumn{9}{|c|}{ Hydrogenotrophic pathway } \\
\hline Mtd & ${ }^{12} \mathrm{CD}-\mathrm{H}_{4} \mathrm{MPT}+\mathrm{F}_{420} \mathrm{HD}$ & ${ }^{12} \mathrm{CD}_{2}-\mathrm{H}_{4} \mathrm{MPT}$ & -196.7 & -173.6 & -153.4 & 0.9868 & 0.9888 & 0.9904 \\
\hline Hmd & ${ }^{12} \mathrm{CD}-\mathrm{H}_{4} \mathrm{MPT}+\mathrm{HD}$ & ${ }^{12} \mathrm{CD}_{2}-\mathrm{H}_{4} \mathrm{MPT}$ & -1450.5 & -1281.7 & -1138.8 & 0.9868 & 0.9888 & 0.9904 \\
\hline Mer & ${ }^{12} \mathrm{CHD}_{-} \mathrm{H}_{4} \mathrm{MPT}^{\dagger}+\mathrm{F}_{420} \mathrm{HD}$ & ${ }^{12} \mathrm{CHD}_{2}-\mathrm{H}_{4} \mathrm{MPT}$ & 44.7 & 32.3 & 22.4 & 0.9846 & 0.9872 & 0.9893 \\
\hline Mer & ${ }^{12} \mathrm{CD}_{2}-\mathrm{H}_{4} \mathrm{MPT}+\mathrm{F}_{420} \mathrm{H}_{2}$ & ${ }^{12} \mathrm{CHD}_{2}-\mathrm{H}_{4} \mathrm{MPT}$ & 163.2 & 137.5 & 116.4 & 0.9978 & 0.9984 & 0.9988 \\
\hline Mtr & ${ }^{12} \mathrm{CHD}_{2}-\mathrm{H}_{4} \mathrm{MPT}$ & ${ }^{12} \mathrm{CHD}_{2}-\mathrm{SCoM}$ & 85.8 & 76.4 & 68.2 & 1.0000 & 1.0000 & 1.0000 \\
\hline Mcr & ${ }^{12} \mathrm{CH}_{2} \mathrm{D}-\mathrm{SCoM}+\mathrm{DS}-\mathrm{CoB}$ & ${ }^{12} \mathrm{CH}_{2} \mathrm{D}_{2}(\mathrm{~g})$ & -598.7 & -550.9 & -508.8 & 0.9818 & 0.9850 & 0.9876 \\
\hline Mcr & ${ }^{12} \mathrm{CHD}_{2}-\mathrm{SCoM}+\mathrm{HS}-\mathrm{CoB}$ & ${ }^{12} \mathrm{CH}_{2} \mathrm{D}_{2}(\mathrm{~g})$ & 107.9 & 86.1 & 68.9 & 0.9972 & 0.9978 & 0.9983 \\
\hline \multicolumn{9}{|c|}{ Acetoclastic pathway } \\
\hline Ack/Pta & ${ }^{12} \mathrm{CH}_{2} \mathrm{D}-\mathrm{COO}^{-}$ & ${ }^{13} \mathrm{CH}_{2} \mathrm{D}-\mathrm{COSCoA}$ & -18.1 & -16.4 & -14.9 & 1.0006 & 1.0005 & 1.0004 \\
\hline $\mathrm{Cdh}$ & ${ }^{12} \mathrm{CH}_{2} \mathrm{D}-\mathrm{COSCoA}$ & ${ }^{13} \mathrm{CH}_{2} \mathrm{D}-\mathrm{H}_{4} \mathrm{MPT}$ & -113.5 & -100.1 & -88.7 & 1.0005 & 1.0004 & 1.0003 \\
\hline \multicolumn{9}{|c|}{ Methylotrophic pathway } \\
\hline Mta & ${ }^{12} \mathrm{CH}_{2} \mathrm{D}-\mathrm{OH}$ & ${ }^{13} \mathrm{CH}_{2} \mathrm{D}-\mathrm{SCoM}$ & 121.4 & 110.0 & 99.7 & 1.0005 & 1.0004 & 1.0003 \\
\hline
\end{tabular}

Notes: $(\dagger){ }^{13} \mathrm{CHD}-\mathrm{H}_{4} \mathrm{MPT}$ with D in the pro-S face. 
Table 10: Scenarios of reversibility control over the net carbon isotopic fractionation in the considered pathways. In all scenarios, the reversibility $f$ (defined as the ratio of the backward and forward fluxes) of each enzymatically catalyzed reaction ranges from 1 (i.e., fully reversible) to 0 (i.e., irreversible). References are to previous reports that used the scenario.

\begin{tabular}{|c|c|c|}
\hline Scenario description & Ref. & $1000 \ln ^{13} \alpha$ \\
\hline \multicolumn{3}{|l|}{ Hydrogenotrophic pathway (Section 4.4.1) } \\
\hline (i) Uniform departure from equilibrium of all reactions $(f=1 \rightarrow 0)$. & 1 & $20 \%$ to $69 \%$ \\
\hline $\begin{array}{l}\text { (ii) Equilibrium between } \mathrm{CO}_{2} \text { and } \mathrm{CH}_{3}-\mathrm{SCoM}(f=1) \text {, gradual } \\
\text { departure from equilibrium of the Mcr-catalyzed reaction }(f=1 \rightarrow 0) \text {. }\end{array}$ & 2,3 & $69 \%$ to $106 \%$ \\
\hline $\begin{array}{l}\text { (iii) Pathway reduced to four carbon reduction steps (Fmd, Mtd, Mer, } \\
\text { Mcr), with } f \text { of either } 0 \text { or } 1 \text { for each. }\end{array}$ & 4 & $20 \%$ to $106 \%$ \\
\hline \multicolumn{3}{|l|}{ Methylotrophic pathway (Section 4.4.3) } \\
\hline $\begin{array}{l}\text { Variable reversibility between } \mathrm{CH}_{3} \mathrm{OH} \text { and } \mathrm{CH}_{3}-\mathrm{SCoM} \text {, and between } \\
\mathrm{CH}_{3}-\mathrm{SCoM} \text { and } \mathrm{CH}_{4} \text { ( } f \text { drawn from a uniform distribution between } 0 \\
\text { and } 1 \text { ). Between } \mathrm{CH}_{3}-\mathrm{SCoM} \text { and } \mathrm{CO}_{2} f \text { is set to } 0.75 \text {. }\end{array}$ & - & $\begin{array}{l}\text { Depends on } R_{r / o} \text {, the } \\
\text { reduction:oxidation } \\
\text { ratio of methanol }\end{array}$ \\
\hline \multicolumn{3}{|l|}{ Acetoclastic pathway (Section 4.4.4) } \\
\hline $\begin{array}{l}\text { Equilibrium between } \mathrm{CH}_{3}-\mathrm{COO}^{-} \text {and } \mathrm{CH}_{3}-\mathrm{SCoM}(f=1) \text {, gradual } \\
\text { departure from equilibrium of the Mcr-catalyzed reaction }(f=1 \rightarrow 0) \text {. }\end{array}$ & - & $16 \%$ to $53 \%$ \\
\hline \multicolumn{3}{|l|}{$A O M$ (Section 4.4.5) } \\
\hline $\begin{array}{l}\text { All reactions are fully reversible }(f=1) \text {, with the exception of a single } \\
\text { reaction that is irreversible }(f=0) \text {. The identity of the irreversible } \\
\text { reaction is varied to produce the range. }\end{array}$ & 2 & $-69 \%$ to $37 \%$ \\
\hline
\end{tabular}

(1) Wang et al. (2015); (2) Alperin \& Hoehler (2009); (3) Stolper et al. (2015); (4) Cao et al. (2019). 
Table 11: Carbon isotopic fractionation during AOM. The maximum net $\mathrm{CH}_{4}-\mathrm{CO}_{2}$ carbon isotope fractionation $\left(1000 \ln ^{13} \alpha_{\mathrm{CH}_{4}-\mathrm{CO}_{2}}\right)$ that can be obtained at a steady state when a single reaction is irreversible $(f=0)$ and all other reactions remain completely reversible $(f=1)$, using the framework outlined in Appendix A. We used the experimentally-determined KFF of Mcr $\left(1000 \ln ^{13} \alpha_{\mathrm{CH}_{4} \rightarrow \mathrm{CH}_{3}-\mathrm{SCoM}}^{\mathrm{kin}}=-38 \%_{0}\right.$; Scheller et al., 2013). The KFFs of the other enzymes were uniformly assigned values of $-5 \%$ or $-40 \%$.

\begin{tabular}{ccc}
\hline & \multicolumn{2}{c}{$1000 \ln ^{13} \alpha_{\mathrm{CH}_{4}-\mathrm{CO}_{2}}$} \\
\hline Irreversible reaction & $1000 \ln ^{13} \alpha^{\mathrm{kin}}=-5 \%$ & $1000 \ln ^{13} \alpha^{\mathrm{kin}}=-40 \% 0$ \\
\hline Mcr & 37.9 & 37.9 \\
Mtr & 3.0 & 37.9 \\
Mer & -14.0 & 20.0 \\
Mtd & -30.6 & 4.4 \\
Mch & -47.8 & -12.7 \\
Ftr & -44.4 & -9.3 \\
Fmd & -49.9 & -14.8 \\
\hline
\end{tabular}




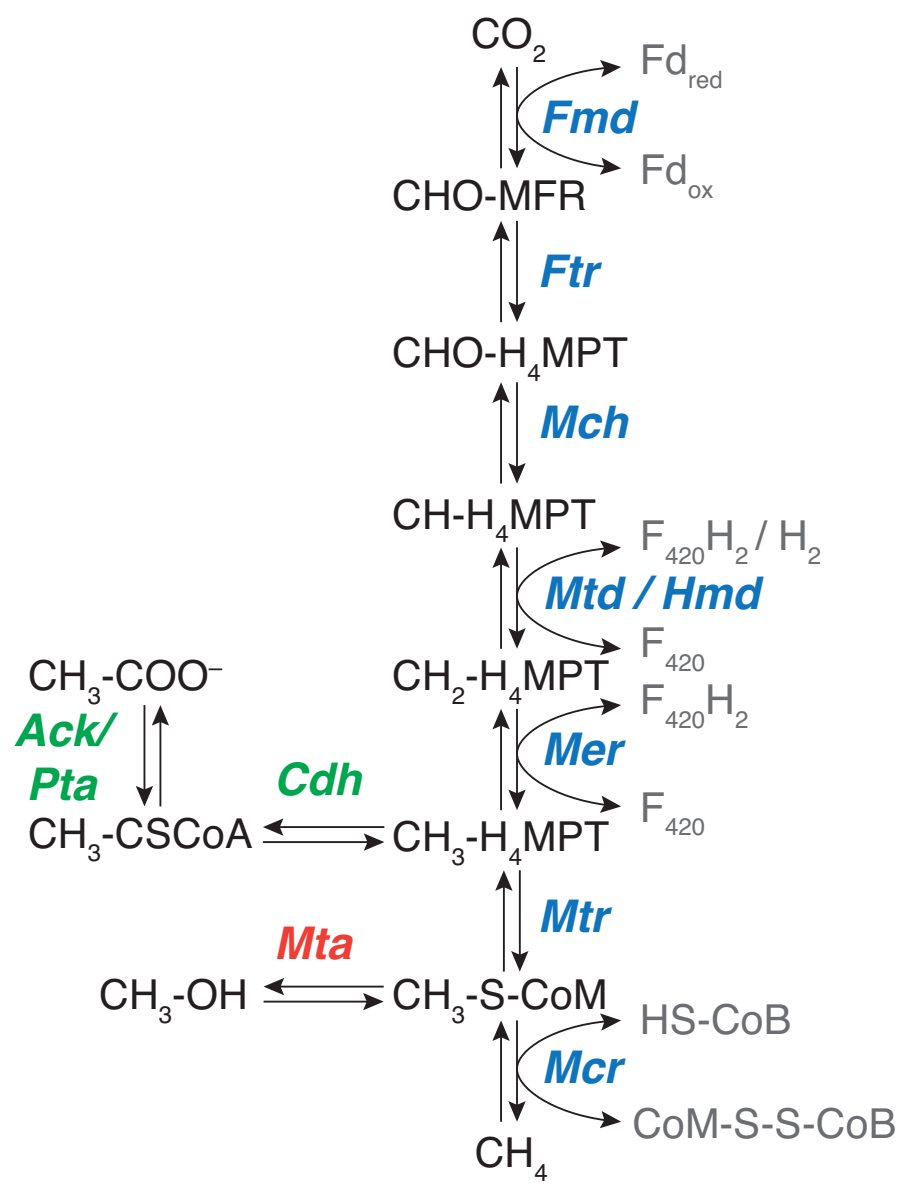

Figure 1: Metabolic pathways of methanogenesis and anaerobic oxidation of methane (AOM). The metabolite names are in black, electron carriers in gray, and enzymes in bold-italicized colored fonts. The reactions that are unique to the acetoclastic and methylotrophic pathways are in green and red, respectively. The reactions in blue are the hydrogenotrophic and AOM pathways, and are common also with the acetoclastic and methylotrophic pathways. All the reactions are assumed to have the potential for full reversibility. 

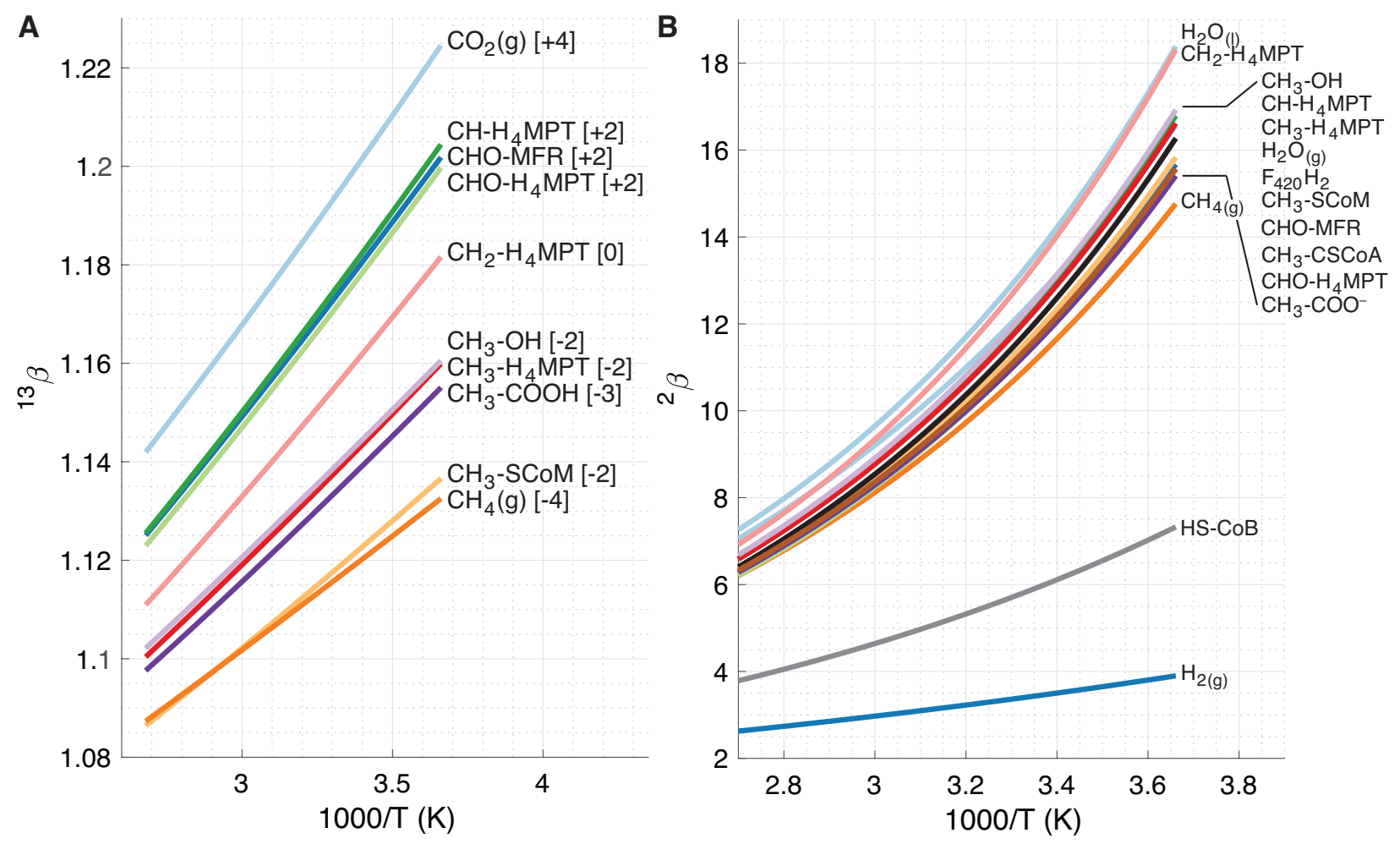

Figure 2: Calculated carbon (A) and hydrogen (B) $\beta$ values. The carbon oxidation state is given in square brackets. The $\beta$ values, including the clumped isotopologues (not plotted here), are listed in Tables 2-4. 

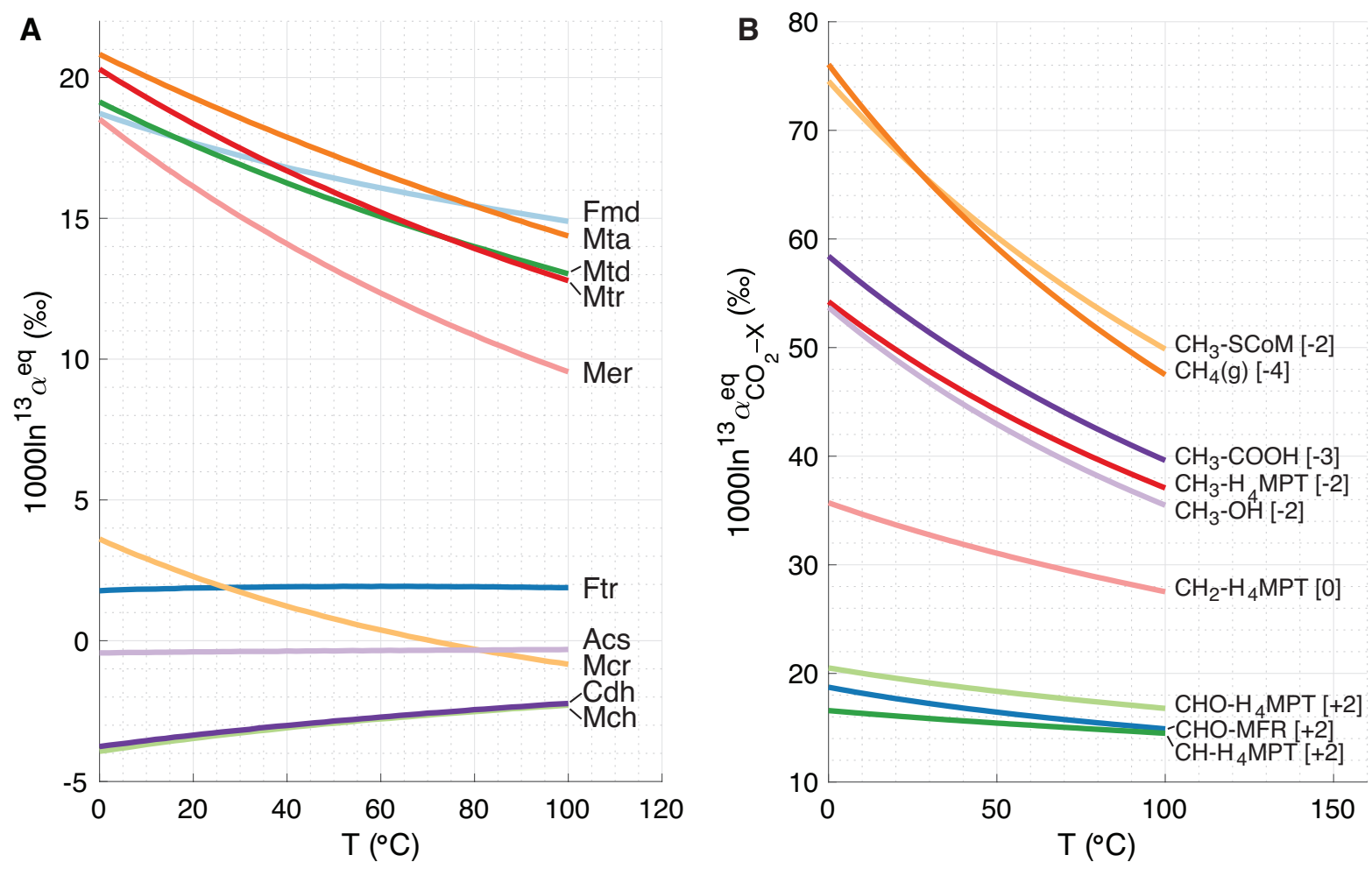

Figure 3: Temperature dependence of the calculated equilibrium carbon isotope fractionation factors (EFFs) for the organic compounds involved in methanogenesis. (A) The EFFs of the reactions catalyzed by the enzymes shown next to the corresponding lines and listed in Table 1. (B) The carbon isotopic EFFs between gas-phase $\mathrm{CO}_{2}$ and the compounds in the methanogenesis pathways $\left(1000 \ln ^{13} \alpha_{\mathrm{CO}_{2}-\mathrm{X}}^{\mathrm{eq}}\right.$, where ' $\mathrm{X}$ ' denotes the intracellular compounds). The carbon oxidation state is given in square brackets. 

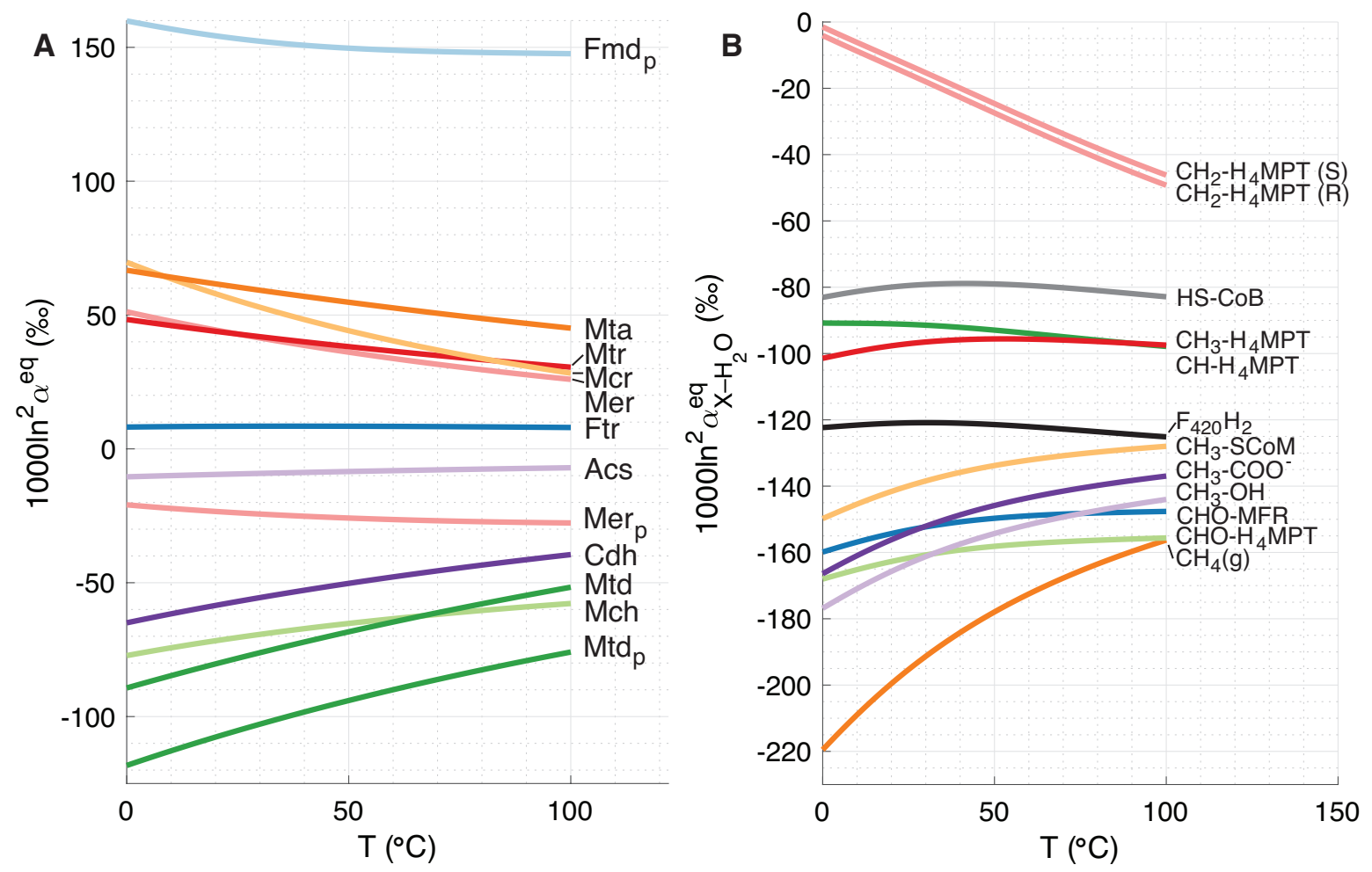

Figure 4: Temperature dependence of the calculated equilibrium hydrogen isotope fractionation factors (EFFs) for the organic compounds involved in methanogenesis. (A) The EFFs of the reactions catalyzed by the enzymes shown next to the corresponding lines and listed in Table 1. A subscripted 'p' next to the enzyme abbreviation denotes a primary EFF. (B) The hydrogen isotopic EFFs between $\mathrm{H}_{2} \mathrm{O}(\mathrm{l})$ and the compounds in the methanogenesis pathways $\left(1000 \ln ^{2} \alpha_{\mathrm{H}_{2} \mathrm{O}-\mathrm{X}}^{\mathrm{eq}}\right.$, where ' $\mathrm{X}$ ' denotes the intracellular compounds). 

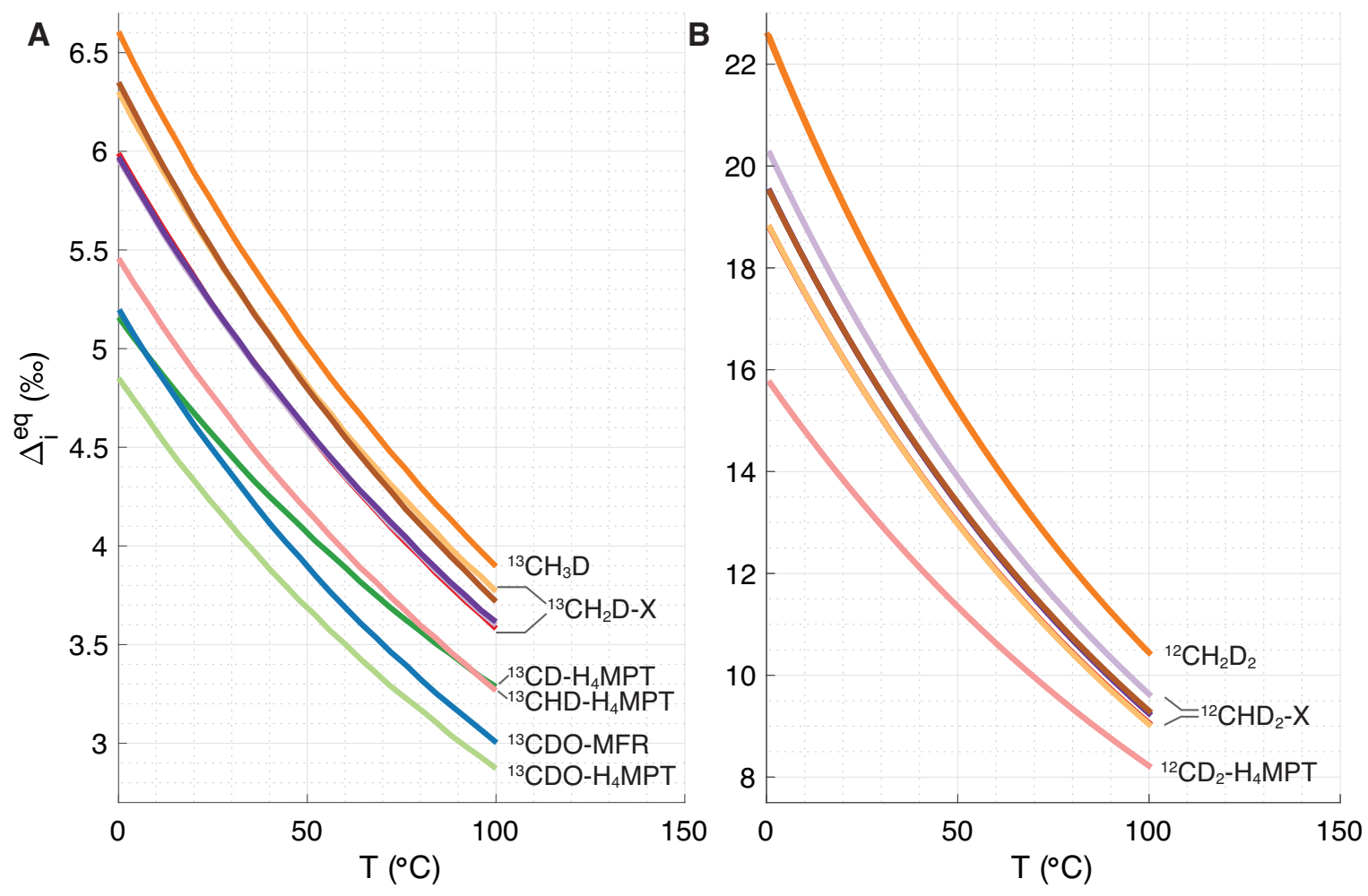

Figure 5: Doubly-substituted ("clumped") isotopologue compositions in methanogenesis. The deviation of the abundance of the clumped isotopologues containing (A) a single ${ }^{13} \mathrm{C}-\mathrm{D}$ bond and $(\mathbf{B})$ two ${ }^{12} \mathrm{C}-\mathrm{D}$ bonds from the stochastic distribution is expressed as $\Delta_{i}^{\mathrm{eq}}=\left(R_{i} / R_{i}^{*}\right)-1$, where $R_{i}$ is the calculated ratio of the doubly-substituted isotopologue to the unsubstituted isotopologue and $R_{i}^{*}$ is this ratio at a stochastic distribution of the rare isotopes. The clumped isotopologues of $\mathrm{CH}_{3}-\mathrm{SCoM}, \mathrm{CH}_{3}-\mathrm{CSCoA}, \mathrm{CH}_{3}-\mathrm{COO}^{-}$, $\mathrm{CH}_{3}-\mathrm{OH}$ and $\mathrm{CH}_{3}-\mathrm{H}_{4} \mathrm{MPT}$ have similar $\Delta_{i}^{\mathrm{eq}}$ values at $100{ }^{\circ} \mathrm{C}$ and are all denoted by ${ }^{13} \mathrm{CH}_{2} \mathrm{D}-\mathrm{X}$ ' or ${ }^{~} 12 \mathrm{CHD}_{2}$ $\mathrm{X}^{\prime}$. The $\Delta_{i}^{\mathrm{eq}}$ values are listed in Table 7. 

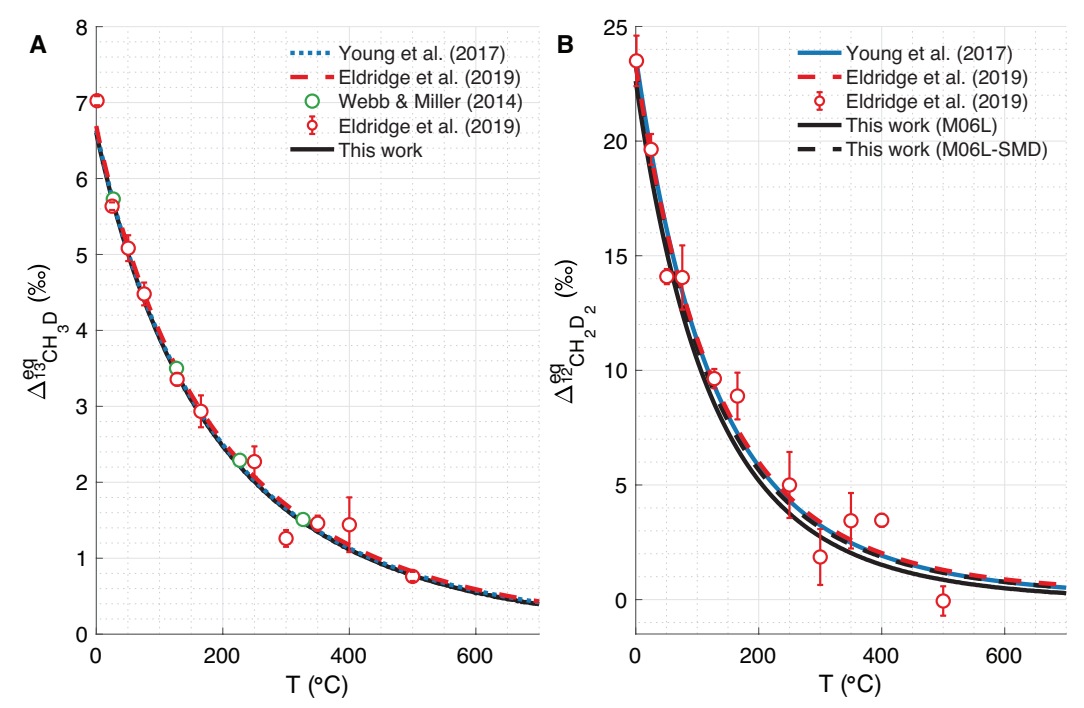

Figure 6: Comparisons of doubly-substituted isotopologue abundances calculated in this study with

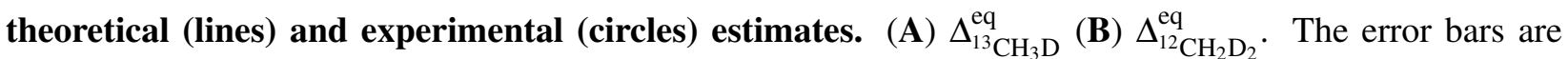
1 standard error. In panel $\mathbf{B}$, the results from Webb \& Miller (2014) are of Path-Integral Monte Carlo calculations.
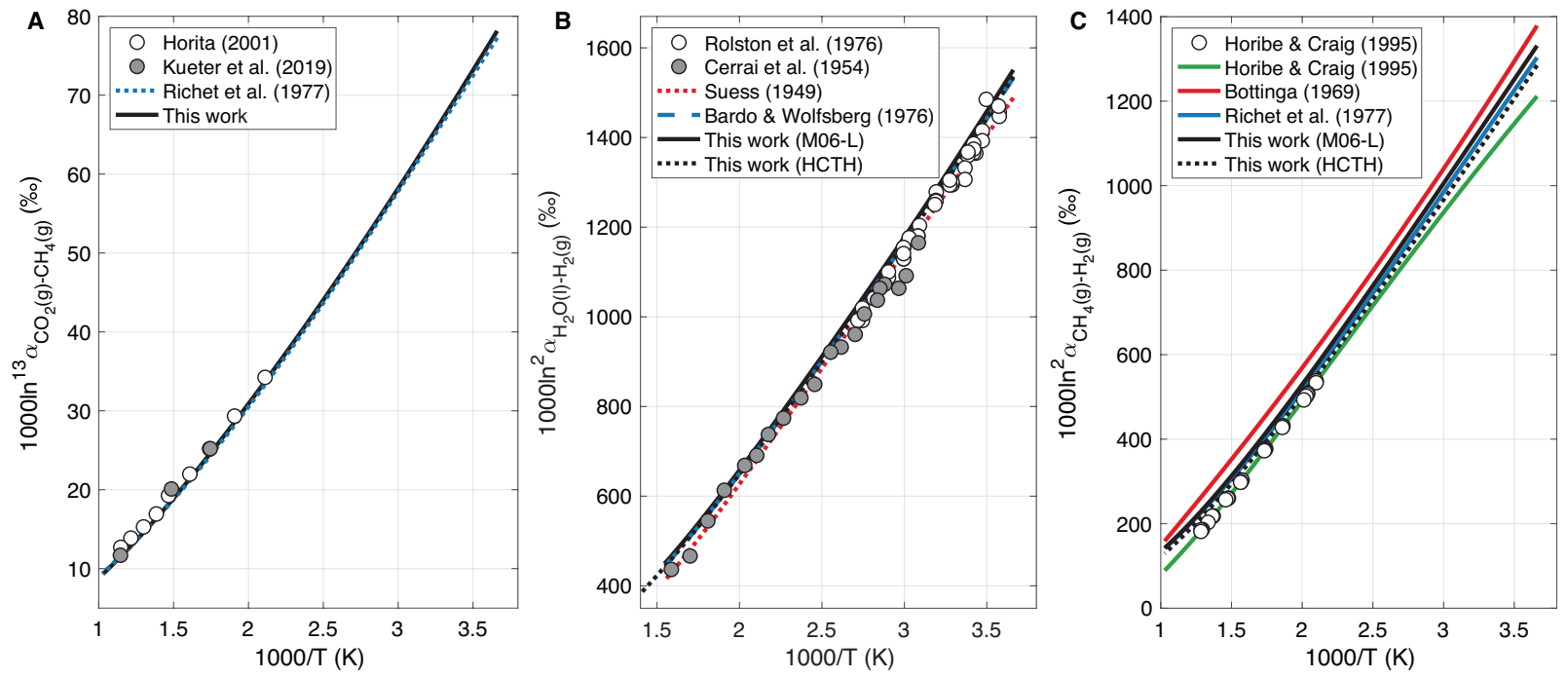

Figure 7: Comparisons of isotope fractionations calculated in this study with theoretical (lines) and experimental (circles) estimates. (A) $\mathrm{CO}_{2(\mathrm{~g})}-\mathrm{CH}_{4(\mathrm{~g})}$ carbon isotope fractionations. (B) $\mathrm{H}_{2} \mathrm{O}_{(\mathrm{l})}-\mathrm{H}_{2(\mathrm{~g})}$ hydrogen isotope fractionations. (C) $\mathrm{CH}_{4(\mathrm{~g})}-\mathrm{H}_{2(\mathrm{~g})}$ hydrogen isotope fractionations. The green line was derived from a linear regression of ${ }^{2} \alpha_{\mathrm{CH}_{4}-\mathrm{H}_{2} \mathrm{O}}$ on $10^{6} / \mathrm{T}^{2}$. 

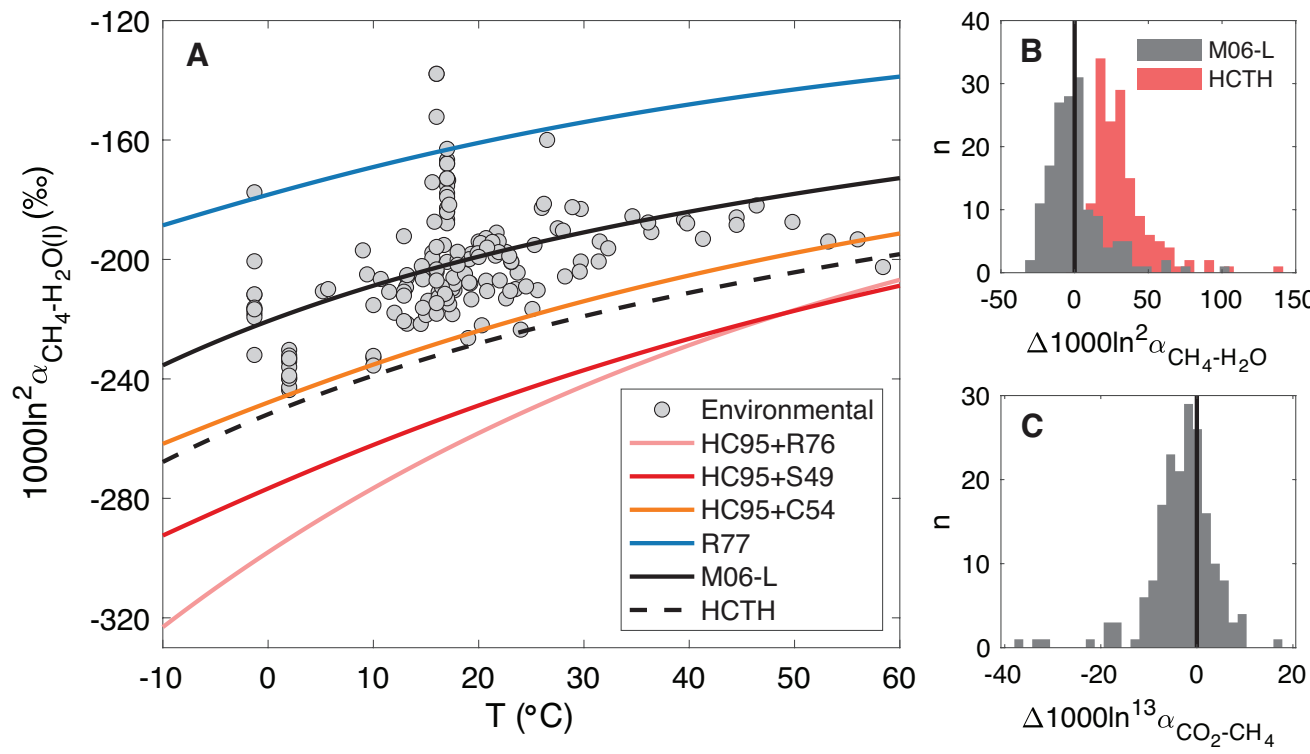

Figure 8: Comparison of $\mathrm{CH}_{4(1)}-\mathrm{H}_{2} \mathrm{O}_{(1)}$ carbon and hydrogen isotope fractionations calculated in this and previous studies with environmental estimates. (A) $1000 \ln ^{2} \alpha_{\mathrm{CH}_{4}-\mathrm{H}_{2} \mathrm{O}}$ from theoretical studies and biogenic environmental samples. The lines were generated from different combinations of fits to experimental and theoretical work (Suess, 1949 (S49); Cerrai et al., 1954 (C54); Bottinga, 1969 (B69); Rolston et al., 1976 (R76); Richet et al., 1977 (R77); Horibe and Craig, 1995 (HC95) and this work using the M06$\mathrm{L}$ and $\mathrm{HCTH}$ functionals). The $\mathrm{H}_{2} \mathrm{O}_{(1)}-\mathrm{H}_{2} \mathrm{O}_{(\mathrm{g})}$ hydrogen isotope fractionations were based on Horita \& Wesolowski (1994), except for the results of Rolston et al. (1976), in which case this is noted in the figure legend. (B) The deviation of environmental 1000 $\ln ^{2} \alpha_{\mathrm{CH}_{4}-\mathrm{H}_{2} \mathrm{O}}$ from the temperature-dependent EFFs calculated in this study with the M06-L and HCTH functionals. (C) The deviation of environmental $1000 \ln ^{13} \alpha_{\mathrm{CO}_{2}-\mathrm{CH}_{4}}$ from the temperature-dependent EFFs calculated in this study with the M06-L functional. A full list of the environmental samples presented in this figure is available in Table S.3 with the corresponding references. 

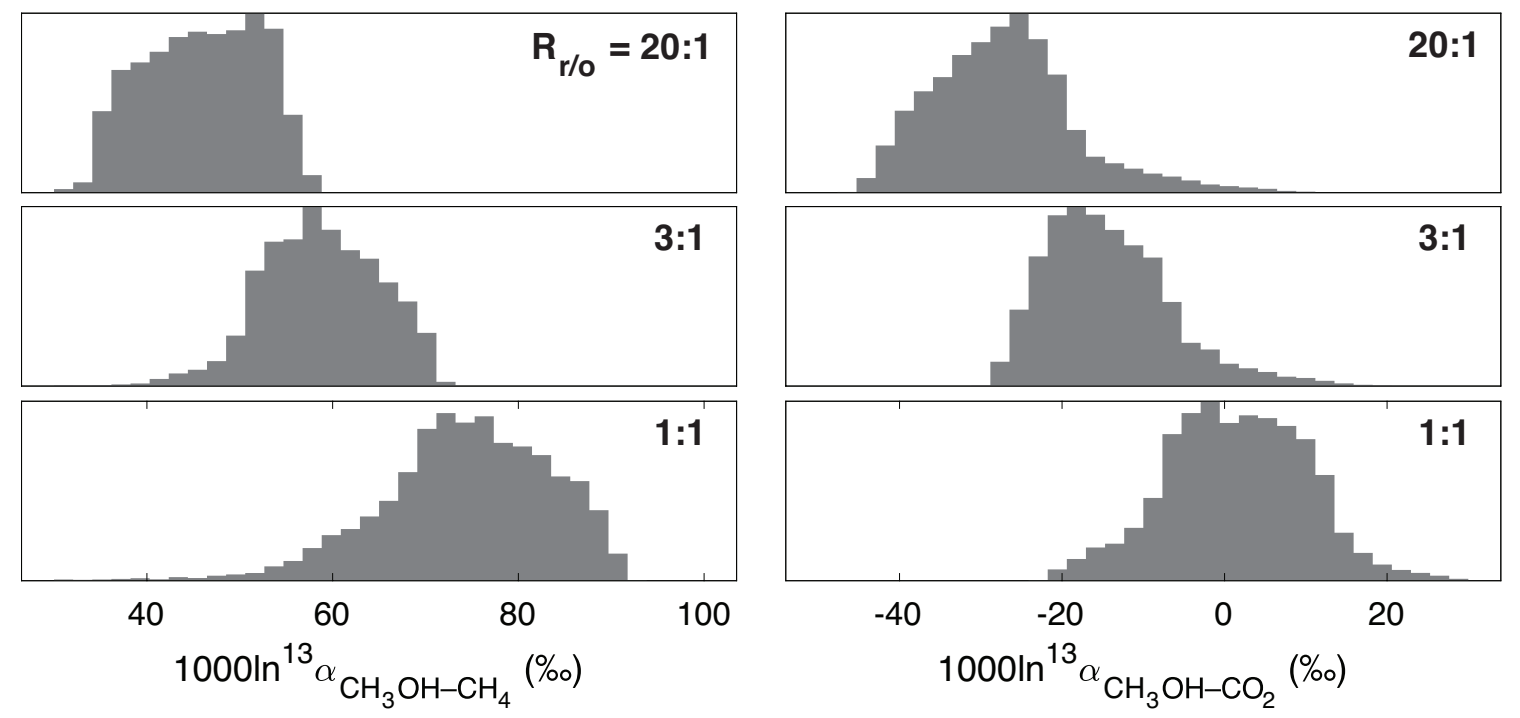

Figure 9: Carbon isotope fractionation between methanol, $\mathbf{C H}_{4(\mathrm{~g})}$ and $\mathbf{C O}_{2(\mathrm{~g})}$. Left: Methanol- $\mathrm{CH}_{4(\mathrm{~g})}$ carbon isotope fractionation; Right: Methanol- $\mathrm{CO}_{2(\mathrm{~g})}$ carbon isotope fractionation. Each histogram represents 10,000 simulations of methylotrophic methanogenesis with KFFs $1000 \ln ^{13} \alpha_{\text {methanol } \rightarrow \mathrm{CH}_{3}-\mathrm{SCoM}}^{\mathrm{kin}}$ and $1000^{13} \alpha_{\mathrm{CH}_{3}-\mathrm{SCoM} \rightarrow \mathrm{CO}_{2}}^{\mathrm{kin}}$ in the range $-30 \%$ to $-50 \%$ and the reversibilities between methanol and $\mathrm{CH}_{3}$ SCoM and between $\mathrm{CH}_{3}-\mathrm{SCoM}$ and $\mathrm{CH}_{4}$ in the range $10^{-3}$ to 1 , each drawn randomly from uniform distributions. The reversibility between $\mathrm{CH}_{3}-\mathrm{SCoM}$ and $\mathrm{CO}_{2}$ was held constant at 0.75 , and the $\mathrm{KFF}$ $1000 \ln ^{13} \alpha_{\mathrm{CH}_{3}-\mathrm{SCoM} \rightarrow \mathrm{CH}_{4}}^{\mathrm{kin}}$ was set to $-40 \%$ (Scheller et al., 2013). The methanol reduction:oxidation ratio, $R_{r / o}$, used for each set of simulations is indicated. 


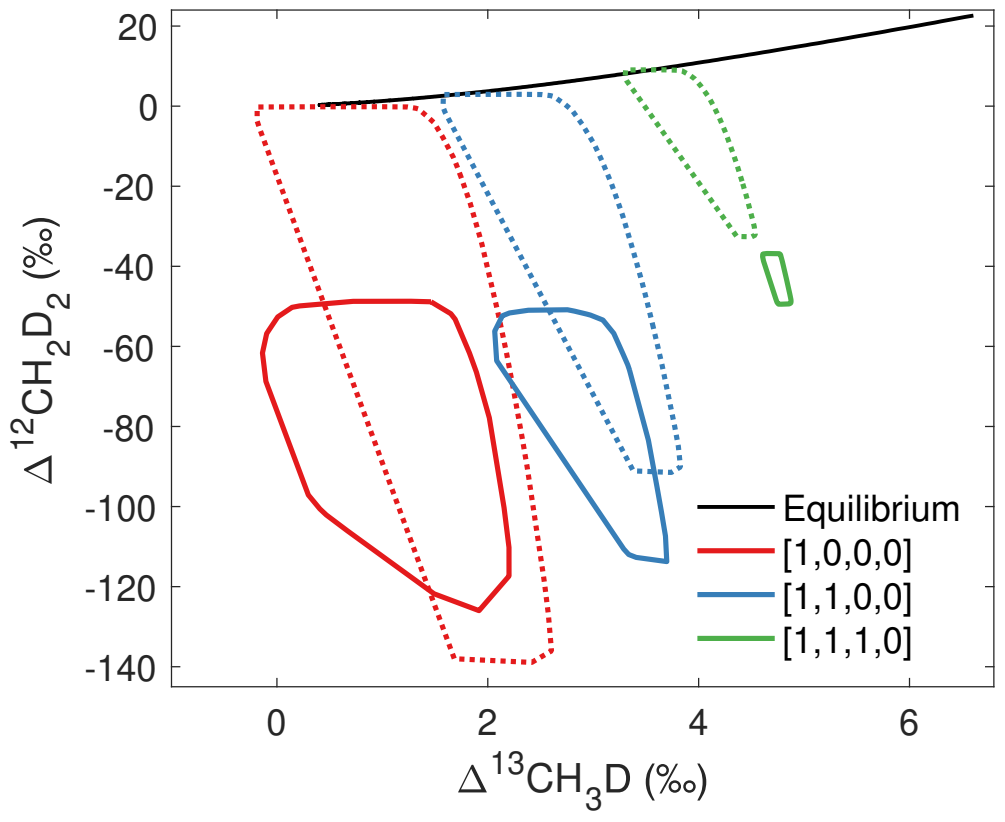

Figure 10: Prediction of the $\Delta^{13} \mathrm{CH}_{3} \mathrm{D}$ and $\Delta^{12} \mathrm{CH}_{2} \mathrm{D}_{2}$ values based on three reversibility scenarios of hydrogenotrophic methanogenesis. A comparison between results obtained with the parameters used in the study of Cao et al. (2019) (dotted lines) and the results based on the EFFs calculated in this study (solid lines). The scenarios refer to combinations of the reversibilities of the four hydrogen addition reactions in the hydrogenotrophic methanogenesis pathway, for fully reversible reactions (1) or irreversible reactions (0). The black line shows the equilibrium covariation of $\Delta{ }^{13} \mathrm{CH}_{3} \mathrm{D}$ and $\Delta{ }^{12} \mathrm{CH}_{2} \mathrm{D}_{2}$ values, calculated at the M06-L/TZVP level of theory. 

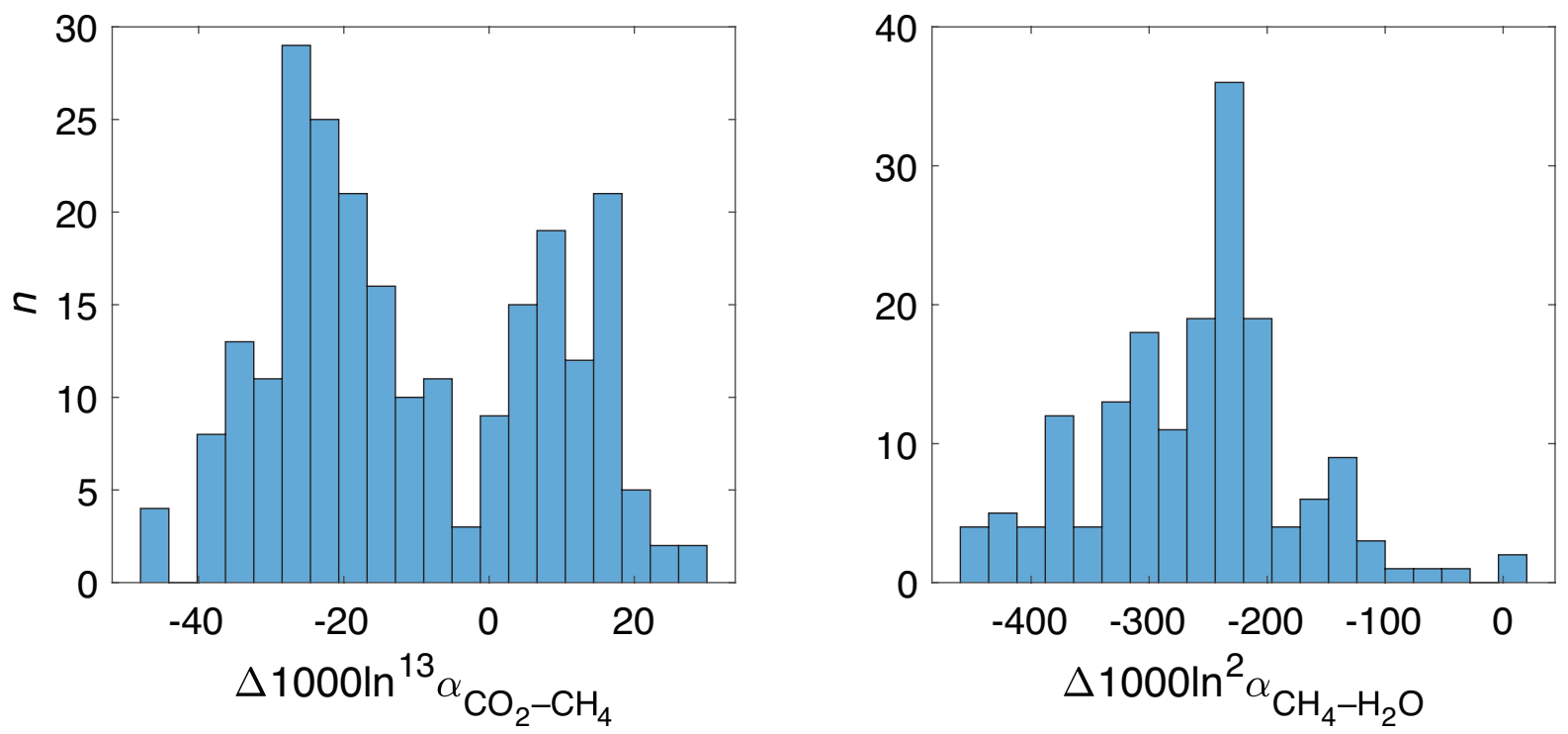

Figure S.1: Deviations from the expected temperature-dependent EFFs in laboratory culture experiments. Left: carbon isotopes $(N=213)$; Right: hydrogen isotopes $(N=172)$. The $n$ on the y-axis label represents the number of samples in each bin. Laboratory data is from Valentine et al. (2004); Penning et al. (2005); Hattori et al. (2012); Okumura et al. (2016); Topçuoğlu et al. (2019). The complete list of samples is available in Table S.12. 


\section{A Isotope fractionation in linear metabolic reaction networks}

\section{A.1 General derivation}

The net isotopic fractionation of any linear metabolic pathway at steady state can be described by a recursive mass balance expression, which requires knowledge of the intermediate reactions' EFFs, forward KFFs and reversibilities, where the reversibility $f$ is defined as the ratio of the reverse and forward mass fluxes (Wing \& Halevy, 2014). We implement here this recursive term for carbon isotopes in the hydrogenotrophic and AOM pathways. Under steady-state conditions, the net fractionation of the general reaction $r \rightleftarrows p$ can be described by:

$$
\alpha_{r-p}^{\mathrm{net}}=\left(\alpha_{r-p}^{\mathrm{eq}}-\alpha_{r \rightarrow p}^{\mathrm{kin}}\right) f_{p, r}+\alpha_{r \rightarrow p}^{\mathrm{kin}},
$$

where $\alpha_{r-p}^{\mathrm{eq}}, \alpha_{r \rightarrow p}^{\mathrm{kin}}$ and $\alpha_{r-p}^{\text {net }}$ are, respectively, the EFF between $r$ and $p$, the KFF between $r$ and the flux of $r$ to $p$, and the net isotope fractionation between $r$ and $p$. This treatment can be applied to linear pathways, such as $s \rightleftarrows r \rightleftarrows p$, by extending Eq. A.1:

$$
\alpha_{s-p}^{\mathrm{net}}=\left(\alpha_{r-p}^{\mathrm{net}} \times \alpha_{s-r}^{\mathrm{eq}}-\alpha_{s \rightarrow r}^{\mathrm{kin}}\right) f_{r, s}+\alpha_{s \rightarrow r}^{\mathrm{kin}}
$$

(full derivation in Wing and Halevy (2014)). Eq. A.2 can be further extended by recursion to any number of reactions in a linear metabolic network at steady state. We use this type of recursive expression to explore carbon isotope fractionation in the hydrogenotrophic (Section 4.4.1)and acetoclastic (Section 4.4.4) methanogenesis, and anaerobic methane oxidation (Section 4.4.5) pathways.

\section{A.2 Equations for hydrogenotrophic methanogenesis and AOM}

We used Eqs. A.3-A.9 to calculate the net carbon isotope fractionation at steady state between $(i)$ $\mathrm{CO}_{2}$ and $\mathrm{CH}_{4}$ (Section 4.4.1) and (ii) $\mathrm{CH}_{4}$ and $\mathrm{CO}_{2}$ (Section 4.4.5). For brevity, we denote here the molecules in the pathway by the letters $\mathrm{A}-\mathrm{H}$, where for case $(i) \mathrm{A}$ is $\mathrm{CO}_{2}$ and $\mathrm{H}$ is $\mathrm{CH}_{4}$, with the intracellular carbon-bearing molecules denoted by B-G, and for case (ii) we use the reverse 
826 notation where $\mathrm{CH}_{4}$ is $\mathrm{A}$ and $\mathrm{CO}_{2}$ is $\mathrm{H}$.

$$
\begin{aligned}
& \alpha_{\mathrm{G}-\mathrm{H}}^{\text {net }}=\left(\alpha_{\mathrm{G}-\mathrm{H}}^{\mathrm{eq}}-\alpha_{\mathrm{G} \rightarrow \mathrm{H}}^{\mathrm{kin}}\right) f_{\mathrm{H}, \mathrm{G}}+\alpha_{\mathrm{G} \rightarrow \mathrm{H}}^{\mathrm{kin}} \\
& \alpha_{\mathrm{F}-\mathrm{H}}^{\text {net }}=\left(\alpha_{\mathrm{G}-\mathrm{H}}^{\mathrm{net}} \times \alpha_{\mathrm{F}-\mathrm{G}}^{\mathrm{eq}}-\alpha_{\mathrm{F} \rightarrow \mathrm{G}}^{\mathrm{kin}}\right) f_{\mathrm{G}, \mathrm{F}}+\alpha_{\mathrm{F} \rightarrow \mathrm{G}}^{\mathrm{kin}} \\
& \alpha_{\mathrm{E}-\mathrm{H}}^{\text {net }}=\left(\alpha_{\mathrm{F}-\mathrm{H}}^{\mathrm{net}} \times \alpha_{\mathrm{E}-\mathrm{F}}^{\mathrm{eq}}-\alpha_{\mathrm{E} \rightarrow \mathrm{F}}^{\mathrm{kin}}\right) f_{\mathrm{F}, \mathrm{E}}+\alpha_{\mathrm{E} \rightarrow \mathrm{F}}^{\mathrm{kin}} \\
& \alpha_{\mathrm{D}-\mathrm{H}}^{\text {net }}=\left(\alpha_{\mathrm{E}-\mathrm{H}}^{\text {net }} \times \alpha_{\mathrm{D}-\mathrm{E}}^{\mathrm{eq}}-\alpha_{\mathrm{D} \rightarrow \mathrm{E}}^{\mathrm{kin}}\right) f_{\mathrm{E}, \mathrm{D}}+\alpha_{\mathrm{D} \rightarrow \mathrm{E}}^{\mathrm{kin}} \\
& \alpha_{\mathrm{C}-\mathrm{H}}^{\text {net }}=\left(\alpha_{\mathrm{D}-\mathrm{H}}^{\mathrm{net}} \times \alpha_{\mathrm{C}-\mathrm{D}}^{\mathrm{eq}}-\alpha_{\mathrm{C} \rightarrow \mathrm{D}}^{\mathrm{kin}}\right) f_{\mathrm{D}, \mathrm{C}}+\alpha_{\mathrm{C} \rightarrow \mathrm{D}}^{\mathrm{kin}} \\
& \alpha_{\mathrm{B}-\mathrm{H}}^{\text {net }}=\left(\alpha_{\mathrm{C}-\mathrm{H}}^{\text {net }} \times \alpha_{\mathrm{B}-\mathrm{C}}^{\mathrm{eq}}-\alpha_{\mathrm{B} \rightarrow \mathrm{C}}^{\mathrm{kin}}\right) f_{\mathrm{C}, \mathrm{B}}+\alpha_{\mathrm{B} \rightarrow \mathrm{C}}^{\mathrm{kin}} \\
& \alpha_{\mathrm{A}-\mathrm{H}}^{\text {net }}=\left(\alpha_{\mathrm{B}-\mathrm{H}}^{\mathrm{net}} \times \alpha_{\mathrm{A}-\mathrm{B}}^{\mathrm{eq}}-\alpha_{\mathrm{A} \rightarrow \mathrm{B}}^{\mathrm{kin}}\right) f_{\mathrm{B}, \mathrm{A}}+\alpha_{\mathrm{A} \rightarrow \mathrm{B}}^{\mathrm{kin}}
\end{aligned}
$$




\section{B Isotope fractionation in nonlinear metabolic reaction networks}

The analytical expression for the calculation of net isotope fractionation presented in Appendix A is only applicable to reversible, linear networks. However, if some of the reactions in the network have more than one source of the atom of interest, an analytical solution is usually not possible, and a numerical solution is required. Consider the reaction:

$$
a \mathrm{Y}_{n}+b \mathrm{Y}_{m} \underset{\phi_{\mathrm{pr}}}{\stackrel{\phi_{\mathrm{rp}}}{\rightleftarrows}} c \mathrm{Y}_{(n+m)}
$$

where $a, b$ and $c$ are are arbitrary organic residues, $\mathrm{Y}$ is the atom of interest, $n$ and $m$ are the stoichiometric coefficients of $\mathrm{Y}$, and $\phi$ is the reaction flux. For brevity, we denote $a \mathrm{Y}_{n}, b \mathrm{Y}_{m}$ and $c \mathrm{Y}_{(n+m)}$ as $r_{1}, r_{2}$ and $p$, respectively. The change of the isotopic composition of compound $p$ with time is:

$$
\begin{aligned}
& \frac{d}{d t} R_{p}=\frac{1}{[p]}\left[\phi_{r p}\left(n \cdot \alpha_{r_{1} \rightarrow p}^{\mathrm{kin}} R_{r_{1}}+m \cdot \alpha_{r_{2} \rightarrow p}^{\mathrm{kin}} R_{r_{2}}\right)-\right. \\
&\left.\phi_{p r} \cdot R_{p}\left(n \cdot \alpha_{p \rightarrow r_{1}}^{\mathrm{kin}}+m \cdot \alpha_{p \rightarrow r_{2}}^{\mathrm{kin}}\right)-R_{p}(m+n)\left(\phi_{r p}-\phi_{p r}\right)\right],
\end{aligned}
$$

where $R_{r_{1}}, R_{r_{2}}$ and $R_{p}$ are the ratios of the rare to abundant isotopes in pools $r_{1}, r_{2}$ and $p$, respectively. In the specific case of a chemical and isotopic steady state, the concentration and isotopic composition of $p$ are constant, and $\frac{d R_{p}}{d t}=\frac{d[p]}{d t}=0$. Rearranging Eq. B.2 yields an analytical solution for $R_{p}$ at steady state:

$$
R_{p}=\frac{\phi_{r p}\left(n \cdot \alpha_{r_{1} \rightarrow p}^{\mathrm{kin}} R_{r_{1}}+m \cdot \alpha_{r_{2} \rightarrow p}^{\mathrm{kin}} R_{r_{2}}\right)}{\phi_{p r}\left(n \cdot \alpha_{p \rightarrow r_{1}}^{\mathrm{kin}}+m \cdot \alpha_{p \rightarrow r_{2}}^{\mathrm{kin}}\right)+(m+n)\left(\phi_{r p}-\phi_{p r}\right)}
$$

(Full derivation in Eq. S5 in Wing and Halevy (2014)). This approach is used here for three specific cases: hydrogen isotope fractionation in hydrogenotrophic methanogenesis (Section 4.4.2), carbon isotope fractionation in methylotrophic methanogenesis (Section 4.4.3) and clumped isotopologue compositions in hydrogenotrophic methanogenesis (Section 4.4.6).

\section{B.1 Hydrogen isotope fractionation in the hydrogenotrophic methanogene- sis pathway}

The last reaction in the hydrogenotrophic methanogenesis pathway, catalyzed by Mcr, has a large negative $\Delta \mathrm{G}_{\mathrm{r}}^{0}\left(\sim-30 \mathrm{~kJ} \mathrm{~mol}^{-1}\right.$ at $\left.25^{\circ} \mathrm{C}\right)$ and is thought to be practically irreversible during methanogenesis (i.e., $\phi_{\mathrm{CH}_{3}-\mathrm{SCoM} \rightarrow \mathrm{CH}_{4}} \ggg \phi_{\mathrm{CH}_{4} \rightarrow \mathrm{CH}_{3} \text {-SCoM}}$ ) (Thauer, 2011). In this case, the reverse reactions from methane will not affect the net isotope composition, and Eq. B.3 can be simplified to:

$$
{ }^{2} R_{\mathrm{CH}_{4}}=\frac{3}{4} \times{ }^{2} \alpha_{\mathrm{CH}_{3}-\mathrm{SCoM} \rightarrow \mathrm{CH}_{4}}{ }^{2 i n} R_{\mathrm{CH}_{3}-\mathrm{SCoM}}+\frac{1}{4} \times{ }^{2} \alpha_{\mathrm{HS}-\mathrm{CoB} \rightarrow \mathrm{CH}_{4}}{ }^{2} R_{\mathrm{HS}-\mathrm{CoB}} .
$$


In the specific case that the reaction between $\mathrm{H}_{2} \mathrm{O}$ and $\mathrm{CH}_{3}-\mathrm{SCoM}$, and coenzyme $\mathrm{B}$ reduction to HS-CoB are at chemical and isotopic equilibrium, then:

$$
{ }^{2} R_{\mathrm{CH}_{3}-\mathrm{SCoM}}={ }^{2} R_{\mathrm{H}_{2} \mathrm{O}} /{ }^{2} \alpha_{\mathrm{H}_{2} \mathrm{O}-\mathrm{CH}_{3}-\mathrm{SCoM}}^{\mathrm{eq}}
$$

and

$$
{ }^{2} R_{\mathrm{HS}-\mathrm{CoB}}={ }^{2} R_{\mathrm{H}_{2} \mathrm{O}} /{ }^{2} \alpha_{\mathrm{H}_{2} \mathrm{O}-\mathrm{HS}-\mathrm{CoB}}^{\mathrm{eq}} \cdot
$$

Eq. B. 4 is then:

$$
\begin{array}{r}
{ }^{2} R_{\mathrm{CH}_{4}}=\frac{3}{4}\left(\alpha_{\mathrm{CH}_{3}-\mathrm{SCoM} \rightarrow \mathrm{CH}_{4}}^{\mathrm{kin}} \cdot{ }^{2} R_{\mathrm{H}_{2} \mathrm{O}} /{ }^{2} \alpha_{\mathrm{H}_{2} \mathrm{O}-\mathrm{CH}_{3}-\mathrm{SCoM}}^{\mathrm{eq}}\right)+ \\
\frac{1}{4}\left({ }^{2} \alpha_{\mathrm{HS}-\mathrm{CoB} \rightarrow \mathrm{CH}_{4}}^{\mathrm{kin}} \cdot{ }^{2} R_{\mathrm{H}_{2} \mathrm{O}} /{ }^{2} \alpha_{\mathrm{H}_{2} \mathrm{O}-\mathrm{HS}-\mathrm{CoB}}^{\mathrm{eq}}\right) .
\end{array}
$$

${ }_{54}$ The net hydrogen isotope fractionation between $\mathrm{CH}_{4}$ and $\mathrm{H}_{2} \mathrm{O},{ }^{2} \alpha_{\mathrm{CH}_{4}-\mathrm{H}_{2} \mathrm{O}}$, can be calculated by dividing both sides of Eq. B.7 by ${ }^{2} R_{\mathrm{H}_{2} \mathrm{O}}$ :

$$
\begin{aligned}
&{ }^{2} \alpha_{\mathrm{CH}_{4}-\mathrm{H}_{2} \mathrm{O}}=\frac{3}{4}\left({ }^{2} \alpha_{\mathrm{CH}_{3}-\mathrm{SCoM} \rightarrow \mathrm{CH}_{4}}^{\mathrm{kin}} /{ }^{2} \alpha_{\mathrm{H}_{2} \mathrm{O}-\mathrm{CH}_{3}-\mathrm{SCoM}}^{\mathrm{eq}}\right)+ \\
& \frac{1}{4}\left({ }^{2} \alpha_{\mathrm{HS}-\mathrm{CoB} \rightarrow \mathrm{CH}_{4}}^{\mathrm{kin}} /{ }^{2} \alpha_{\mathrm{H}_{2} \mathrm{O}-\mathrm{HS}-\mathrm{CoB}}^{\mathrm{eq}}\right) .
\end{aligned}
$$

\section{B.2 Carbon isotope fractionation in the methylotrophic methanogenesis path- way}

In the methylotrophic methanogenesis pathway, methanol is converted to $\mathrm{CH}_{3}-\mathrm{SCoM}$, which is then either oxidized to $\mathrm{CO}_{2}$ in the reverse methanogenic pathway or reduced to $\mathrm{CH}_{4}$ by the Mcrcatalyzed reaction (Fig. 1):

$$
(n+m) \cdot \mathrm{CH}_{3} \mathrm{OH} \rightleftarrows(n+m) \cdot \mathrm{CH}_{3}-\mathrm{S}-\mathrm{CoM} \rightleftarrows n \cdot \mathrm{CH}_{4}+m \cdot \mathrm{CO}_{2},
$$

where $n$ and $m$ are stoichiometric coefficients. This is a simplified view of the pathway, yet it includes the pathway's three main branches. We define $R_{r / o} \equiv n: m$, the ratio of the reduced and oxidized branches. If all methanol molecules are converted to either $\mathrm{CO}_{2}$ or $\mathrm{CH}_{4}, R_{r / o}$ is expected to be 3:1, as the source of the 2 electrons for $\mathrm{CH}_{3}-\mathrm{SCoM}$ reduction to $\mathrm{CH}_{4}$ is from the full oxidation of $\mathrm{CH}_{3}-\mathrm{SCoM}$ to $\mathrm{CO}_{2}$, which yields 6 electrons. However, if some of the $\mathrm{CH}_{3}-\mathrm{SCoM}$ is instead converted to biomass, $R_{r / o}$ may vary. For brevity, we denote the metabolites here as $\mathrm{A}\left(\mathrm{CH}_{3} \mathrm{OH}\right), \mathrm{B}$ $\left(\mathrm{CH}_{3}-\mathrm{SCoM}\right), \mathrm{C}\left(\mathrm{CH}_{4}\right)$ and $\mathrm{D}\left(\mathrm{CO}_{2}\right)$. The change in the isotopic composition of $\mathrm{B}\left(R_{B}\right)$ with time is:

$$
\begin{gathered}
\frac{d}{d t}{ }^{13} R_{\mathrm{B}}=\frac{1}{[\mathrm{~B}]}\left[(n+m) \cdot \phi_{\mathrm{AB}}{ }^{13} \alpha_{\mathrm{A} \rightarrow \mathrm{B}}^{\mathrm{kin}}{ }^{13} R_{\mathrm{A}}+n \cdot \phi_{\mathrm{CB}}{ }^{13} \alpha_{\mathrm{C} \rightarrow \mathrm{B}}^{\mathrm{kin}}{ }^{13} R_{\mathrm{C}}+m \cdot \phi_{\mathrm{DB}}{ }^{13} \alpha_{\mathrm{D} \rightarrow \mathrm{B}}^{\mathrm{kin}}{ }^{13} R_{\mathrm{D}}-\right. \\
{ }^{13} R_{\mathrm{B}}\left((n+m) \cdot \phi_{\mathrm{BA}}{ }^{13} \alpha_{\mathrm{B} \rightarrow \mathrm{A}}^{\mathrm{kin}}+n \cdot \phi_{\mathrm{BC}}{ }^{13} \alpha_{\mathrm{B} \rightarrow \mathrm{C}}^{\mathrm{kin}}+m \cdot \phi_{\mathrm{BD}}{ }^{13} \alpha_{\mathrm{B} \rightarrow \mathrm{D}}^{\mathrm{kin}}\right)- \\
\left.{ }^{13} R_{\mathrm{B}}\left((n+m)\left(\phi_{\mathrm{AB}}-\phi_{\mathrm{BA}}\right)+n\left(\phi_{\mathrm{CB}}-\phi_{\mathrm{BC}}\right)+m\left(\phi_{\mathrm{DB}}-\phi_{\mathrm{BD}}\right)\right)\right] .
\end{gathered}
$$


We write similar time derivatives for $\mathrm{C}$ and $\mathrm{D}$ :

$$
\frac{d}{d t}{ }^{13} R_{\mathrm{C}}=\frac{1}{[\mathrm{C}]} \cdot n\left[\phi_{\mathrm{BC}}{ }^{13} \alpha_{\mathrm{B} \rightarrow \mathrm{C}}^{\mathrm{kin}}{ }^{13} R_{\mathrm{B}}-\phi_{\mathrm{CB}}{ }^{13} \alpha_{\mathrm{C} \rightarrow \mathrm{B}}^{\mathrm{kin}} R_{\mathrm{C}}-{ }^{13} R_{\mathrm{C}}\left(\phi_{\mathrm{BC}}-\phi_{\mathrm{CB}}\right)\right],
$$

$$
\frac{d}{d t}{ }^{13} R_{\mathrm{D}}=\frac{1}{[\mathrm{D}]} \cdot m\left[\phi_{\mathrm{BD}}{ }^{13} \alpha_{\mathrm{B} \rightarrow \mathrm{D}}^{\mathrm{kin}}{ }^{13} R_{\mathrm{B}}-\phi_{\mathrm{DB}}{ }^{13} \alpha_{\mathrm{D} \rightarrow \mathrm{B}}^{\mathrm{kin}}{ }^{13} R_{\mathrm{D}}-{ }^{13} R_{\mathrm{D}}\left(\phi_{\mathrm{BD}}-\phi_{\mathrm{DB}}\right)\right] .
$$

The metabolic network of the methyltrophic pathway as presnted in Eq. B.9 is non-linear. Thus, the isotope fractionations between A, C and D are not independent of each other, and an analytical solution is nontrivial and provides little intuition. Instead, a numerical solution to this system is possible, by forward integration of Eqs. B.10-B.12 until the steady-state solution is obtained. To solve this systen, we used the ode 15 s solver in MATLAB ${ }^{\circledR}$. We assigned the reversibility of the reactions $(f)$, the net rate $\left(\phi_{\text {net }}\right),{ }^{13} R_{\mathrm{A}}$, and the forward KFFs ${ }^{13} \alpha^{\mathrm{kin}}$. We calculated the backward KFFs by the relation $\alpha_{\mathrm{A}-\mathrm{B}}^{\mathrm{eq}}=\alpha_{\mathrm{B} \rightarrow \mathrm{A}}^{\mathrm{kin}} / \alpha_{\mathrm{A} \rightarrow \mathrm{B}}^{\mathrm{kin}}$. We assumed that the reaction from $\mathrm{CH}_{3}-\mathrm{SCoM}$ to $\mathrm{CO}_{2}$ is partially reversible, i.e., $\phi_{\mathrm{DB}} / \phi_{\mathrm{BD}}=0.75$, to obtain the ideal fit to the observed ranges of methanol- $-\mathrm{CH}_{4}$ and methanol- $\mathrm{CO}_{2}$ carbon isotope fractionations. The forward and reverse fluxes are related to the net rate and the $f \mathrm{~s}$ :

$$
\phi_{\mathrm{AB}}=\frac{\phi_{\text {net }}}{1-f_{\mathrm{B}, \mathrm{A}}}
$$

$$
\phi_{\mathrm{BA}}=\frac{\phi_{\text {net }} \times f_{\mathrm{B}, \mathrm{A}}}{1-f_{\mathrm{B}, \mathrm{A}}} .
$$

\section{B.3 Clumped isotopologue compositions of methane in the hydrogenotrophic pathway}

We consider a simplification of the hydrogenotrophic pathway, which includes the four steps of hydrogen addition under three scenarios of reversibility, as presented by Cao et al. (2019). Each scenario is denoted by a vector of ones (fully reversible reaction) and zeros (irreversible reaction), e.g., $[1,1,1,0]$ represents three reversible reactions from $\mathrm{CO}_{2}$ and $\mathrm{H}_{2} \mathrm{O}$ to $\mathrm{CH}_{3}-\mathrm{SCoM}$, and an irreversible reaction from $\mathrm{CH}_{3}-\mathrm{SCoM}$ and $\mathrm{HS}-\mathrm{CoB}$ to $\mathrm{CH}_{4}$. Notably, Cao et al. (2019) assume that the intracellular hydrogen pools $\left(\mathrm{F}_{420} \mathrm{H}_{2}\right.$ and $\left.\mathrm{HS}-\mathrm{CoB}\right)$, which are the source of the hydrogen added to carbon to ultimately form methane, are at equilibrium with $\mathrm{H}_{2} \mathrm{O}$, and that the EFFs and KFFs of the different steps in the pathway are identical, allowing derivation of elegant solutions for $\Delta^{13} \mathrm{CH}_{3} \mathrm{D}$ and $\Delta^{12} \mathrm{CH}_{2} \mathrm{D}_{2}$ values. We explored the effect of using our calculated EFFs on the same scenarios, and used similar solutions but without the assumption of identical EFFs along the pathway. The original equations and parameters are presented in Tables 1 and 2 in Cao et al. (2019), we use similar distributions of unknown KFFs and the respective kinetic $\gamma$ values. We show here the equations that we used with our calculated EFFs to find the $\Delta^{13} \mathrm{CH}_{3} \mathrm{D}$ and $\Delta^{12} \mathrm{CH}_{2} \mathrm{D}_{2}$ values (Fig. 10). 


\section{B.3.1 Scenario $[1,0,0,0]$}

Following equations A.11a-d in Cao et al. (2019) we get:

$$
\Delta^{13} \mathrm{CH}_{3} \mathrm{D}=\frac{\left(\begin{array}{c}
13,2 \\
{ }^{2} \alpha^{k i n}\left(1+\Delta_{13}^{\mathrm{eq}}\right. \\
+{ }^{13,2} \gamma_{p}{ }^{2} \alpha_{p}^{k i n 2} \alpha_{\mathrm{F}_{420} \mathrm{H}_{2}-\mathrm{CHO}-\mathrm{MFR}}^{\mathrm{eq}} \cdots \\
+{ }^{13,2} \gamma_{p}{ }^{2} \alpha_{p}^{k i n 2} \alpha_{\mathrm{HS}-\mathrm{CoB}-\mathrm{CHO}-\mathrm{MFR}}^{\mathrm{eq}}
\end{array}\right)}{\left(\begin{array}{c}
{ }^{2} \alpha^{k i n}+{ }^{2} \alpha_{p}^{k i n 2} \alpha_{\mathrm{F}_{420} \mathrm{H}_{2}-\mathrm{CHO}-\mathrm{MFR}}^{\mathrm{eq}} \cdots \\
+{ }^{2} \alpha_{p}^{k i n 2} \alpha_{\mathrm{HS}-\mathrm{CoB}-\mathrm{CHO}-\mathrm{MFR}}^{\mathrm{eq}}
\end{array}\right)}-1,
$$

where the $\gamma$ and $\gamma_{p}$ are for the deviation of the clumped KFF from the bulk KFF, as defined by Wang et al. (2015) for secondary and primary KFFs, respectively, and ${ }^{2} \alpha^{k i n}$ and ${ }^{2} \alpha_{p}^{k i n}$ are secondary and primary KFFs drawn from uniform distributions, respectively.

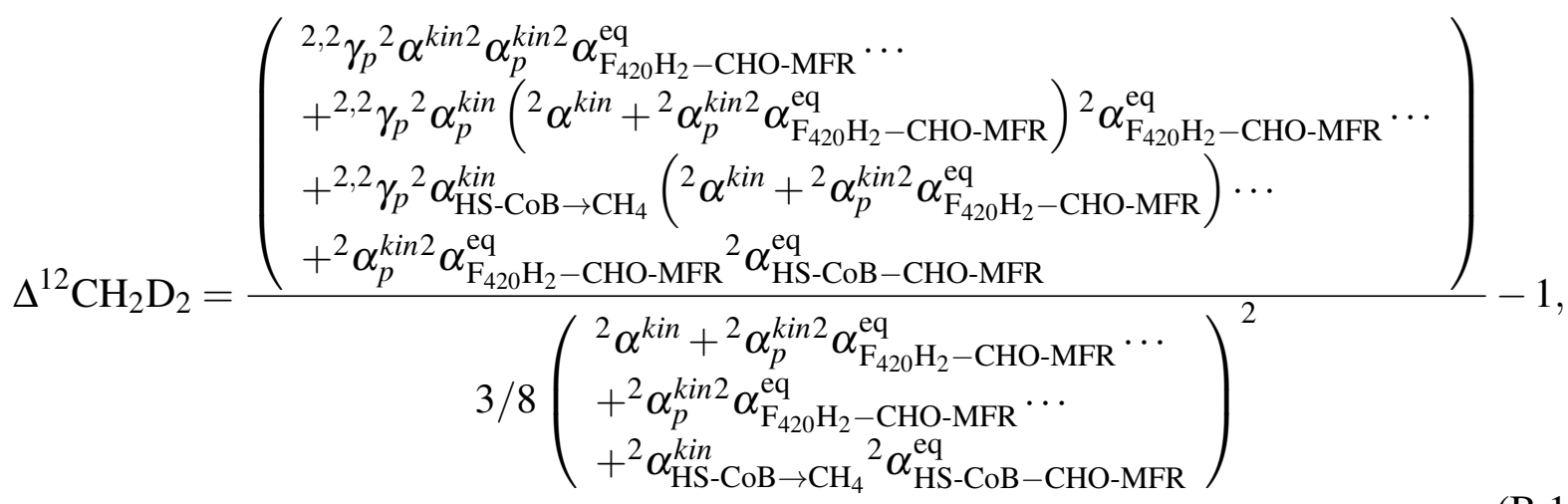

\section{B.3.2 Scenario $[1,1,0,0]$}

Following equations A.15a-d in Cao et al. (2019) we get:

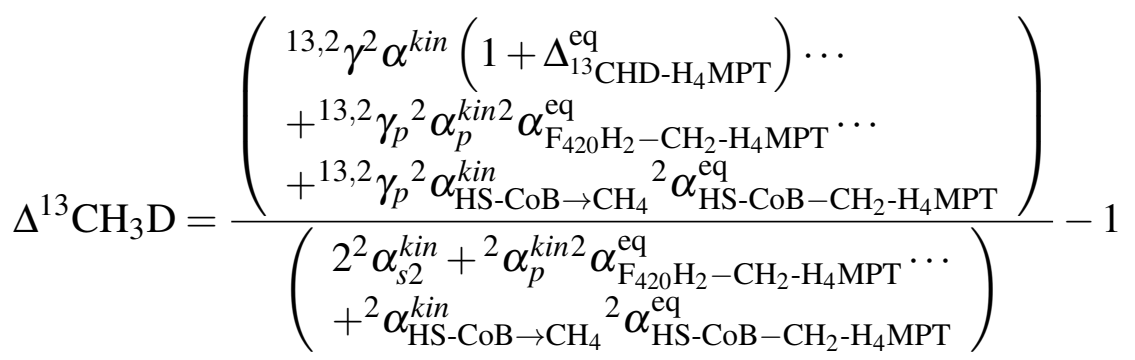

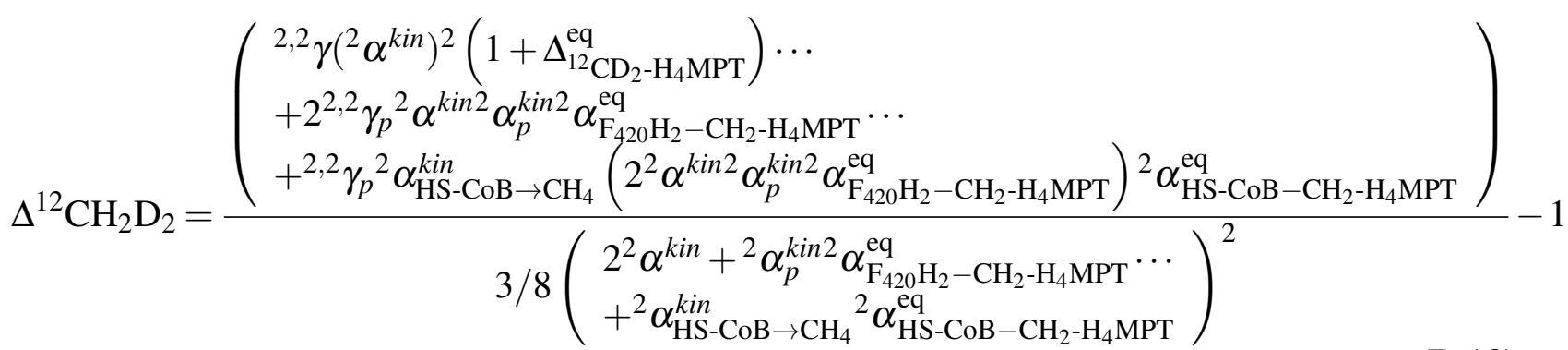


B.3.3 Scenario $[1,1,1,0]$

908 Following equations A.19a-d in Cao et al. (2019) we get:

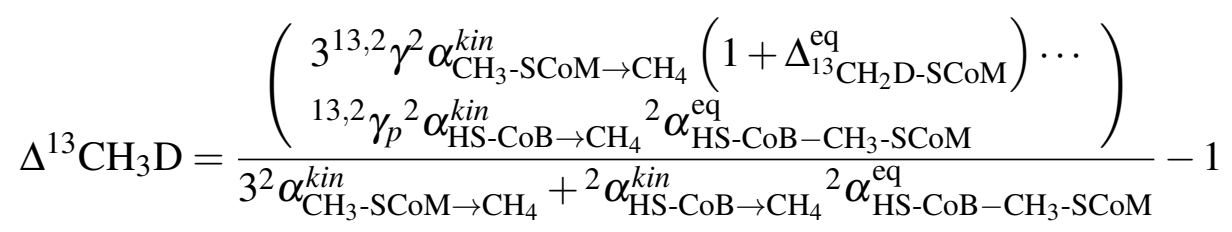

909

$$
\Delta^{12} \mathrm{CH}_{2} \mathrm{D}_{2}=\frac{\left(\begin{array}{l}
8^{2} \alpha_{\mathrm{CH}_{3}-\mathrm{SCoM} \rightarrow \mathrm{CH}_{4}}^{\text {kin }}\left({ } ^ { 2 , 2 } \gamma ^ { 2 } \alpha _ { \mathrm { CH } _ { 3 } - \mathrm { SCoM } \rightarrow \mathrm { CH } _ { 4 } } ^ { k i n } \left(1+\Delta_{12}^{\mathrm{eq}} \mathrm{CHD}_{2}-\mathrm{SCoM}\right.\right. \\
\left.+{ }^{2,2} \gamma_{p}{ }^{2} \alpha_{\mathrm{HS}-\mathrm{CoB} \rightarrow \mathrm{CH}_{4}}^{k i n}{ }^{2} \alpha_{\mathrm{HS}-\mathrm{CoB}-\mathrm{CH}_{3}-\mathrm{SCoM}}^{\mathrm{eq}}\right)
\end{array}\right)}{3^{2} \alpha_{\mathrm{CH}_{3}-\mathrm{SCoM} \rightarrow \mathrm{CH}_{4}}^{k i n}+{ }^{2} \alpha_{\mathrm{HS}-\mathrm{CoB} \rightarrow \mathrm{CH}_{4}}^{k i n} \alpha_{\mathrm{HS}-\mathrm{CoB}-\mathrm{CH}_{3}-\mathrm{SCoM}}^{\mathrm{eq}}}-1
$$




\section{References}

Alperin, M. J., \& Hoehler, T. M. (2009). Anaerobic methane oxidation by archaea/sulfate-reducing bacteria aggregates: 2. Isotopic constraints. Am J Sci, 309, 958-984. doi:10.2475/10.2009.02.

Alstad, K. P., \& Whiticar, M. J. (2011). Carbon and hydrogen isotope ratio characterization of methane dynamics for Fluxnet Peatland Ecosystems. Org. Geochem., 42, 548-558. doi:10.1016/j.orggeochem.2011.03.004.

Andrae, D., Häußermann, U., Dolg, M., Stoll, H., \& Preuß, H. (1990). Energy-adjustedab initio pseudopotentials for the second and third row transition elements. Theoret. Chim. Acta, 77, 123-141. doi:10.1007/BF01114537.

Ash, J., Egger, M., Treude, T., Kohl, I., Cragg, B., Parkes, R., Slomp, C., Sherwood Lollar, B., \& Young, E. (2019). Exchange catalysis during anaerobic methanotrophy revealed by 12CH2D2 and 13CH3D in methane. Geochem. Perspect. Lett., (pp. 26-30). doi:10.7185/geochemlet.1910.

Bardo, R. D., \& Wolfsberg, M. (1976). A theoretical calculation of the equilibrium constant for the isotopic exchange reaction between water and hydrogen deuteride. J. Phys. Chem., 80, 10681071. doi:10.1021/j100551a009.

Berghuis, B. A., Yu, F. B., Schulz, F., Blainey, P. C., Woyke, T., \& Quake, S. R. (2019). Hydrogenotrophic methanogenesis in archaeal phylum Verstraetearchaeota reveals the shared ancestry of all methanogens. Proc. Natl. Acad. Sci., 116, 5037-5044. doi:10.1073/pnas.1815631116.

Bigeleisen, J., \& Mayer, M. G. (1947). Calculation of Equilibrium Constants for Isotopic Exchange Reactions. J. Chem. Phys., 15, 261-267. doi:10.1063/1.1746492.

Black, J. R., Yin, Q.-Z., Rustad, J. R., \& Casey, W. H. (2007). Magnesium Isotopic Equilibrium in Chlorophylls. J. Am. Chem. Soc., 129, 8690-8691. doi:10.1021/JA072573I.

Boese, A. D., \& Handy, N. C. (2001). A new parametrization of exchange-correlation generalized gradient approximation functionals. J. Chem. Phys., 114, 5497-5503. doi:10.1063/1.1347371.

Bottinga, Y. (1969). Calculated fractionation factors for carbon and hydrogen isotope exchange in the system calcite-carbon dioxide-graphite-methane-hydrogen-water vapor. Geochim. Cosmochim. Acta, 33, 49-64. doi:10.1016/0016-7037(69)90092-1.

Bradley, A. S., Leavitt, W. D., Schmidt, M., Knoll, A. H., Girguis, P. R., \& Johnston, D. T. (2016). Patterns of sulfur isotope fractionation during microbial sulfate reduction. Geobiology, 14, 91101. doi:10.1111/gbi.12149. 
Cao, X., Bao, H., \& Peng, Y. (2019). A kinetic model for isotopologue signatures of methane generated by biotic and abiotic $\mathrm{CO} 2$ methanation. Geochim. Cosmochim. Acta, 249, 59-75. doi:10.1016/J.GCA.2019.01.021.

Cao, X., \& Liu, Y. (2012). Theoretical estimation of the equilibrium distribution of clumped isotopes in nature. Geochim. Cosmochim. Acta, 77, 292-303. doi:10.1016/j.gca.2011.11.021.

Cerrai, E., Marchetti, C., Renzoni, R., Roseo, L., Silvesti, M., \& Villari, S. (1954). A Thermal Method for Concentrating Heavy Water. Chem. Eng. Prog. Symp, 50, 292-303.

Chuang, P.-C., Frank Yang, T., Wallmann, K., Matsumoto, R., Hu, C.-Y., Chen, H.-W., Lin, S., Sun, C.-H., Li, H.-C., Wang, Y., \& Dale, A. W. (2018). Carbon isotope exchange during anaerobic oxidation of methane (AOM) in sediments of the northeastern South China Sea. Geochim. Cosmochim. Acta, 246, 138-155. doi:10.1016/J.GCA.2018.11.003.

Clog, M., Lawson, M., Peterson, B., Ferreira, A. A., Santos Neto, E. V., \& Eiler, J. M. (2018). A reconnaissance study of 13C-13C clumping in ethane from natural gas. Geochim. Cosmochim. Acta, 223, 229-244. doi:10.1016/J.GCA.2017.12.004.

DePaolo, D. J. (2011). Surface kinetic model for isotopic and trace element fractionation during precipitation of calcite from aqueous solutions. Geochim. Cosmochim. Acta, 75, 1039-1056. doi:10.1016/j.gca.2010.11.020.

Domagal-Goldman, S. D., \& Kubicki, J. D. (2008). Density functional theory predictions of equilibrium isotope fractionation of iron due to redox changes and organic complexation. Geochim. Cosmochim. Acta, 72, 5201-5216. doi:10.1016/j.gca.2008.05.066.

Douglas, P., Stolper, D., Smith, D., Walter Anthony, K., Paull, C., Dallimore, S., Wik, M., Crill, P., Winterdahl, M., Eiler, J., \& Sessions, A. (2016). Diverse origins of Arctic and Subarctic methane point source emissions identified with multiply-substituted isotopologues. Geochim. Cosmochim. Acta, 188, 163-188. doi:10.1016/j.gca.2016.05.031.

Douglas, P. M. J., Moguel, R. G., Anthony, K. M. W., Wik, M., Crill, P. M., Dawson, K. S., Smith, D. A., Yanay, E., Lloyd, M. K., Stolper, D. A., Eiler, J. M., \& Sessions, A. L. (2020). Clumped Isotopes Link Older Carbon Substrates With Slower Rates of Methanogenesis in Northern Lakes. Geophys. Res. Lett., 47, e2019GL086756. doi:10.1029/2019GL086756.

Egger, M., Riedinger, N., Mogollón, J. M., \& Jørgensen, B. B. (2018). Global diffusive fluxes of methane in marine sediments. Nat. Geosci., 11, 421-425. doi:10.1038/s41561-018-0122-8.

Eldridge, D., Guo, W., \& Farquhar, J. (2016). Theoretical estimates of equilibrium sulfur isotope effects in aqueous sulfur systems: Highlighting the role of isomers in the sulfite and sulfoxylate systems. Geochim. Cosmochim. Acta, 195, 171-200. doi:10.1016/J.GCA.2016.09.021. 
Eldridge, D. L., Korol, R., Lloyd, M. K., Turner, A. C., Webb, M. A., Miller, T. F., \& Stolper, D. (2019). Comparison of Experimental vs. Theoretical Abundances of 13CH3D and 12CH2D2 for Isotopically Equilibrated Systems From 1-500oC. ACS Earth Space Chem., 3, 2747-2764. doi:10.1021/acsearthspacechem.9b00244.

Frisch, M., Trucks, G., Schlegel, H., Scuseria, G., Robb, M., Cheeseman, J., Scalmani, G., Barone, V., Petersson, G., Nakatsuji, H. et al. (2016). Gaussian 16. Revis. A, 3.

Fujii, T., Moynier, F., Blichert-Toft, J., \& Albarède, F. (2014). Density functional theory estimation of isotope fractionation of $\mathrm{Fe}, \mathrm{Ni}, \mathrm{Cu}$, and $\mathrm{Zn}$ among species relevant to geochemical and biological environments. Geochim. Cosmochim. Acta, 140, 553-576. doi:10.1016/J.GCA.2014.05.051.

Galimov, E. (2006). Isotope organic geochemistry. Org. Geochem., 37, 1200-1262. doi:10.1016/j.orggeochem.2006.04.009.

Gelwicks, J. T., Risatti, J. B., \& Hayes, J. M. (1994). Carbon isotope effects associated with aceticlastic methanogenesis. Appl. Environ. Microbiol., 60, 467-72.

Giunta, T., Young, E. D., Warr, O., Kohl, I., Ash, J. L., Martini, A., Mundle, S. O., Rumble, D., Pérez-Rodríguez, I., Wasley, M., LaRowe, D. E., Gilbert, A., \& Sherwood Lollar, B. (2019). Methane sources and sinks in continental sedimentary systems: New insights from paired clumped isotopologues 13CH3D and 12CH2D2. Geochim. Cosmochim. Acta, 245, 327351. doi:10.1016/J.GCA.2018.10.030.

Goevert, D., \& Conrad, R. (2009). Effect of substrate concentration on carbon isotope fractionation during acetoclastic methanogenesis by Methanosarcina barkeri and M. acetivorans and in rice field soil. Appl. Environ. Microbiol., 75, 2605-2612. doi:10.1128/AEM.02680-08.

Gruen, D. S., Wang, D. T., Könneke, M., Topçuoğlu, B. D., Stewart, L. C., Goldhammer, T., Holden, J. F., Hinrichs, K.-U., \& Ono, S. (2018). Experimental investigation on the controls of clumped isotopologue and hydrogen isotope ratios in microbial methane. Geochim. Cosmochim. Acta, 237, 339-356. doi:10.1016/J.GCA.2018.06.029.

Hattori, S., Nashimoto, H., Kimura, H., Koba, K., Yamada, K., Shimizu, M., Watanabe, H., Yoh, M., \& Yoshida, N. (2012). Hydrogen and carbon isotope fractionation by thermophilic hydrogenotrophic methanogens from a deep aquifer under coculture with fermenters. Geochem. J., 46, 193-200. doi:10.2343/geochemj.1.0161.

He, Y., Bao, H., \& Liu, Y. (2020). Predicting equilibrium intramolecular isotope distribution within a large organic molecule by the cutoff calculation. Geochimica et Cosmochimica Acta, 269, 292302. doi:10.1016/j.gca.2019.10.032. 
Hohenberg, P., \& Kohn, W. (1964). Inhomogeneous Electron Gas. Phys. Rev., 136, B864-B871. doi:10.1103/PhysRev.136.B864.

Holler, T., Wegener, G., Knittel, K., Boetius, A., Brunner, B., Kuypers, M. M. M., \& Widdel, F. (2009). Substantial $13 \mathrm{C} / 12 \mathrm{C}$ and $\mathrm{D} / \mathrm{H}$ fractionation during anaerobic oxidation of methane by marine consortia enriched in vitro. Environ. Microbiol. Rep., 1, 370-376. doi:10.1111/j.17582229.2009.00074.x.

Horibe, Y., \& Craig, H. (1995). D/H fractionation in the system methane-hydrogen-water. Geochim. Cosmochim. Acta, 59, 5209-5217. doi:10.1016/0016-7037(95)00391-6.

Horita, J. (2001). Carbon isotope exchange in the system CO2-CH4 at elevated temperatures. Geochim. Cosmochim. Acta, 65, 1907-1919. doi:10.1016/S0016-7037(01)00570-1.

Horita, J., \& Wesolowski, D. J. (1994). Liquid-vapor fractionation of oxygen and hydrogen isotopes of water from the freezing to the critical temperature. Geochim. Cosmochim. Acta, 58, 34253437. doi:10.1016/0016-7037(94)90096-5.

Iron, M. A., \& Gropp, J. (2019). Cost-Effective Density Functional Theory (DFT) Calculations of Equilibrium Isotopic Fractionation in Large Organic Molecules. Phys. Chem. Chem. Phys., 21, 17555-17570. doi:10.1039/C9CP02975C.

Kaupp, M., Schleyer, P. v. R., Stoll, H., \& Preuss, H. (1991). Pseudopotential approaches to Ca, $\mathrm{Sr}$, and Ba hydrides. Why are some alkaline earth MX2 compounds bent? J. Chem. Phys., 94, 1360-1366. doi:10.1063/1.459993.

Kawagucci, S., Kobayashi, M., Hattori, S., Yamada, K., Ueno, Y., Takai, K., \& Yoshida, N. (2014). Hydrogen isotope systematics among $\mathrm{H} 2-\mathrm{H} 2 \mathrm{O}-\mathrm{CH} 4$ during the growth of the hydrogenotrophic methanogen Methanothermobacter thermautotrophicus strain $\Delta \mathrm{H}$. Geochim. Cosmochim. Acta, 142, 601-614. doi:10.1016/j.gca.2014.07.020.

Kesharwani, M. K., Karton, A., \& Martin, J. M. L. (2016). Benchmark ab Initio Conformational Energies for the Proteinogenic Amino Acids through Explicitly Correlated Methods. Assessment of Density Functional Methods. J. Chem. Theory Comput., 12, 444-54. doi:10.1021/acs.jctc.5b01066.

Kohn, W., \& Sham, L. J. (1965). Self-Consistent Equations Including Exchange and Correlation Effects. Phys. Rev., 140, A1133-A1138. doi:10.1103/PhysRev.140.A1133.

Krzycki, J. A., Kenealy, W. R., Deniro, M. J., \& Zeikus, J. G. (1987). Stable Carbon Isotope Fractionation by Methanosarcina barkeri during Methanogenesis from Acetate, Methanol, or Carbon Dioxide-Hydrogen. Appl. Environ. Microbiol., 53, 2597-9. 
Kueter, N., Schmidt, M. W., Lilley, M. D., \& Bernasconi, S. M. (2019). Experimental determination of equilibrium CH4-CO2-CO carbon isotope fractionation factors (300-1200 oC). Earth Planet. Sci. Lett., 506, 64-75. doi:10.1016/J.EPSL.2018.10.021.

Leininger, T., Nicklass, A., Küchle, W., Stoll, H., Dolg, M., \& Bergner, A. (1996). The accuracy of the pseudopotential approximation: Non-frozen-core effects for spectroscopic constants of alkali fluorides XF (X = K, Rb, Cs). Chemical Physics Letters, 255, 274-280. doi:10.1016/00092614(96)00382-X.

Li, X., \& Liu, Y. (2011). Equilibrium Se isotope fractionation parameters: A first-principles study. Earth Planet. Sci. Lett., 304, 113-120. doi:10.1016/J.EPSL.2011.01.022.

Liu, Q., \& Liu, Y. (2016). Clumped-isotope signatures at equilibrium of CH4, NH3, H2O, H2S and SO2. Geochim. Cosmochim. Acta, 175, 252-270. doi:10.1016/J.GCA.2015.11.040.

Liu, Q., Tossell, J. A., \& Liu, Y. (2010). On the proper use of the Bigeleisen-Mayer equation and corrections to it in the calculation of isotopic fractionation equilibrium constants. Geochim. Cosmochim. Acta, 74, 6965-6983. doi:10.1016/J.GCA.2010.09.014.

Londry, K. L., Dawson, K. G., Grover, H. D., Summons, R. E., \& Bradley, A. S. (2008). Stable carbon isotope fractionation between substrates and products of Methanosarcina barkeri. Org. Geochem., 39, 608-621. doi:10.1016/j.orggeochem.2008.03.002.

Luxem, K. E., Leavitt, W. D., \& Zhang, X. (2020). Large hydrogen isotope fractionations distinguish nitrogenase-derived methane from other sources. Appl. Environ. Microbiol. doi:10.1128/AEM.00849-20.

Mardirossian, N., \& Head-Gordon, M. (2016). $\omega$ B97M-V: A combinatorially optimized, rangeseparated hybrid, meta-GGA density functional with VV10 nonlocal correlation. J. Chem. Phys., 144, 214110. doi:10.1063/1.4952647.

Marenich, A. V., Cramer, C. J., \& Truhlar, D. G. (2009). Universal Solvation Model Based on Solute Electron Density and on a Continuum Model of the Solvent Defined by the Bulk Dielectric Constant and Atomic Surface Tensions. J. Phys. Chem. B, 113, 6378-6396. doi:10.1021/jp810292n.

McGlynn, S. E. (2017). Energy Metabolism during Anaerobic Methane Oxidation in ANME Archaea. Microbes Environ., 32, 5-13. doi:10.1264/jsme2.ME16166.

Méheut, M., Lazzeri, M., Balan, E., \& Mauri, F. (2007). Equilibrium isotopic fractionation in the kaolinite, quartz, water system: Prediction from first-principles density-functional theory. Geochim. Cosmochim. Acta, 71, 3170-3181. doi:10.1016/j.gca.2007.04.012. 
Metz, B., Stoll, H., \& Dolg, M. (2000). Small-core multiconfiguration-Dirac-Hartree-Fockadjusted pseudopotentials for post-d main group elements: Application to $\mathrm{PbH}$ and $\mathrm{PbO} . J$. Chem. Phys., 113, 2563-2569. doi:10.1063/1.1305880.

Milucka, J., Ferdelman, T. G., Polerecky, L., Franzke, D., Wegener, G., Schmid, M., Lieberwirth, I., Wagner, M., Widdel, F., \& Kuypers, M. M. M. (2012). Zero-valent sulphur is a key intermediate in marine methane oxidation. Nature, 491, 541-546. doi:10.1038/nature11656.

Moynier, F., \& Fujii, T. (2017). Theoretical isotopic fractionation of magnesium between chlorophylls. Sci. Rep., 7, 6973. doi:10.1038/s41598-017-07305-6.

Okumura, T., Kawagucci, S., Saito, Y., Matsui, Y., Takai, K., \& Imachi, H. (2016). Hydrogen and carbon isotope systematics in hydrogenotrophic methanogenesis under $\mathrm{H} 2$-limited and $\mathrm{H} 2$ enriched conditions: Implications for the origin of methane and its isotopic diagnosis. Prog. Earth Planet. Sci., 3, 14. doi:10.1186/s40645-016-0088-3.

Ono, S., Rhim, J. H., Gruen, D. S., Taubner, H., Kölling, M., \& Wegener, G. (2020). Clumped Isotopologue Fractionation by Microbial Cultures Performing the Anaerobic 10 Oxidation of Methane. ChemRxiv. doi:10.26434/chemrxiv.12888347.v1.

Ono, S., Wang, D. T., Gruen, D. S., Sherwood Lollar, B., Zahniser, M. S., McManus, B. J., \& Nelson, D. D. (2014). Measurement of a doubly substituted methane isotopologue, ${ }^{13} \mathrm{CH} 3 \mathrm{D}$, by tunable infrared laser direct absorption spectroscopy. Anal. Chem., 86, 6487-94. doi:10.1021/ac5010579.

Otake, T., Lasaga, A. C., \& Ohmoto, H. (2008). Ab initio calculations for equilibrium fractionations in multiple sulfur isotope systems. Chem. Geol., 249, 357-376. doi:10.1016/J.CHEMGEO.2008.01.020.

Penger, J., Conrad, R., \& Blaser, M. (2012). Stable carbon isotope fractionation by methylotrophic methanogenic archaea. Appl. Environ. Microbiol., 78, 7596-602. doi:10.1128/AEM.01773-12.

Penger, J., Conrad, R., \& Blaser, M. (2014). Stable carbon isotope fractionation of six strongly fractionating microorganisms is not affected by growth temperature under laboratory conditions. Geochim. Cosmochim. Acta, 140, 95-105. doi:10.1016/j.gca.2014.05.015.

Penning, H., Claus, P., Casper, P., \& Conrad, R. (2006). Carbon isotope fractionation during acetoclastic methanogenesis by Methanosaeta concilii in culture and a lake sediment. Appl. Environ. Microbiol., 72, 5648-52. doi:10.1128/AEM.00727-06.

Penning, H., Plugge, C. M., Galand, P. E., \& Conrad, R. (2005). Variation of carbon isotope fractionation in hydrogenotrophic methanogenic microbial cultures and environmental 
samples at different energy status. Glob. Change Biol., 11, 2103-2113. doi:10.1111/j.13652486.2005.01076.x.

Proskurowski, G., Lilley, M. D., Kelley, D. S., \& Olson, E. J. (2006). Low temperature volatile production at the Lost City Hydrothermal Field, evidence from a hydrogen stable isotope geothermometer. Chem. Geol., 229, 331-343. doi:10.1016/J.CHEMGEO.2005.11.005.

Richet, P., Bottinga, Y., \& Javoy, M. (1977). A Review of Hydrogen, Carbon, Nitrogen, Oxygen, Sulphur, and Chlorine Stable Isotope Fractionation Among Gaseous Molecules. Annu. Rev. Earth Planet. Sci., 5, 65-110. doi:10.1146/annurev.ea.05.050177.000433.

Röckmann, T., Popa, M. E., Krol, M. C., \& Hofmann, M. E. G. (2016). Statistical clumped isotope signatures. Sci. Rep., 6, 31947. doi:10.1038/srep31947.

Rolston, J. H., Den Hartog, J., \& Butler, J. P. (1976). The deuterium isotope separation factor between hydrogen and liquid water. J. Phys. Chem., 80, 1064-1067. doi:10.1021/j100551a008.

Roothaan, C. C. J. (1951). New Developments in Molecular Orbital Theory. Rev. Mod. Phys., 23, 69-89. doi:10.1103/RevModPhys.23.69.

Rosenfeld, W. D., \& Silverman, S. R. (1959). Carbon Isotope Fractionation in Bacterial Production of Methane. Science, 130, 1658-1659. doi:10.1126/science.130.3389.1658-a.

Rustad, J. R. (2009). Ab initio calculation of the carbon isotope signatures of amino acids. Org. Geochem., 40, 720-723. doi:10.1016/j.orggeochem.2009.03.003.

Rustad, J. R., Nelmes, S. L., Jackson, V. E., \& Dixon, D. A. (2008). Quantum-chemical calculations of carbon-isotope fractionation in $\mathrm{CO} 2(\mathrm{~g})$, aqueous carbonate species, and carbonate minerals. J. Phys. Chem. A, 112, 542-55. doi:10.1021/jp076103m.

Scheller, S., Ermler, U., \& Shima, S. (2017). Catabolic Pathways and Enzymes Involved in Anaerobic Methane Oxidation. In Anaerobic Utilization of Hydrocarbons, Oils, and Lipids (pp. 1-29). Springer International Publishing. doi:10.1007/978-3-319-33598-8-3-1.

Scheller, S., Goenrich, M., Boecher, R., Thauer, R. K., \& Jaun, B. (2010). The key nickel enzyme of methanogenesis catalyses the anaerobic oxidation of methane. Nature, 465, 606-8. doi:10.1038/nature09015.

Scheller, S., Goenrich, M., Thauer, R. K., \& Jaun, B. (2013). Methyl-coenzyme M reductase from methanogenic archaea: Isotope effects on the formation and anaerobic oxidation of methane. $J$. Am. Chem. Soc., 135, 14975-84. doi:10.1021/ja406485z. 
Shuai, Y., Etiope, G., Zhang, S., Douglas, P. M., Huang, L., \& Eiler, J. M. (2018). Methane clumped isotopes in the Songliao Basin (China): New insights into abiotic vs. biotic hydrocarbon formation. Earth Planet. Sci. Lett., 482, 213-221. doi:10.1016/J.EPSL.2017.10.057.

Sim, M. S., Ogata, H., Lubitz, W., Adkins, J. F., Sessions, A. L., Orphan, V. J., \& McGlynn, S. E. (2019). Role of APS reductase in biogeochemical sulfur isotope fractionation. Nat. Commun., 10, 44. doi:10.1038/s41467-018-07878-4.

Stolper, D., Lawson, M., Davis, C. L., Ferreira, A. A., Santos Neto, E. V., Ellis, G. S., Lewan, M. D., Martini, A. M., Tang, Y., Schoell, M., Sessions, A. L., \& Eiler, J. M. (2014a). Formation temperatures of thermogenic and biogenic methane. Science, 344, 1500-1503. doi:10.1126/science.1254509.

Stolper, D., Martini, A., Clog, M., Douglas, P., Shusta, S., Valentine, D., Sessions, A., \& Eiler, J. (2015). Distinguishing and understanding thermogenic and biogenic sources of methane using multiply substituted isotopologues. Geochim. Cosmochim. Acta, 161, 219-247. doi:10.1016/j.gca.2015.04.015.

Stolper, D., Sessions, A., Ferreira, A., Santos Neto, E., Schimmelmann, A., Shusta, S., Valentine, D., \& Eiler, J. (2014b). Combined 13C-D and D-D clumping in methane: Methods and preliminary results. Geochim. Cosmochim. Acta, 126, 169-191. doi:10.1016/j.gca.2013.10.045.

Suess, H. E. (1949). Das Gleichgewicht H2 + HDO = HD + H2O und die weiteren Austauschgleichgewichte im System H2, D2 und H2O. Z. Für Naturforschung A, 4, 328-332. doi:10.1515/ZNA-1949-0502.

Taenzer, L., Carini, P. C., Masterson, A. M., Bourque, B., Gaube, J. H., \& Leavitt, W. D. (2020). Microbial Methane From Methylphosphonate Isotopically Records Source. Geophys. Res. Lett., 47, e2019GL085872. doi:10.1029/2019GL085872.

Takai, K., Nakamura, K., Toki, T., Tsunogai, U., Miyazaki, M., Miyazaki, J., Hirayama, H., Nakagawa, S., Nunoura, T., \& Horikoshi, K. (2008). Cell proliferation at 122 degrees C and isotopically heavy $\mathrm{CH} 4$ production by a hyperthermophilic methanogen under high-pressure cultivation. Proc. Natl. Acad. Sci. U. S. A., 105, 10949-54. doi:10.1073/pnas.0712334105.

Tennant, A., Rauk, A., \& Wieser, M. E. (2017). Computational modelling of the redistribution of copper isotopes by proteins in the liver. Metallomics, 9, 1809-1819. doi:10.1039/C7MT00248C.

Thauer, R. K. (2011). Anaerobic oxidation of methane with sulfate: On the reversibility of the reactions that are catalyzed by enzymes also involved in methanogenesis from $\mathrm{CO}$ 2. Curr. Opin. Microbiol., 14, 292-299. doi:10.1016/j.mib.2011.03.003. 
Thauer, R. K., Kaster, A.-K., Seedorf, H., Buckel, W., \& Hedderich, R. (2008). Methanogenic archaea: Ecologically relevant differences in energy conservation. Nat. Rev. Microbiol., 6, 579591. doi:10.1038/nrmicro1931.

Tomasi, J., Mennucci, B., \& Cammi, R. (2005). Quantum Mechanical Continuum Solvation Models. Chem. Rev., 105, 2999-3093. doi:10.1021/cr9904009.

Topçuoğlu, B. D., Meydan, C., Nguyen, T. B., Lang, S. Q., \& Holden, J. F. (2019). Growth Kinetics, Carbon Isotope Fractionation, and Gene Expression in the Hyperthermophile Methanocaldococcus jannaschii during Hydrogen-Limited Growth and Interspecies Hydrogen Transfer. Appl. Environ. Microbiol., 85, 1-14. doi:10.1128/AEM.00180-19.

Urey, H. C. (1947). The thermodynamic properties of isotopic substances. J. Chem. Soc. Resumed, (pp. 562-581). doi:10.1039/jr9470000562.

Valentine, D. L., Chidthaisong, A., Rice, A., Reeburgh, W. S., \& Tyler, S. C. (2004). Carbon and hydrogen isotope fractionation by moderately thermophilic methanogens. Geochim. Cosmochim. Acta, 68, 1571-1590. doi:10.1016/j.gca.2003.10.012.

Vanwonterghem, I., Evans, P. N., Parks, D. H., Jensen, P. D., Woodcroft, B. J., Hugenholtz, P., \& Tyson, G. W. (2016). Methylotrophic methanogenesis discovered in the archaeal phylum Verstraetearchaeota. Nat. Microbiol., 1, 16170. doi:10.1038/nmicrobiol.2016.170.

Wang, D. T., Gruen, D. S., Lollar, B. S., Hinrichs, K.-U., Stewart, L. C., Holden, J. F., Hristov, A. N., Pohlman, J. W., Morrill, P. L., Könneke, M., Delwiche, K. B., Reeves, E. P., Sutcliffe, C. N., Ritter, D. J., Seewald, J. S., McIntosh, J. C., Hemond, H. F., Kubo, M. D., Cardace, D., Hoehler, T. M., \& Ono, S. (2015). Nonequilibrium clumped isotope signals in microbial methane. Science, 348, 428-431. doi:10.1126/science.aaa4326.

Wang, D. T., Reeves, E. P., McDermott, J. M., Seewald, J. S., \& Ono, S. (2017). Clumped isotopologue constraints on the origin of methane at seafloor hot springs. Geochim. Cosmochim. Acta, 223, 141-158. doi:10.1016/j.gca.2017.11.030.

Wang, D. T., Welander, P. V., \& Ono, S. (2016). Fractionation of the methane isotopologues $13 \mathrm{CH} 4,12 \mathrm{CH} 3 \mathrm{D}$, and 13CH3D during aerobic oxidation of methane by Methylococcus capsulatus (Bath). Geochim. Cosmochim. Acta, 192, 186-202. doi:10.1016/j.gca.2016.07.031.

Wang, Y., Sessions, A. L., Nielsen, R. J., \& Goddard, W. A. (2009a). Equilibrium 2H/1H fractionations in organic molecules: I. Experimental calibration of ab initio calculations. Geochim. Cosmochim. Acta, 73, 7060-7075. doi:10.1016/J.GCA.2009.08.019. 
Wang, Y., Sessions, A. L., Nielsen, R. J., \& Goddard, W. A. (2009b). Equilibrium 2H/1H fractionations in organic molecules. II: Linear alkanes, alkenes, ketones, carboxylic acids, esters, alcohols and ethers. Geochim. Cosmochim. Acta, 73, 7076-7086. doi:10.1016/J.GCA.2009.08.018.

Wang, Y., Sessions, A. L., Nielsen, R. J., \& Goddard, W. A. (2013). Equilibrium 2H/1H fractionation in organic molecules: III. Cyclic ketones and hydrocarbons. Geochim. Cosmochim. Acta, 107, 82-95. doi:10.1016/J.GCA.2013.01.001.

Webb, M. A., \& Miller, T. F. (2014). Position-specific and clumped stable isotope studies: Comparison of the Urey and path-integral approaches for carbon dioxide, nitrous oxide, methane, and propane. J. Phys. Chem. A, 118, 467-74. doi:10.1021/jp411134v.

Webb, M. A., Wang, Y., Braams, B. J., Bowman, J. M., \& Miller, T. F. (2017). Equilibrium clumped-isotope effects in doubly substituted isotopologues of ethane. Geochim. Cosmochim. Acta, 197, 14-26. doi:10.1016/J.GCA.2016.10.001.

Weigend, F., \& Ahlrichs, R. (2005). Balanced basis sets of split valence, triple zeta valence and quadruple zeta valence quality for $\mathrm{H}$ to Rn: Design and assessment of accuracy. Phys. Chem. Chem. Phys., 7, 3297. doi:10.1039/b508541a.

Welte, C., \& Deppenmeier, U. (2014). Bioenergetics and anaerobic respiratory chains of aceticlastic methanogens. Biochim. Biophys. Acta BBA - Bioenerg., 1837, 1130-1147. doi:10.1016/J.BBABIO.2013.12.002.

Wenk, C. B., Wing, B. A., \& Halevy, I. (2017). Electron carriers in microbial sulfate reduction inferred from experimental and environmental sulfur isotope fractionations. ISME J., 12, 495507. doi:10.1038/ismej.2017.185.

Whitehill, A. R., Joelsson, L. M. T., Schmidt, J. A., Wang, D. T., Johnson, M. S., \& Ono, S. (2017). Clumped isotope effects during $\mathrm{OH}$ and $\mathrm{Cl}$ oxidation of methane. Geochim. Cosmochim. Acta, 196, 307-325. doi:10.1016/J.GCA.2016.09.012.

Whiticar, M. J. (1999). Carbon and hydrogen isotope systematics of bacterial formation and oxidation of methane. Chem. Geol., 161, 291-314. doi:10.1016/S0009-2541(99)00092-3.

Wing, B. A., \& Halevy, I. (2014). Intracellular metabolite levels shape sulfur isotope fractionation during microbial sulfate respiration. Proc. Natl. Acad. Sci. U. S. A., 111, 18116-25. doi:10.1073/pnas.1407502111.

Yeung, L. Y. (2016). Combinatorial effects on clumped isotopes and their significance in biogeochemistry. Geochim. Cosmochim. Acta, 172, 22-38. doi:10.1016/j.gca.2015.09.020. 
Yoshinaga, M. Y., Holler, T., Goldhammer, T., Wegener, G., Pohlman, J. W., Brunner, B., Kuypers, M. M. M., Hinrichs, K.-U., \& Elvert, M. (2014). Carbon isotope equilibration during sulphatelimited anaerobic oxidation of methane. Nat. Geosci., 7, 190-194. doi:10.1038/ngeo2069.

Yoshioka, H., Sakata, S., \& Kamagata, Y. (2008). Hydrogen isotope fractionation by Methanothermobacter thermoautotrophicus in coculture and pure culture conditions. Geochim. Cosmochim. Acta, 72, 2687-2694. doi:10.1016/j.gca.2008.03.015.

Young, E., Kohl, I., Lollar, B. S., Etiope, G., Rumble, D., Li, S., Haghnegahdar, M., Schauble, E., McCain, K., Foustoukos, D., Sutclife, C., Warr, O., Ballentine, C., Onstott, T., Hosgormez, H., Neubeck, A., Marques, J., Pérez-Rodríguez, I., Rowe, A., LaRowe, D., Magnabosco, C., Yeung, L., Ash, J., \& Bryndzia, L. (2017). The relative abundances of resolved 12CH2D2 and $13 \mathrm{CH} 3 \mathrm{D}$ and mechanisms controlling isotopic bond ordering in abiotic and biotic methane gases. Geochim. Cosmochim. Acta, 203, 235-264. doi:10.1016/j.gca.2016.12.041.

Young, E. D. (2019). A Two-Dimensional Perspective on CH4 Isotope Clumping. In Deep Carbon: Past to Present (pp. 388-414). Cambridge University Press.

Young, E. D., Rumble, D., Freedman, P., \& Mills, M. (2016). A large-radius high-mass-resolution multiple-collector isotope ratio mass spectrometer for analysis of rare isotopologues of O2, N2, CH4 and other gases. Int. J. Mass Spectrom., 401, 1-10. doi:10.1016/J.IJMS.2016.01.006.

Zaarur, S., Wang, D. T., Ono, S., \& Bosak, T. (2017). Influence of Phosphorus and Cell Geometry on the Fractionation of Sulfur Isotopes by Several Species of Desulfovibrio during Microbial Sulfate Reduction. Front. Microbiol., 8, 890. doi:10.3389/fmicb.2017.00890.

Zhao, Y., Schultz, N. E., \& Truhlar, D. G. (2006). Design of Density Functionals by Combining the Method of Constraint Satisfaction with Parametrization for Thermochemistry, Thermochemical Kinetics, and Noncovalent Interactions. J. Chem. Theory Comput., 2, 364-382. doi:10.1021/ct0502763.

Zhao, Y., \& Truhlar, D. G. (2011). Applications and validations of the Minnesota density functionals. Chem. Phys. Let., 502, 1-13. doi:10.1016/j.cplett.2010.11.060.

Zhuang, G.-C., Heuer, V. B., Lazar, C. S., Goldhammer, T., Wendt, J., Samarkin, V. A., Elvert, M., Teske, A. P., Joye, S. B., \& Hinrichs, K.-U. (2018). Relative importance of methylotrophic methanogenesis in sediments of the Western Mediterranean Sea. Geochim. Cosmochim. Acta, 224, 171-186. doi:10.1016/j.gca.2017.12.024. 